\title{
Simulação Numérica Euleriana de Escoamento Gás-Sólido em Riser com Dimensões Reduzidas Aplicando Malhas Refinadas.
}

Ms. Fernando Luiz Pio dos Santos

Tese apresentada à Escola de Engenharia de São Carlos, da Universidade de São Paulo, como parte dos requisitos para a obtenção do título de Doutor em Engenharia Mecânica.

ORIENTADOR: Prof. Dr. Fernando Eduardo Milioli

USP - São Carlos

Maio de 2008 
"Adoramos a perfeição, porque não a podemos ter; repugna-la-íamos, se a tivéssemos. O perfeito é desumano, porque o humano é imperfeito."

(Fernando Pessoa) 


\section{Agradecimentos}

Agradeço ao meu orientador Professor Dr. Fernando E. Milioli, pela oportunidade, pela confiança e por todo suporte dado na realização deste trabalho.

Ao Professor Dr. Valdemir G. Ferreira, pela amizade e discussões ao longo do desenvolvimento desse projeto.

Ao Professor Dr. Luben C. Gómez, pelas importantes colaborações no início desse projeto.

Ao Jorge Nicolau, pelo auxílio no entendimento e instalação de programas necessários para as simulações.

Ao Robreto Prata, pela suporte dado na manutenção dos microcomputadores.

À minha noiva Monica R. Gaiotto, por todo amor, carinho, compreensão e incentivos em todos os momentos. À todos os seus familiares e, principalmente, à sua Mãe Nadir B. Gaiotto e irmão Charles B. Gaitto, pelo incentivo.

Aos amigos de São Carlos, pela amizade e momentos de descontração. Ao Cássio Oishi, por aceitar dividir seu quarto para minha estada em São Carlos. Aos demais amigos, por todo incentivo.

Minha sincera gratidão ao meus familiares, por toda ajuda e apoio dados ao longo da

minha carreira acadêmica. À minha Mãe Anália E. dos Santos e em memórias do meu Pai Domingos P. dos Santos e irmão Domingos L. dos Santos. Dedico este trabalhos à todos eles.

À agência CAPES, pelo suporte financeiro para o desenvolvimento deste projeto. 


\section{Sumário}

Resumo $\quad x v$

Abstract $\quad$ xvii

1 Introdução 1

1.1 Caracterização e Objetivo do Trabalho . . . . . . . . . . . . . . . . 1

1.2 Organização do Trabalho . . . . . . . . . . . . . . . . . . . 2

1.3 Resenha sobre Modelagem Numérica e Aplicações . . . . . . . . . . . . . 3

1.3.1 Escoamento Multifásico Computacional . . . . . . . . . . . 3

1.3.2 Regimes de Fluidização e Leito Fluidizado Circulante . . . . . . . 7

1.4 Estado-da-Arte sobre Simulações de Escoamentos Gás-Sólido em Risers de $\mathrm{LFC} \ldots \ldots \ldots \ldots$

1.4.1 Simulações Numéricas de Escoamentos Multifásicos Gás-Sólido em

LFC com Diferentes Geometrias . . . . . . . . . . . . . . 12

1.4.2 Simulações Numéricas em Risers com Dimensões Reduzidas . . . 13

1.5 Formulações Eulerianas para Escoamentos Gás-Sólido em LFC . . . . . . 14

1.5.1 Formulação Euler-Langrange . . . . . . . . . . . . . . . . . . 14

1.5.2 Formulação Euler-Euler . . . . . . . . . . . . . . . . . 16

2 Modelagem Euler-Euler e Solução Numérica de Escoamentos Bifásicos Gás-Sólido $\quad 19$

2.1 Introdução . . . . . . . . . . . . . . . . . . . . . . . 19

2.2 Esquema de Discretização . . . . . . . . . . . . . . . . . . . . 22

2.2.1 Técnica de Volumes Finitos . . . . . . . . . . . . . . 22

2.3 Formulação Euler-Euler para o Escoamento Bifásico Gás-Sólido . . . . . 31

2.4 Desenvolvimento do Modelo de Fases Separadas . . . . . . . . . . . . . . 33 
2.5 Leis Constitutivas . . . . . . . . . . . . . . . . . . . . . . . 34

2.6 Modelos Hidrodinâmicos para Formulação Euler-Euler . . . . . . . . . 38

2.6.1 Modelo Hidrodinâmico A . . . . . . . . . . . . . . . . . . 38

2.6.2 Modelo Hidrodinâmico B . . . . . . . . . . . . . . . . . . . . . 39

2.6.3 Equações de Fechamento para o Modelo B . . . . . . . . . . . . . 39

2.6 .4 Condições de contorno . . . . . . . . . . . . . . . . . . 41

3 Ambiente de Simulação Numérica 45

3.1 Introdução . . . . . . . . . . . . . . . . . . . . . . . . . 45

3.2 O Ambiente de Simulação do Código MFIX . . . . . . . . . . . . . 45

3.3 Procedimento Iterativo . . . . . . . . . . . . . . . . . . 47

3.4 Técnica Numérica . . . . . . . . . . . . . . . . . . . . . . . . . . . . . 48

3.5 Arquitetura Computacional utilizada para as Simulações . . . . . . . . . 49

4 Resultados Numéricos de Simulação $\quad 51$

4.1 Introdução . . . . . . . . . . . . . . . . . . . 51

4.2 Domínio Computacional e Condições de Contorno para o Tubo Ascendente 51

4.3 Influência do Esquema de Interpolação nos Resultados Numéricos . . . . 54

4.4 Influência da Malha Computacional nos Resultados de Simulação . . . 57

4.5 Comparação dos Resultados considerando as Diversas Malhas Computa-

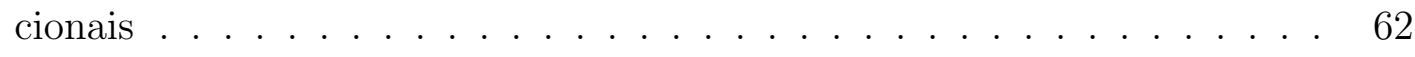

4.6 Resultados obtidos com o Ajuste da Coluna Ascendente e Refinamento da Malha . . . . . . . . . . . . . . . . . . . . . 68

4.6.1 Resultados numéricos de simulação para domínio de $2 \mathrm{~cm} \times 24 \mathrm{~cm} \quad 68$

4.6.2 Resultados numéricos para domínio de $4 \mathrm{~cm} \times 72 \mathrm{~cm} \ldots \ldots . . .77$

4.6.3 Resultados numéricos para domínio de $2 \mathrm{~cm} \times 144 \mathrm{~cm}$ e $4 \mathrm{~cm} \times 144 \mathrm{~cm} 82$

5 Conclusões e Recomendações para Futuros Trabalhos $\quad 91$

5.1 Conclusões . . . . . . . . . . . . . . . . . . . . . . . . . . . . . . . 91

5.2 Recomendações para Futuros Trabalhos . . . . . . . . . . . . . . . . . . 94

$\begin{array}{lr}\text { Referências Bibliográficas } & 95\end{array}$

$\begin{array}{ll}\text { Anexo A } & 105\end{array}$ 
Anexo B 


\section{Lista de Figuras}

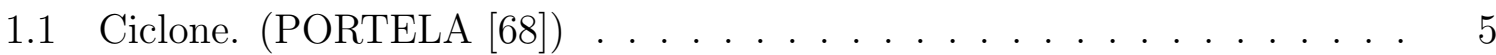

1.2 Visualização numérica de um processo de separação das partículas do gás no interior de um ciclone (PORTELA [68]). . . . . . . . . . . 6

1.3 Unidade FCC $($ PORTELA $[68]) \ldots \ldots \ldots \ldots \ldots$

1.4 Diagrama de um LFC. . . . . . . . . . . . . . . . . . . . . . 9

1.5 Formulação Euler-Euler: Modelo de fases separada. . . . . . . . . . . . . 16

2.1 Volume de controle $(V)$ e localização das faces north $(n)$, west $(w)$, south

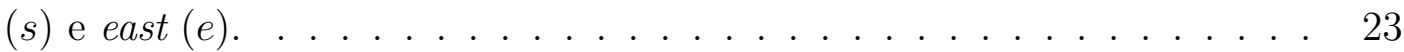

2.2 Notação e localização das faces ao longo da direção do escoamento (SYAMLAL $[84]) \ldots \ldots \ldots \ldots \ldots \ldots$

2.3 Diagrama de Variável Normalizada. . . . . . . . . . . . . . . . . . . . . . 29

2.4 Volume de Controle fixo contendo duas fases, com interface móvel. . . . . 33

2.5 Tubo ascendente de um leito circulante com saída lateral . . . . . . . . . 44

3.1 Volume de controle com malha deslocada na direção $x$ considerada para discretização da equação de Momentum. . . . . . . . . . . . . . . . . . 47

3.2 Malha numérica utilizada no código MFIX (SYAMLAL [84]). . . . . . . . 49

4.1 Domínio para o tubo ascendente considerado para a simulação do escoamento gás-sólido. . . . . . . . . . . . . . . . . . . . . 52

4.2 Comparação entre os perfis radiais das velocidades e frações volumétricas para ambas as fases em $t=50 \mathrm{~s}$ a $4,8 \mathrm{~cm}$ acima da entrada. Métodos Foup e Superbee. Malha: $40 \times 160$; Resolução: $0,5 m m \times 0,5 m m \ldots \ldots . . .56$

4.3 Perfis radiais da velocidade axial e fração volumétrica da fase sólida em $t=50 \mathrm{~s}$ avaliadas a $0,4 \mathrm{~cm}$ acima da entrada. Malha $5 \times 20$; Resolução: $4 \mathrm{~mm} \times 4 \mathrm{~mm} \ldots \ldots \ldots \ldots \ldots \ldots \ldots \ldots \ldots$ 
4.4 Perfis radiais da velocidade axial e fração volumétrica da fase sólida em $t=50 \mathrm{~s}$ avaliadas a $0,4 \mathrm{~cm}$ acima da entrada. Malha $10 \times 40$. Resolução: $2 \mathrm{~mm} \times 2 \mathrm{~mm} \ldots \ldots \ldots \ldots \ldots \ldots$

4.5 Perfis radiais da velocidade axial e fração volumétrica para a fase sólida em tempo $t=50 \mathrm{~s}$ avaliadas a $0,4 \mathrm{~cm}$ acima da entrada. Malha $20 \times 80$.

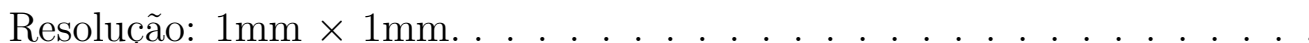

4.6 Perfis radiais da velocidade axial para ambas as fases avaliadas a $0,4 \mathrm{~cm}$, acima da entrada, no tempo $t=50 \mathrm{~s}$. Malha $40 \times 160$. Resolução: $0,5 \mathrm{~mm}$ $\times 0,5 \mathrm{~mm} \ldots \ldots \ldots \ldots \ldots$

4.7 Perfis radiais da fração volumétrica para ambas as fases avaliadas a $0,4 \mathrm{~cm}$, acima da entrada, no tempo $t=50 \mathrm{~s}$. Malha $40 \times 160$. Resolução: $0,5 \mathrm{~mm}$ $\times 0,5 \mathrm{~mm} \ldots \ldots \ldots \ldots \ldots \ldots$

4.8 Perfis radiais da velocidade axial para a fase gasosa $e m t=50 \mathrm{~s}$ avaliadas a $0,4 \mathrm{~cm}$ acima da entrada. Malhas: $5 \times 20 ; 10 \times 40 ; 20 \times 80$ e $40 \times 160$. $\quad 63$

4.9 Comportamento da velocidade axial da fase gás no domínio, no tempo $t=1$, 0 s. Malhas: (a) $20 \times 80$; (b) $40 \times 160$.

4.10 Comportamento da velocidade axial da fase sólida no domínio, no tempo $t=1.0$ s. Malhas: (a) $20 \times 80$; (b) $40 \times 160$. . . . . . . . . . . .

4.11 Evolução da Fração Volumétrica da fase sólida no domínio, no tempo $t=1,0$ s. Malhas: (a) $10 \times 40$; (b) $20 \times 80$; (c) $40 \times 160$. . . . . . . .

4.12 Evolução da Fração Volumétrica da fase sólida nos primeiros cinco segundos de simulação para malha $40 \times 160$. Resolução $0,5 \mathrm{~mm} \times 0,5 \mathrm{~cm}$; (a) $t=1 s$; (b) $t=2 s$; (c) $t=3 s$; (d) $t=4 s$; (e) $t=5 s$. Contornos com linhas brancas indicam a região com alta concentração da fase sólido no

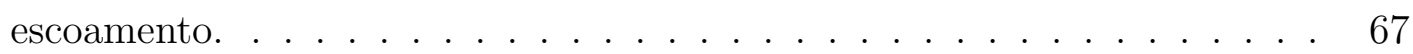

4.13 Tubo ascendente $2 \mathrm{~cm} \times 24 \mathrm{~cm}$ para simulação . . . . . . . . . . . . . 69

4.14 Variação da fração volumétrica da fase sólida ao longo do tubo ascendente. Domínio: $2 \mathrm{~cm} \times 24 \mathrm{~cm}$. Malha computacional: $80 \times 320$. Resolução:

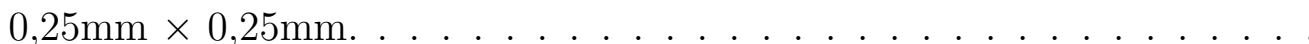

4.15 Variação temporal da velocidade axial da fase gasosa. Domínio: $2 \mathrm{~cm} \times$ 24cm; Malha computacional: $80 \times 320$; Resolução: $0,25 \mathrm{~mm} \times 0,25 \mathrm{~mm}$. 
4.16 Variações temporais médias das velocidade axiais de ambas as fases na seção $12 \mathrm{~cm}$ acima da entrada. Domínio: $2 \mathrm{~cm} \times 24 \mathrm{~cm}$; Malha computacional: $80 \times 320$; Resolução: $0,25 \mathrm{~mm} \times 0,25 \mathrm{~mm}$. . . . . . . . . . . 72

4.17 Variações temporais médias das frações volumétricas de ambas as fases na seção $12 \mathrm{~cm}$ acima da entrada. Domínio: $2 \mathrm{~cm} \times 24 \mathrm{~cm}$; Malha computacional: $80 \times 320$; Resolução: $0,25 \mathrm{~mm} \times 0,25 \mathrm{~mm} . \quad \ldots \ldots$. . . . . . . 73

4.18 Variação temporal da fração volumétrica da fase gasosa no domínio. Domínio: $2 \mathrm{~cm} \times 24 \mathrm{~cm}$; Malha computacional: $80 \times 320$; Resolução: 0,25mm × $0,25 \mathrm{~mm}$; Intervalo de $0,1 \mathrm{~s}$ do instante $t=2,3 \mathrm{~s}$ até $t=4,0 \mathrm{~s}$ entre os sucessivos quadros. . . . . . . . . . . . . . . . . 74

4.19 Variação temporal da fração volumétrica da fase sólida no domínio. Domínio: $2 \mathrm{~cm} \times 24 \mathrm{~cm}$; Malha computacional: $80 \times 320$; Resolução: 0,25mm × $0,25 \mathrm{~mm}$; Intervalo de $0,1 \mathrm{~s}$ do instante $t=2,3 \mathrm{~s}$ até $t=4,0 \mathrm{~s}$ entre os sucessivos quadros. . . . . . . . . . . . . . . . . 75

4.20 Compararação qualitativa da fração volumétrica da fase sólida. (a) AGRAWAL [1] (Tonalidade preta indica altas frações de sólido, o branco baixas frações de sólido); Domínio: $5 \mathrm{~cm} \times 20 \mathrm{~cm}$; Resolução: $2 \mathrm{~mm} \times 2 \mathrm{~mm}$. (b) Presente Trabalho (Tonalidade vermelha indica altas frações de sólido, o azul baixas frações de sólido); Domínio: $2 \mathrm{~cm} \times 24 \mathrm{~cm}$; Resolução $0,25 \mathrm{~mm} \times 0,25 \mathrm{~mm}$.

4.21 Tubo ascendente $4 \mathrm{~cm} \times 72 \mathrm{~cm}$ para simulação . . . . . . . . . . . . . 77

4.22 Variação temporal da fração volumétrica da fase gasosa ao longo da coluna. Domínio: 0,04m × 0,72m; Malha computacional: $20 \times 80$; Resolução: $1 \mathrm{~mm} \times 1 \mathrm{~mm}$; Intervalo de $0,1 \mathrm{~s}$ do instante $t=3,7 \mathrm{~s}$ até $5,2 \mathrm{~s}$ entre os sucessivos quadros; A tonalidade cinza claro indica altas frações de gás, o preto indica baixas frações de gás. . . . . . . . . . . . . . . 78

4.23 Variação da fração volumétrica da fase gasosa nas regiões (a) entrada, (b) centro e (c) saída da coluna. Vetores apontam o direcionamento da velocidade do gás nas três regiões do riser. Tempo: $t=4,2 s$. Domínio: 0,04m × 0,72m; Malha computacional: $20 \times 80$; Resolução: $1 \mathrm{~mm} \times 1 \mathrm{~mm}$. A tonalidade cinza clara indica altas frações de gás, o preto indica baixas frações de gás. . . . . . . . . . . . . . . . . . . . . . 
4.24 Variação temporal da fração volumétrica da fase gasosa ao longo da coluna. Domínio: $4 \mathrm{~cm} \times 72 \mathrm{~cm}$; Malha computacional: $40 \times 160$. Resolução: $0,5 \mathrm{~mm} \times 0,5 \mathrm{~mm}$; Intervalo de $0,1 \mathrm{~s}$ do instante $t=4,0 \mathrm{~s}$ até $5,9 \mathrm{~s}$ entre os sucessivos quadros. A tonalidade azul indica altas frações de gás, o vermelho indica baixas frações de gás. . . . . . . . . . . . . . .

4.25 Variação das velocidades das fases (a) gasosa, (b) sólida e (c) fração volumétrica da fase gasosa avaliadas no centro da coluna no tempo $t=4 \mathrm{~s}$. Domínio: 0,04m × 0,72m; Malha computacional: 40 × 160; Resolução: 0,5mm × 0,5mm; A tonalidade azul indica altas velocidades (a) gás e (b) sólido e (c) altas frações de gás, o vermelho indica baixas velocidades (gás e sólido) e baixas fração de gás; Vetores apontam a direção da velocidade de cada fase. . . . . . . . . . . . . . . . . . . .

4.26 Tubo ascendente $2 \mathrm{~cm} \times 144 \mathrm{~cm}$ para simulação . . . . . . . . . . . .

4.27 Variação das velocidades das fases (a) sólida, (b) gasosa e (c) variação da fração volumétrica dos gás. Tempo: $t=38 s$; Domínio: 0,02m $\times$ 1,44m; Malha computacional: $20 \times 80$; Resolução: $1 \mathrm{~mm} \times 1 \mathrm{~mm}$. A tonalidade azul indica altas velocidades (gás e sólido) e altas frações de gás, o vermelho indica baixas velocidades (gás e sólido) e baixas fração de gás; Vetores apontam o direcionamento das velocidades na direção de

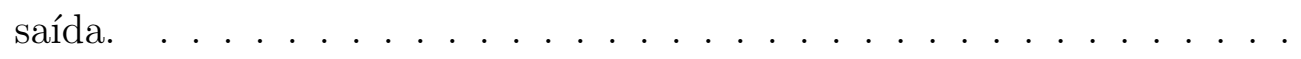

4.28 Tubo ascendente $2 \mathrm{~cm} \times 144 \mathrm{~cm}$ para simulação . . . . . . . . . . . . .

4.29 Variação temporal da fração volumétrica da fase gasosa ao longo da coluna. Domínio: $4 \mathrm{~cm} \times 144 \mathrm{~cm}$; Malha computacional: $40 \times 160$; Resolução: $0,5 \mathrm{~mm} \times 0,5 \mathrm{~mm}$; Intervalo de $0,2 \mathrm{~s}$ do instante $t=7,8 \mathrm{~s}$ até $11,8 s$ entre os sucessivos quadros. A tonalidade azul indica altas frações de gás, o vermelho indica baixas frações de gás. . . . . . . . . . . . . .

4.30 Variação temporal da fração volumétrica da fase gasosa ao longo da coluna. Domínio: 4cm × 144cm; Malha computacional: $40 \times 160$; Resolução: $0,5 \mathrm{~mm} \times 0,5 \mathrm{~mm}$; Intervalo de $1 \mathrm{~s}$ do instante $t=20 \mathrm{~s}$ até $30 \mathrm{~s}$ entre os sucessivos quadros; A tonalidade azul indica altas frações de gás, o vermelho indica baixas frações de gás. . . . . . . . . . . . . . 
4.31 Variação temporal da velocidade da fase sólida em vários intervalos de tempo avaliada a $72 \mathrm{~cm}$ da entrada da coluna. Domínio: $4 \mathrm{~cm} \times 144 \mathrm{~cm}$; Malha computacional: $40 \times 160$; Resolução: $0,5 \mathrm{~mm} \times 0,5 \mathrm{~mm}$. . . . . . 87

4.32 Variação temporal da velocidade da fase gasosa em vários intervalos de tempos avaliada a $72 \mathrm{~cm}$ da entrada da coluna. Domínio: $4 \mathrm{~cm} \times 144 \mathrm{~cm}$; Malha computacional: $40 \times 160$; Resolução: $0,5 \mathrm{~mm} \times 0,5 \mathrm{~mm}$. . . . . . 88 


\section{Lista de Tabelas}

$2.1 \quad D F W$ para Esquemas de Discretização. . . . . . . . . . . . . . . . . . 31

3.1 Configuração dos Microcomputadores utilizados nas simulações. . . . . . 50

4.1 Parâmentos numéricos de simulação para os experimentos computacionais no domínio de $2 \mathrm{~cm} \times 8 \mathrm{~cm} \ldots \ldots \ldots \ldots \ldots \ldots$

4.2 Propriedades físicas do gás e do sólido utilizadas nas simulações. . . . . . 53

4.3 Condições de contorno na entrada. . . . . . . . . . . . . . . . 53

4.4 Parâmentos Numéricos para as simulações computacionais. . . . . . . . . 55

4.5 Malhas Numéricas para os experimentos computacionais considerando refinamento da malha. . . . . . . . . . . . . . . 57 


\section{Lista de Símbolos}

$C_{D_{S}} \quad$ Coeficiente de arrasto para uma partícula num meio infinito

$c, d \quad$ Fase contínua e fase dispersa, respectivamente

$d_{p} \quad$ Diâmetro médio da partícula, $[\mathrm{m}]$

$f \quad$ Função geral

g Aceleração da gravidade, $\left[\mathrm{m} / \mathrm{s}^{2}\right]$

$G \quad$ Módulo de elasticidade da fase sólida, [Pa]

$\mathbf{i}, \mathbf{j}, \mathbf{k}$ Vetores unitários da base canônica

$\overline{\bar{I}} \quad$ Tensor unitário

$L_{p} \quad$ Caminho livre médio das partículas, $[\mathrm{m}]$

$m^{\prime}{ }_{k} \quad$ Fluxo de massa da fase $k$ por unidade de área da interface, $\left[\mathrm{kg} / \mathrm{m}^{2}\right.$-s $]$

n Vetor unitário normal externo à superfície; direção normal

$P \quad$ Pressão termodinâmica, $[\mathrm{Pa}]$

$P_{g} \quad$ Pressão da fase gasosa, $[\mathrm{Pa}]$

$\mathbf{r} \quad$ Superfície geométrica

$r \quad$ Raio, [m]; Direção radial, [m]; Diâmetro, [m]

$R \quad$ Constante universal dos gases ideais, $[\mathrm{J} / \mathrm{kg}-\mathrm{K}](\mathrm{R}=8314 \mathrm{~J} / \mathrm{kg}-\mathrm{K})$

$R e_{p} \quad$ Número adimensional de Reynolds

$t \quad$ Tempo, $[\mathrm{s}]$

$T \quad$ Temperatura, $[K]$

$\overline{\bar{T}}_{k} \quad$ Tensor das tensões da fase $k,[\mathrm{~Pa}]$

$u_{k} \quad$ Velocidade local da fase $k,[\mathrm{~m} / \mathrm{s}]$

$u_{g}, v_{g}$ Velocidades radial e axial da fase gasosa médias no volume de controle, $[\mathrm{m} / \mathrm{s}]$

$u_{s}, v_{s}$ Velocidades radial e axial da fase sólida médias no volume de controle, $[\mathrm{m} / \mathrm{s}]$

$V \quad$ Volume, $\left[m^{3}\right]$

$x \quad$ Coordenada das abscissas, [m]; Direção radial, $[\mathrm{m}]$

y Coordenada das ordenadas, [m]; Direção axial, [m]; Normal, [m]; 


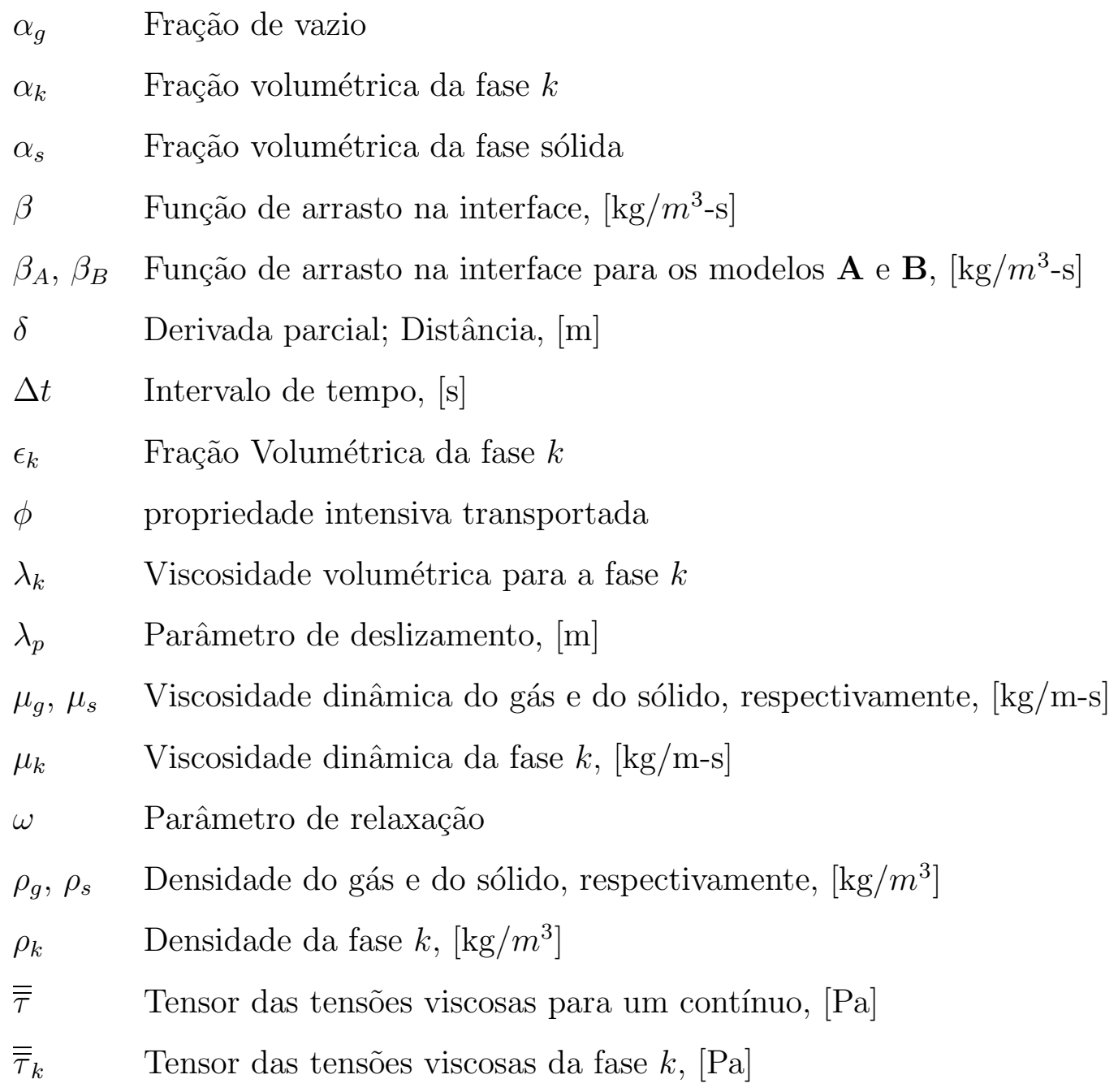

\section{Subscritos}

$g \quad$ Fase gasosa

$i \quad$ Subíndice nas equações discretizadas em diferenças finitas indicando a direção horizontal

j Subíndice nas equações discretizadas em diferenças finitas indicando a direção vertical

$k$ Índice da fase

p Particulado

$s \quad$ Fase sólido

Sobrescritos

col Colisões

T Matriz trasnposta 


\begin{tabular}{|c|c|}
\hline$\nabla \cdot$ & Divergente \\
\hline$\nabla$ & Gradiente \\
\hline\langle\rangle & Valor médio volumétrico, temporal ou estatístico; Or \\
\hline \multicolumn{2}{|c|}{ Abreviaturas e Siglas } \\
\hline ANL & Argone National Laboratory \\
\hline $\mathrm{DFC}$ & Dinâmica dos Fluidos Computacional \\
\hline DNS/LES & Direct Numeric Simulation/Large-Eddy Simulations \\
\hline DWF & Down Wind Factor; Limitador Universal \\
\hline EDP & Equação Diferencial Parcial \\
\hline $\mathrm{FCC}$ & Fluid Catalytic Cracking \\
\hline FOUP & First Ordem Upwind \\
\hline IFC & Intel Fortran Compiler \\
\hline IIT & Illinois Institute of Technology \\
\hline $\mathrm{LF}$ & Leito Fluidizado \\
\hline LFB & Leito Fluidizado Borbulhante \\
\hline $\mathrm{LFC}$ & Leito Fluidizado Circulante \\
\hline $\mathrm{MFC}$ & Mecânica dos Fluidos Computacional \\
\hline MFIX & Multiphase Flow Interphase Exchanges \\
\hline NVD & Normalized Variable Diagram \\
\hline RANS & Reynolds Average Navier-Stokes Simulation \\
\hline SIMPLE & SemiImplicit Method for Pressure Linked Equation \\
\hline TCEG & Teoria Cinética dos Escoamentos Granulares \\
\hline TVD & Total Variation Diminishing \\
\hline
\end{tabular}




\section{Resumo}

Santos, F. L. P. Simulação Numérica Euleriana de Escoamentos Gás-Sólido em Riser com Dimensões Reduzidas Aplicando Malhas Refinadas. São Carlos, Tese (Doutorado) Escola de Engenharia de São Carlos - EESC, Universidade de São Paulo - USP, 2008.

Dada a complexidade hidrodinâmica de escoamentos gás-sólidos em leitos fluidizados muitas pesquisas têm sido realizadas abordando questões relativas a natureza altamente instável desse processo de fluidização. O conhecimento dessa hidrodinâmica permite estabelecer os parâmetros corretos para reação e transporte de massa em um reator de leito fluidizado, permitindo tomada de decisões à respeito do desempenho do reator. Modelos Eulerianos do contínuo, onde as fases coexistentes são tratadas como meios contínuos interpenetrantes, representam a aproximação mais prática para simular a hidrodinâmica de escoamentos gás-sólido em reatores de leito fluidizado. Aplicando-se procedimentos de médias de Euler obtém-se os modelos hidrodinâmicos A e B desenvolvidos por GIDASPOW [27] do IIT/ANL, representando as equações conservativas e constitutivas de modelos de duas fases separadas para escoamentos gás-sólido. Neste trabalho, aplica-se um modelo Euleriano de duas fases separadas, desenvolvendo simulações numéricas para diferentes dimensões de colunas ascendentes de leito fluidizado circulante. Para resolução das equações discretas no domínio bidimensional, aplica-se malhas refinadas. Analisa-se os efeitos nos resultados de simulação causados por essas malhas. Apresenta-se uma discussão geral sobre o modelo aplicado em torno dos resultados obtidos.

Palavras-chave: escoamento bifásico gás-sólido, simulação mumérica, leito fluidizado circulante, malha refinada. 
xvi 


\section{Abstract}

Santos, F. L. P. Eulerian Numerical Simulation of Gas-Solid Flows in Risers of Reduced Dimensions Applying Refined Meshes. São Carlos, Tese (Doutorado) - Escola de engenharia de São Carlos - EESC, Universidade de São Paulo - USP, 2008.

Due to the hydrodynamic complexity of gas-solid flows in fluidized beds, several researches have been conducted addressing issues concerning the highly unstable nature of this fluidization process. The knownledge of its hydrodynamics allows establishing the correct parameters for the reaction and mass transport in a fluidized bed reactor, improving its performance. Continuous Eulerian models, where the phases are treated as a continuum, represent the most practical approach to simulate the hydrodynamics of gas-solid flows in fluidized bed reactors. By applying Euler average procedures, it is possible to obtain the hydrodynamic models A and B, developed by GIDASPOW [27] at IIT/ANL. These models represent the conservative and constitutive equations for the models of two separate phases for gas-solid flows. In this work, an Eulerian two-fluids model is applied, developing numerical simulations for different risers of circulating fluidized bed. For the resolution of the discrete equations in the two-dimensional domain, refined meshes are used. An analysis of their effects on the results of the simulation is

performed. A general discussion about the results obtained by the model applied is also presented.

keywords: gas-solid flow, numerical simulation, circulating fluidized bed, refined mesh. 


\section{Capítulo 1}

\section{Introdução}

\subsection{Caracterização e Objetivo do Trabalho}

Dadas as já conhecidas limitações que impedem que se possam trabalhar com malhas refinadas, devido os enormes domínios a serem resolvidos, o alto custo computacional (tempo de processamento e consumo de memória virtual) e o elevado custo monetário para se ter uma arquitetura adequada para uma investigação efetiva de simulação numérica de escoamento multifásico, novas técnicas computacionais e numéricas têm sido largamente pesquisadas por ser de grande interesse de toda a comunidade científica na área de Mecânica dos Fluidos Computacional (MFC).

Por isso, grandes esforços têm sido empregados no desenvolvimento de novas técnicas numéricas, na tentativa de se eliminar as restrições que impedem a obtenção de resultados compatíveis com o realismo do fenômeno investigado e que possam servir em aplicações industriais.

Este trabalho consiste em realizar simulações numéricas de escoamento bifásico gás sólido bidimensional em Leitos Fluidizados Circulantes (LFC).

O objetivo é investigar os efeitos da aplicação de malhas numéricas refinadas na simulação numérica considerando um LFC com dimensões reduzidas, de forma a contribuir com a discussão sobre melhorias dos modelos físicos e numéricos dispostos atualmente 
na literatura.

A consideração de dimensões reduzidas do leito fluidizado possibilita que malhas mais finas possam ser empregadas no domínio numérico para as simulações com escoamento bifásico gás-sólido.

A técnica numérica implementada no modelo hidrodinâmico do código MFIX (Multiphase Flow Interphase Exchanges) de SYAMLAL [84] foi utilizada para os estudos reportados aqui.

\subsection{Organização do Trabalho}

Este trabalho está dividido em cinco capítulos, a saber:

Capítulo 1: Apresentação sucinta sobre modelagem numérica e aplicações focado em aspectos relacionados ao escoamento multifásico computacional. Apresenta-se o Estado-da-Arte sobre simulações de escoamento gás-sólido em risers de LFC de dimensões reduzidas. Descrição das formulações eulerianas para escoamento bifásico gássólido em LFC.

Capítulo 2: Expõe-se a base teórica para escoamento bifásico baseado nos modelos hidrodinâmicos A e B de GIDASPOW [27], bem como as leis constitutivas, equações de fechamento e de contorno para o modelo de fases separadas.

Capítulo 3: Apresenta-se uma breve descrição do ambiente de simulação numérica MFIX (Multiphase Flow Interphase Exchanges de SYAMLAL [84] utilizado neste trabalho.

Capítulo 4: Discussão dos resultados de simulação obtidos aplicando-se domínios de dimensões reduzidas e malhas refinadas com base nos perfis de velocidades e de frações volumétricas para ambas as fases e, comparação com resultados numéricos de outros autores. 
Capítulo 5: Apresenta-se uma síntese das conclusões obtidas por meio dos resultados numéricos de simulação e, finalmente, apresenta-se as recomendações para trabalhos futuros.

\subsection{Resenha sobre Modelagem Numérica e Aplicações}

De um modo geral simulação numérica de escoamentos de fluidos é uma área da MFC que tem diversas aplicações industriais importantes, tais como refino e distribuição de petróleo e gás natural e, com um papel importante no segmento de transporte, produção, desenvolvimento da engenharia de processos e unidades operacionais.

A MFC que trata de simulação de escoamentos de fluidos tem obtido sucesso graças ao estudo de novas técnicas numéricas, juntamente com o avanço significativo dos atuais computadores, permitindo assim que os resultados de tais simulações sejam mais precisos e efetuados em tempo relativamente menor. Isto tem diminuido os custos e viabilizado pesquisas nesta área.

\subsubsection{Escoamento Multifásico Computacional}

Escoamento multifásico ocorre em inúmeros processos industriais cobrindo uma grande classe de fenômenos e escalas diferentes. No caso da computação de escoamentos de uma única fase, a física é frequentemente bem entendida e métodos relativamente gerais podem ser empregados. Isso não ocorre em escoamentos multifásicos, onde o entendimento fundamental do fenômeno físico envolvido é ainda muito pobre, PORTELA [68]. Além disso, há significativas diferenças de comportamento entre diferentes escoamentos. Por essa razão, a técnica apropriada da simulação dependerá do tipo de escoamento que se quer tratar, já que os modelos matemáticos tornam-se específicos.

Um tipo muito comum de escoamento multifásico é aquele que considera duas fases, sendo, portanto, um escoamento bifásico. Este tipo de escoamento é importante nas mais variadas aplicações industriais complexas, como por exemplo na geração e conversão de energia, produção de papel, produção de alimentos, aplicações na área médica, entre 
outras.

O escoamento bifásico é de grande interesse para o desenvolvimento dessas aplicações, pois daí pode-se obter um entendimento básico dessas aplicações. ISHII [41] oferece uma classificação geral para escoamento bifásico subdividindo em gás-sólido, gás-líquido, sólido-líquido ou ainda dois líquidos imiscíveis. Esta classificação, bem como uma classificação de modelos e formulações de escoamento bifásico, pode ser encontrada também em ENWALD et al. [20]. ISHII [41] faz também uma classificação quanto à topologica do escoamento, ou seja, separados, misturados ou dispersos. Os escoamentos dispersos subdividem-se ainda em bolhas de gás em líquidos, gotas em gás, partículas sólidas em líquidos e partículas sólidas em gás. Essa classificação é útil para a compreensão de formulações de modelos numéricos para escoamento multifásico.

Neste trabalho são de interesse os escoamentos dispersos, em partícular escoamentos de partículas sólidas em gás.

Problemas de escoamentos bifásicos dispersos podem ser modelados de diversas maneiras. Em algumas aplicações, por exemplo, as duas fases podem ser modeladas considerando as equações estabelecidas para um escomento monofásico, mas com fronteira móvel entre as fases. Outro exemplo é a aplicação com mistura de fases quando o número de partículas sólidas (ou bolhas) em uma fase dispersa é muito alto. Em ambos os casos procedimentos de médias são necessários para que se possa conseguir uma formulação para o problema. São aplicados procedimentos de média no espaço, no tempo e valores médios estatísticos (ensemble average).

As aplicações comuns de simulação de escoamento multifásico ocorrem, por exemplo, em colunas de bolhas largamente utilizadas em indústrias bioquímicas; tanque misturador, utilizado em inúmeros processos tais como cristalização e aglomeração de partículas, misturando diferentes líquidos; e escoamento envolvendo reações químicas com partículas catalizadoras, que é outro exemplo bastante comum de aplicação de escoamento multifásico em indústrias. 
Em inúmeros processos industriais deseja-se separar diferentes tipos de fases. Em escoamento bifásico gás-sólido, por exemplo, o dispositivo separador é denominado ciclone. Trata-se de um tubo cônico em que as partículas e o gás são alimentados radialmente, conforme ilustrado na Figura 1.1. Devido à força centrifuga, as partículas são jogadas para a parede e, em seguida, escorregam para a parte de baixo do dispositivo devido à força da gravidade, e a partir daí estas partículas são coletadas em um recipiente e o gás deixa o separador pelo topo, limpo de partículas, [68].

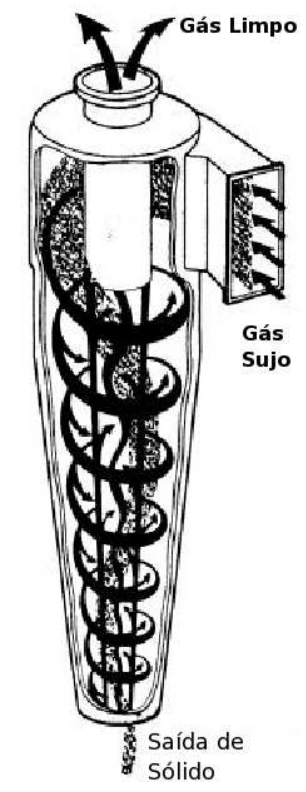

Figura 1.1: Ciclone. (PORTELA [68])

A Figura 1.2 mostra a simulação numérica da evolução no tempo das partículas no interior de um ciclone convergindo para a base deste dispositivo, [68].

Geralmente configurações de escoamento multifásico são utilizadas não separadamente, mas como parte de um processo complexo, como numa unidade FCC (Fluid Catalytic Cracking), ilustrada na Figura 1.3.

Trata-se de uma operação de alto custo monetário e componente crucial em refinarias de petróleo. Neste caso, esta unidade pode ter, por exemplo, a função de converter um hidrocarboneto residual pesado em produto de baixo peso molecular, tal como a gasolina. 


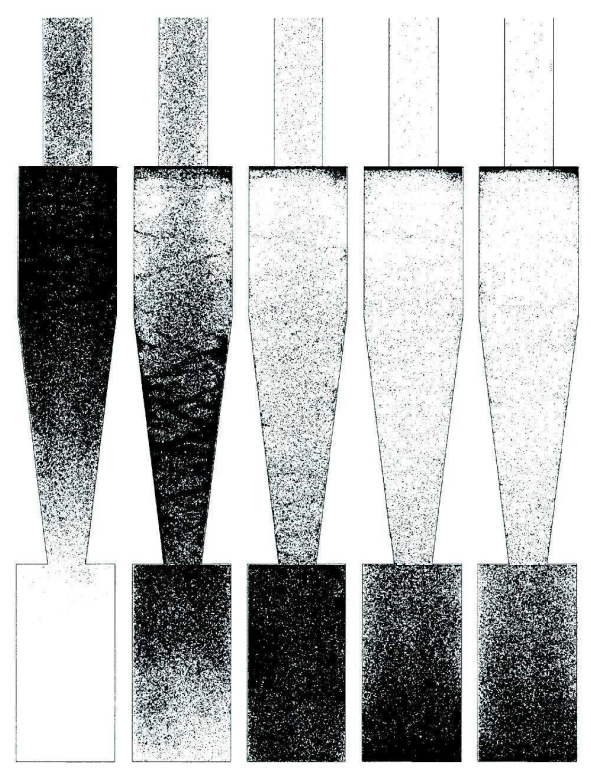

Figura 1.2: Visualização numérica de um processo de separação das partículas do gás no interior de um ciclone (PORTELA [68]).

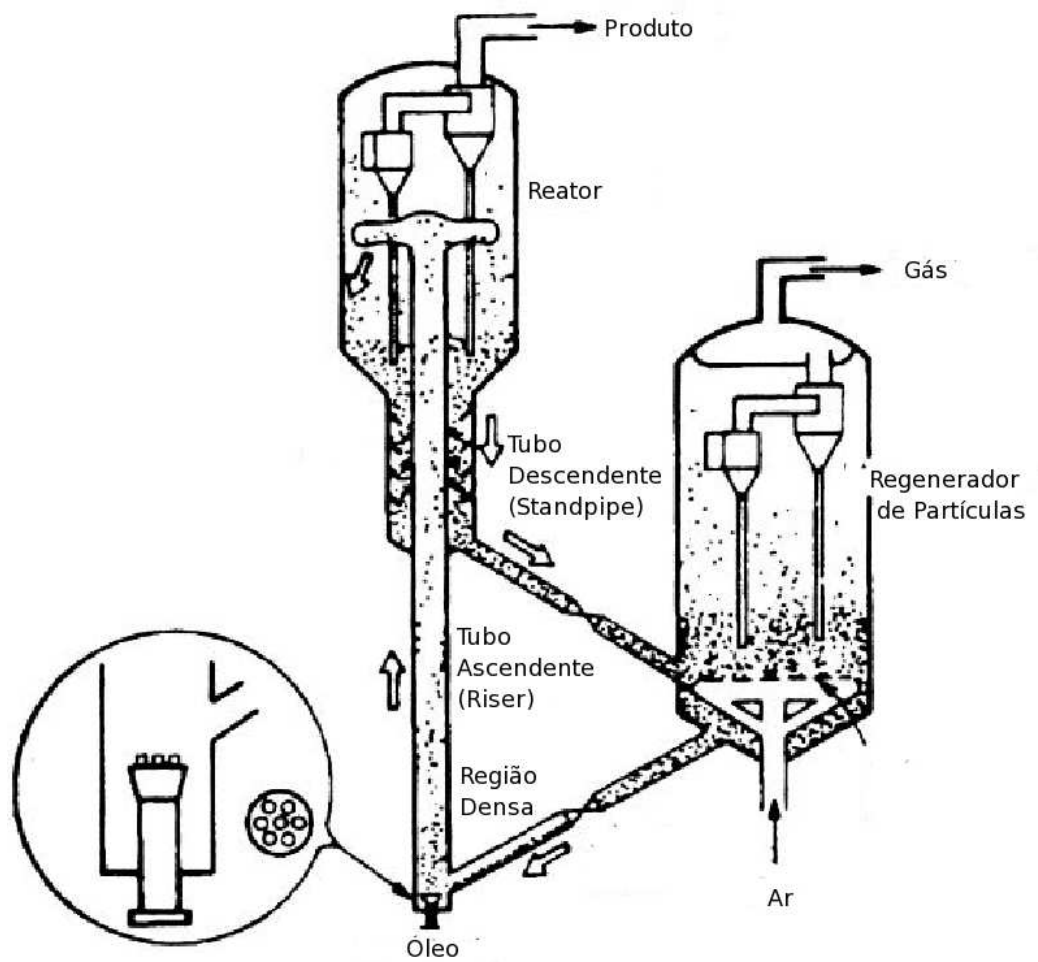

Figura 1.3: Unidade FCC (PORTELA [68]).

O funcionamento básico de uma unidade FCC pode ser explicado da seguinte forma: o óleo pesado é introduzido na parte de baixo denominado leito ou riser na forma de 
vapor, onde se reune com partículas catalisadoras aquecidas.

$\mathrm{Na}$ interface partículas-vapor ocorre a reação de craqueamento, transformando óleo pesado em hidrocarbonetos mais leves. Na saída do riser, as partículas catalíticas são separadas deste produto por meio de uma série de ciclones com funcionamento conforme explicado anteriormente, e são raramente recirculantes para a base do riser.

Este processo envolve uma larga combinação de dispositivos de escoamento multifásico operando em diferentes condições de fluidização, ou seja, desde escoamento diluído até muito denso em termos de concentração de particulado sólido misturado ao gás.

\subsubsection{Regimes de Fluidização e Leito Fluidizado Circulante}

As indústrias de petróleo, de geração de energia, bem como as indústrias químicas utilizam largamente reatores denominados de Leito Fluidizado (LF). Estes reatores são utilizados, por exemplo, na combustão de carvão e combustíveis alternativos para geração de energia em larga escala. Outro exemplo do uso desses reatores de LF é no craqueamento catalítico do petróleo para a geração de gasolina e outros combustíveis derivados do petróleo, conforme descrito na seção anterior.

Conforme descreve AGRAWAL [1], o fenômeno de fluidização em um leito contendo, por exemplo, partículas sólidas ocorre pela descarga de gás para o interior desse leito, e que flui pelos espaços deixados entre as partículas. Se a vazão desse gás for baixa, o arrasto sobre as partículas pode não vencer seu peso, e estas permanecerão estáticas. Sendo o arrasto suficiente para vencer o peso das partículas, estas passam a flutuar e o leito é dito estar em estado de "mínima fluidização". Um aumento adicional na vazão do gás geralmente causa o aparecimento de bolhas de gás. Neste caso tem-se o regime de "fluidização borbulhante".

Aumentando-se ainda mais a vazão de gás, o escoamento pode atingir um desenvolvimento sem padrão definido. Neste caso, tem-se o denominado regime de "fluidização 
turbulenta".

Na condição em que a velocidade do gás se torna maior do que a velocidade terminal das partículas, estas são sopradas para fora do leito pela parte superior. Este é o denominado regime de "fluidização rápida". Devido à importância do contato dessas partículas no processo de reação química de interesse, tem-se a necessidade de reposição rápida dessas partículas, o que é feito pela parte inferior do leito, definindo assim o regime de "fluidização recirculante".

A partir da condição de regime de fluidização rápida e aumentando-se novamente a vazão de gás no interior do leito, tem-se o denominado regime de "transporte pneumático". Em BAI et al. [8] são apresentos características hidrodinâmicas de diferentes regimes de escoamento e comparadas com resultados experimentais obtidos em uma unidade de craqueamento catalítico.

O escoamento gás-sólido em leitos fluidizados circulantes caracteriza-se: (1) distribuição não uniforme de partículas sólidas no interior do leito; (2) velocidades de deslizamento acentuadas entre gás e partícula; (3) recirculação de partículas e (4) escoamento descendente de partículas próximo às paredes do leito. Basicamente as causas da complexidade deste tipo de escoamento são iterações partícula-partícula e partícula-gás.

Basicamente, existem dois tipos de LF de grande aplicação prática: (a) Leito Fluidizado Borbulhante (LFB) caraterizado por altas densidades de particulado e, principalmente, pelo desenvolvimento de bolhas de gás no interior do leito. A característica hidrodinâmica marcante neste tipo de leito é que a velocidade do gás no interior do leito é menor que a velocidade terminal das partículas. (b) LFC, mostrado na Figura 1.4, cujas características são: (1) baixas frações volumétricas de partículado; (2) altas taxas de circulação e, consequentemente, (3) um regime de fluidização rápida.

Ao contrário do LFB, no LFC a velocidade terminal do particulado é menor do que a velocidade do gás. Isto implica que o particulado é removido do interior do leito e, portanto, sendo necessária a recirculação do particulado sólido, GELTART (1986) e BASU 
E FRASER (1991). Este trabalho concentra-se na simulação bifásico gás-solido em LFC.

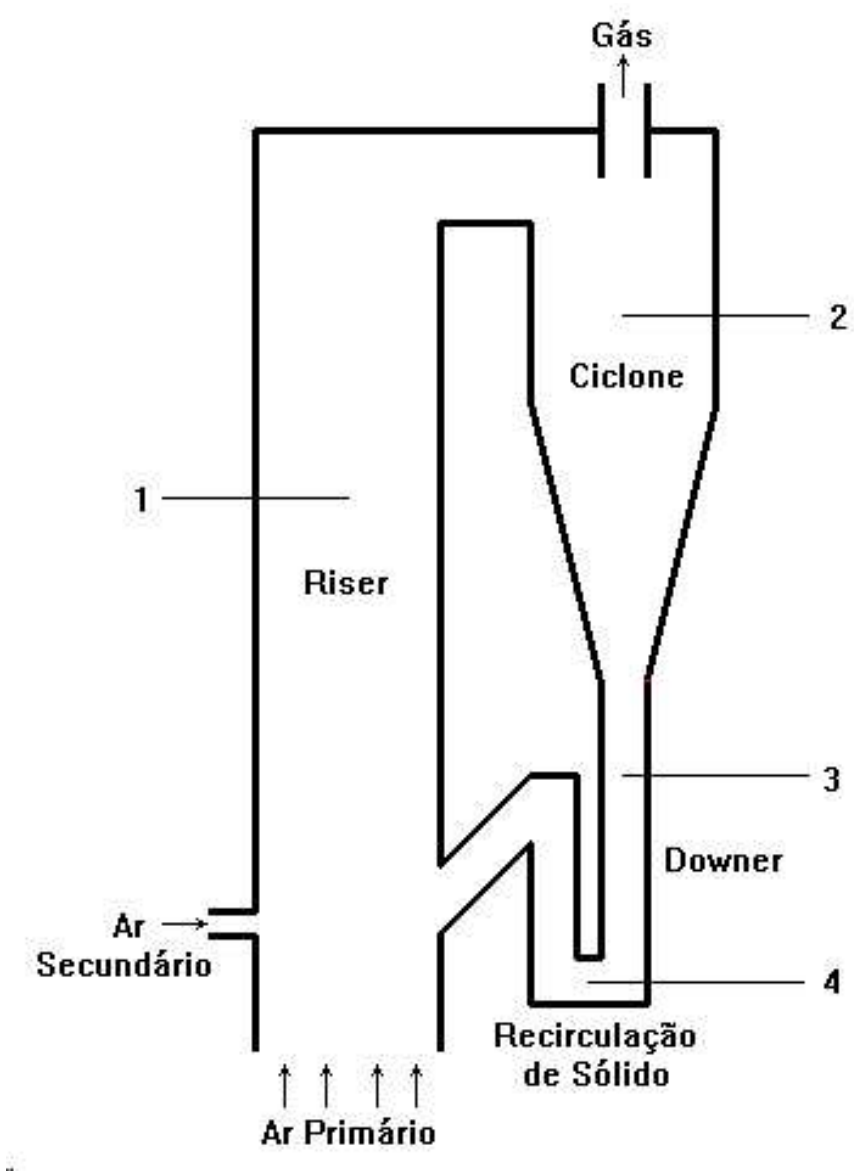

Figura 1.4: Diagrama de um LFC.

As principais partes de um reator de LFC, Figura 1.4, são: (1) coluna ascendente (riser); (2) ciclones separadores que recirculam o leito; (3) coluna de retorno do particulado sólido (downer) e (4) válvula de recirculação de sólido ligando a coluna de retorno com o (riser).

A simplicidade de um LF está apenas no seu aspecto geométrico, pois sobre o aspecto hidrodinâmico no interior deste leito, devido ao escoamento multifásico, a situação é bem mais complexa e isto justifica a necessidade de investimentos em pesquisas que investiguem os aspectos hidrodinâmicos que ocorrem neste dispositivo.

O riser essencialmente é um tubo que pode chegar a centenas de metros de altura e várias unidades de metros de diâmetro, dependendo da instalação e interesse de 
aplicação. O riser de um LFC é a região onde ocorrem os processos reativos de interesse, e o presente esforço de simulação é concentrado nessa região. Além disso, o estado atual de hardware (processador e memória virtual) não permite simular o ciclo todo com uma malha suficientemente fina.

O gás pode escoar pelo interior deste tubo a uma velocidade na ordem de dezenas de metros por segundo. Em plantas de FCC, as partículas catalisadoras têm tipicamente o tamanho de $30 \mu \mathrm{m}$, podendo chegar a $100 \mu \mathrm{m}$.

Tipicamente em escoamente bifásico gás-sólido em LFC, a fração volumétrica do particulado é da ordem de 1\%, podendo chegar a $5 \%$ da fração volumétrica do gás para a combustão de carvão e, para craquemamento catalítico a concentração pode ser da ordem de 20\%. Mesmo que a fração volumétrica da partícula seja pequena, não pode ser negligenciada e desde que a densidade das partículas é muito maior que a densidade do gás, a fração mássica de partículas pode ser muito alta.

Segundo TSUO [92], os principais fatores de investigação relacionados a hidrodinâmica dos LFC's são: (1) a distribuição axial e radial não homogênea de ambas as fases (gás e sólido); (2) A formação de agregados de partículas que acontece no regime de fluidização rápida dispersa e (3) o padrão de escoamento anular que pode ocorrer no regime de fluidização rápida densa.

\subsection{Estado-da-Arte sobre Simulações de Escoamen- tos Gás-Sólido em Risers de LFC}

Segundo ZHANG \& VANDERHEYDEN [103], embora os esforços até agora sobre simulação numérica de escoamentos bifásicos tenham trazidos relativos sucessos, o conhecimento em escoamentos gás-sólido ainda permanece longe do ideal. Sobre trabalhos envolvendo simulações numéricas variando sistematicamente as dimensões de um riser, os autores concluem que, embora haja resultados descrevendo os efeitos de escala de risers (e downers) no desenvolvimento do escoamento gás-sólido, ainda não há nenhum traba- 
lho que tenha realizado simulações numéricas variando sistematicamente suas dimensões.

Desde HARLOW \& AMSDEN [31], muitas outros pesquisadores têm concentrado seus esforços em simulações numéricas envolvendo escoamentos multifásicos [42], [68], [72], [73], [94], [95], e, particulamente, em escoamento bifásico, [1], [12]- [15], [21], [27] - [25], [39], [41], [48], [49], [64] - [65], [78]. Isso é devido ao grande interesse em obter informações da alta complexidade hidrodinâmica normalmente encontrada nos escoamentos multifásicos, e também devido sua vasta aplicabibilidade em indústrias químicas, de petróleo e de geração de energia.

A hidrodinâmica de escoamentos gás-sólido em LFC tem sido estudada via simulação numérica e experimental. No primeiro grupo estão os modelos matemáticos que tetam incorporar a física e a química envolvidas nos processos e ferramentas numéricas de solução. No segundo grupo, grandes aparatos experimentais são montados em escalas reduzidas ou reais na busca de métodos de medição precisos para investigar o escoamento. Uma comparação entre soluções numéricas obtidas por meio de modelos de dois-fluidos com resultados experimentais é feita em [20]. Comparações semelhantes podem ser encontradas em [55], [71], [87]. Em [68] são analisadas as possibilidades e limitações de simulações computacionais de escoamentos do tipo disperso envolvendo turbulência. No grupo dos experimentalistas, encontram-se vários autores [17], [33], [35], [52], [96], [100], [104]. Na linha de resolução por computação numérica de escoamento gás-sólido tem-se, [12] [15], [20], [27], [38], [39], [48], , [49], [63], [86], [91], [92], entre muitos outros autores.

Diferentes aspectos hidrodinâmicos em escoamentos gás-sólido em LFC são estudados numericamente, experimentalmente, ou utilizando ambas as abordagens. Por exemplo, aspectos ligados ao tipo de regime de escoamento, dependendo dos parâmetros estabelecidos, tais como formação de cluster [34], [36] (aglomerações) em risers, [91], [102], formação de bolhas [19], [86], fluidização rápida [7], [8], transporte pneumático [40], turbulência [25], [35], [52], [56] (investiga a turbulência em coluna de bolhas), [64], [65], [67], [88] dentre outros, são importantes para a compreensão do processo de fluidização. Em [9] é possível encontrar uma revisão sobre o regime de fluidização gás-sólido turbulento. 


\subsubsection{Simulações Numéricas de Escoamentos Multifásicos Gás- Sólido em LFC com Diferentes Geometrias}

A geometria do riser tem sido um aspecto de interesse de investigação na sua influência no desenvolvimento de um escoamento gás-sólido em LFC. As dimensões de um riser podem ser consideradas como comprimentos de escala podendo afetar o desenvolvimento do escoamento. Segundo ANDREWS IV et al. [4], as equações do modelo do contínuo para escoamentos não estacionários em risers, por exemplo, contêm modos instáveis, cujos menores comprimentos de escala são da ordem de dez diâmetros de uma partícula. Os autores afirmam ainda que devido às limitações computacionais, estes escoamentos são rotineiramente simulados resolvendo-se modelos do contínuo utilizando malhas espaciais grosseiras. Assim, para a maioria das aplicações industriais, que envolvem grandes volumes, torna-se impraticável capturar todas as estruturas de fina-escala e, portanto, os efeitos dessas estruturas devem ser recuperadas através de modelos submalha.

Já HARRIS et al. [33] em seus experimentos fazem medições da influência da geometria da saída de um riser, afirmando que se trata de um aspecto de impacto significativo no comportamento hidrodinâmico da unidade toda. HARRIS et al. [33] argumentam que os efeitos de saída do riser parecem ser função de várias condições operacionais, propriedades da partícula e dimensões do riser (diâmetro e altura).

CHENG et al. [17] sugerem que os efeitos de entrada e saída da coluna, são importantes na modelagem de um escoamento em riser, posto que afetam sua hidrodinâmica significativamente. ZHANG et al. [104] mediram a fração de sólido local transiente e a velocidade da partícula em um leito fluidizado de $0,42 \mathrm{~m}$ de diâmetro e $18 \mathrm{~m}$ de altura, comparando a formação de cluster no riser com um downer de mesmo diâmetro e 6,5m de altura. Notaram que a concentração de sólido no downer vem a ser menor do que no riser e, portanto, com formação de clusters menos intensa. ZHANG et al. [104] afirmam que os diferentes mecanismos de escoamento de clusters entre riser e downer resultam em uma diferença significativa na estrutura de macro escala do escoamento. 


\subsubsection{Simulações Numéricas em Risers com Dimensões Reduzi- das}

ZHANG \& VANDERHEYDEN [103] realizaram simulações considerando um domínio tridimensional de dimensões $20 \mathrm{~cm}$ x $20 \mathrm{~cm}$ e $200 \mathrm{~cm}$ de altura com saída posicionada abaixo de $180 \mathrm{~cm}$. Os autores indicam que apesar de usarem modelos bifásicos simples que negligenciam a física associada com a interação entre partículas, os resultados convergidos concordam com dados experimentais. Contudo alertam sobre a necessidade do uso de malhas mais finas e sugerem, também, o uso de modelos de meso-escala para descrever as propriedades do escoamento de escala.

Nesta linha de simulações com risers de dimensões reduzidas MATHIESEN et al. [55] apresentam um estudo computacional de escoamento gás-sólido com modelo euleriano utilizando um domínio de dimensões $0,2 \mathrm{~m} \times 2.0 \mathrm{~m}$ focando o estudo na variação do tamanho da partícula sólida. Utiliza uma malha grosseira de dimensões 5,4mm x 19,8mm para o domínio considerado. O trabalho não apresenta análise acerca do efeito do domínio e malha nos resultados de simulação.

YAN et al. [100] analisaram experimentalmente a influência do diâmetro do riser nos fluxos de sólido radial e axial, bem como no desenvolvimento do escoamento. Considerando três diâmetros diferentes para o riser, a saber: $76 \mathrm{~mm}$ e altura de $15 \mathrm{~m}, 100 \mathrm{~mm}$ e altura de 10m e 203m também com altura de 10m. Observam que o perfil radial do fluxo de sólido é menos uniforme no riser mais amplo do que nos menores, e que o desenvolvimento do escoamento torna-se mais lento com o aumento do diâmentro do riser.

É objetivo deste trabalho investigar os efeitos das diferentes malhas numéricas computacionais na simulação numérica em riser de um LFC considerando dimensões reduzidas. 


\subsection{Formulações Eulerianas para Escoamentos Gás- Sólido em LFC}

Modelos para escoamentos bifásicos também são classificados de acordo com a sua formulação. A respeito da física do modelo considerado, há basicamente dois tipos de formulação para a computaçao de escoamento multifásico disperso: são as formulações Euler-Lagrange, também denominada de Particle-Tracking, e Euler-Euler, também conhecida como modelo de dois-fluidos ou ainda modelo de fases separadas. As utilizações de modelos de fases separadas, bem como Euler-Lagrange são claramente descritas em [12] - [15], [20], [27], [21], [55], [61], [68], [91], dentre outros.

\subsubsection{Formulação Euler-Langrange}

Na formulação Euler-Langrange aplica-se a segunda lei de Newton a cada partícula individualmente do escoamento, enquanto a fase contínua é descrita a partir das equações conservativas do meio contínuo. Para fases contínuas, é comum a aplicação de simulação RANS (Reynolds Average Navier-Stokes Simulation) ou DNS/LES (Direct Numeric Simulation/Large-Eddy Simulations), [18], [23], [45], [46], [50], [67], [76], [90].

Na simulação do tipo RANS as equações são essencialmente as mesmas da formulação Euler-Euler, porém as partículas são seguidas utilizando um modelo de força entre as partículas e o fluido. Modelos adicionais considerando colisão entre partículas e também das partículas na parede podem ser acrescentados.

PORTELA [68] aponta que as duas maiores dificuldades das formulações EulerLagrange são: (1) um grande número de partículas pode ser necessário e, assim, seguir este grande número de partículas pode ser uma tarefa de alto custo computacional e até mesmo impossível de ser realizada. (2) A incorporação dos efeitos de turbulência na trajetória e dispersão das partículas.

Para minimizar a dificuldade (1), pode-se considerar a introdução de partículas representativas e o modelo de colisão fictícia de partículas descrita por SOMMERFELD [79]. No caso da dificuldade (2), pode-se considerar as flutuações de velocidade utilizando a 
energia cinética e a de dissipação turbulenta obtida da simulação RANS. Com isso um modelo extra é introduzido, que, no entanto, pode não representar adequadamente a complexidade das interações turbulentas entre partículas.

A formulação Euler-Lagrange tem sido utilizada em inúmeros escoamentos originados de problemas industriais que vão desde de escoamentos muito diluidos (ciclones), transportes pneumáticos [40], até escoamentos em leitos fluidizados.

Em Euler-Lagrange as partículas são consideradas como ponto, e a interação entre a partícula e o fluido circundante se dá através de uma força localizada nesse ponto. Assim, juntamente com equações de conservação da massa e de momentum para a fase contínua, resolve-se também a equação de movimento de cada partícula individual.

$$
\begin{gathered}
\nabla \cdot \tilde{\mathbf{u}}=0 \\
\rho\left\{\frac{\partial \tilde{\mathbf{u}}}{\partial t}+(\nabla \tilde{\mathbf{u}}) \cdot \tilde{\mathbf{u}}\right\}=-\nabla \mathbf{P}+\mu \nabla^{2} \tilde{\mathbf{u}}+\nabla \cdot \tilde{\sigma}_{\mathbf{s}}+\tilde{\mathbf{f}} \\
M_{p} \frac{d \vec{V}_{p}}{d t}=\vec{F}_{p}
\end{gathered}
$$

sendo $\mu$ a viscosidade, $\vec{\sigma}_{s}$ o tensor de tensões viscosas na fase contínua, $\tilde{\mathbf{f}}$ a força por unidade de volume devido ao arrasto sobre as partículas. $M_{p}, V_{p}$ e $\vec{F}_{p}$ são a massa, a velocidade e a força que age na partícula individual $p$, respectivamente.

A formulação Euler-Lagrange é largamente utilizada para se obter um entendimento da interação partícula-turbulência. No grupo de PORTELA [68], esta formulação tem sido utilizada para investigar a dinâmica do escoamento próxima à parede (paredefronteira) com partículas pequenas e, após isso, dar suporte para o desenvolvimento de modelos melhorados que serão utilizados em simulações com formulação Euler-Lagrange (RANS) ou Euler-Euler. 


\subsubsection{Formulação Euler-Euler}

A formulação Euler-Euler existe desde 1960, sendo largamente utilizada em simulações de problemas industriais, não somente considerando escoamento bifásico, (gás-sólido, líquido-sólido ou gás-líquido) como também em escoamentos multifásicos envolvendo bolhas e pequenas partículas catalisadoras, GUENTHER e SYAMLAL [86].

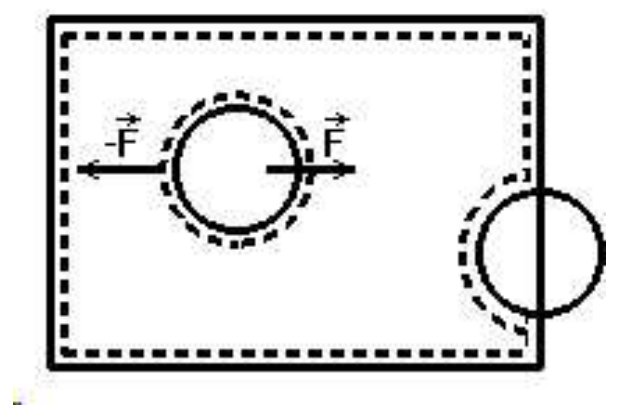

Figura 1.5: Formulação Euler-Euler: Modelo de fases separada.

Conforme descreve PORTELA [68], esta formulação tem gerado informações úteis quando utilizada para melhoraria do desempenho de um equipamento que utiliza escoamento multifásico. Ainda segundo o autor, a maior dificuldade dessa formulação é a dependência nos modelos constitutivos utilizados em conjunto com as equações conservativas de meio contínuo que formam o modelo Euler-Euler propriamente dito. Porém, esta formulação tem trazido bons resultados qualitativos em simulações cuja geométria é relativamente complexa, geralmente encontrados em problemas industriais.

Nas formulações Euler-Euler tanto fases contínuas quanto dispersas são tratadas como meios contínuos. As equações de conservação da massa e de momentum na formulação Euler-Euler para cada fase $k$ são da seguinte forma, de acordo com a descrição de GIDASPOW [27]:

- Equação da continuidade para a fase k:

$$
\frac{\partial}{\partial t}\left(\alpha_{k} \rho_{k}\right)+\nabla \cdot\left(\alpha_{k} \rho_{k} \mathbf{u}_{\mathbf{k}}\right)=m^{\prime}{ }_{k}
$$


sendo que $k=c$ denota a fase contínua e $k=d$ denota a fase dispersa. No caso específico em que se tem um escoamento bifásico gás-sólido, as partículas sólidas formam a fase dispersa e o gás a fase contínua. Neste caso, utiliza-se $k=s$ e $k=g$, respectivamente para denotar as fases sólida e gasosa. O termo $m^{\prime}{ }_{k} \mathbf{u}_{k}$ representa variação de momentum devido à troca de massa entre fases, como ocorrem, por exemplo, em evaporação e reações químicas. Neste trabalho, admite-se que $m^{\prime}{ }_{k} \mathbf{u}_{k}=0$, conforme será descrito no Capítulo seguinte sobre modelagem euleriana levando-se em conta a hidrodinâmica do escoamento bifásico gás-sólido.

\section{- Equação de momentum para a fase k:}

$$
\begin{aligned}
\frac{\partial}{\partial t}\left(\alpha_{k} \rho_{k} \mathbf{u}_{k}\right)+\nabla \cdot\left(\alpha_{k} \rho_{k} \mathbf{u}_{k} \mathbf{u}_{k}\right) & =\alpha_{k} \rho_{\mathbf{k}} \mathbf{F}_{\mathbf{k}}+\nabla \cdot \mathbf{T}_{\mathbf{k}}+\sum_{l} \beta\left(\mathbf{u}_{l}-\mathbf{u}_{k}\right)+ \\
& +m^{\prime}{ }_{k} \mathbf{u}_{k}
\end{aligned}
$$

sendo que $\alpha, \rho, \mathbf{u}, \mathbf{T}$ e $\beta$ denotam, respectivamente, a fração volumétrica, a densidade, a velocidade, o tensor das tensões viscosas e o coeficiente de fricção para interação sólido-fluido. O primeiro termo do lado direito da Equação (1.5) representa as forças de campo. O segundo e o terceiro termos denotam o tensor das tensões viscosas e as forças de arrasto (ou interações gás-partícula), respectivamente.

Há dificuldades a serem superadas tanto em formulações Euler-Lagrange quanto em formulações Euler-Euler. Contudo, no que se refere a leitos fluidizados as formulações Euler-Euler se mostram mais praticáveis em vista do elevadíssimo número de partículas presentes nos escoamentos, conforme observado por SUNDARESSAN [80]. Assim, neste trabalho aplica-se a formulação Euler-Euler. 


\section{Capítulo 2}

\section{Modelagem Euler-Euler e Solução Numérica de Escoamentos Bifásicos Gás-Sólido}

Este capítulo descreve a teoria básica dos modelos para escoamento bifásico, bem como as leis constitutivas, as condições iniciais e de contorno para simulação de um leito fluidizado gás-sólido.

Também neste capítulo, faz-se um desenvolvimento básico teórico que servirá para ilustrar a técnica de volumes finitos utilizada na discretização das equações que modelam o escoamento bifásico gás-sólido bidimensional.

\subsection{Introdução}

No modelo hidrodinâmico Euler-Euler, ou de dois fluidos, para escoamento bifásico gás-sólido as fases são consideradas interpenetrantes, contínuas e o escoamento é modelado por um conjunto de equações de balanço de massa e de momentum, conforme exposto no Capítulo anterior.

Cada fase aqui será considerada como um meio contínuo, onde as propriedades do escoamento são descritas em termos das grandezas macroscópicas, pressão, velocidade e densidade aparente (densidade do fluido multiplicada pela respectiva fração volumétrica). 
O fluxo de uma grandeza (massa, energia, momentum) pode ser difinido como sendo a quantidade dessa grandeza que atravessa uma fronteira com uma determinada área $A$ por unidade de tempo. A quantidade líquida de uma grandeza $\phi$ que atravessa as fronteiras de um volume de controle $V$ por unidade de tempo é calculada pela integração sobre essas fronteiras da diferença entre os fluxos que entram e os fluxo que saem de $V$. Estes fluxos podem ser do tipo convectivo ou difusivo.

O fluxo do tipo convectivo é causado pela velocidade do fluido. De uma forma geral, o termo convectivo é dado por $\rho \phi \vec{u}$, sendo $\rho$ a densidade (massa específica), $\phi$ a propriedade trasportada ou convectada e $\mathbf{u}$ a velocidade do fluido. Uma componente do fluxo convectivo na direção de um vetor unitário $\mathbf{n}$ qualquer é dada por $\rho \phi \mathbf{u} \cdot \mathbf{n}$.

O fluxo difusivo é causado pela não uniformidade da distribuição espacial de $\phi$. Sendo $\Gamma$ o coeficiente de difusividade e $\nabla$ o operador que, em coordenadas cartesianas bidimensionais, é dado por:

$$
\nabla=\mathbf{i} \frac{\partial}{\partial \mathbf{x}}+\mathbf{j} \frac{\partial}{\partial \mathbf{y}}
$$

onde $\mathbf{i}$ e $\mathbf{j}$ são os vetores unitários nas direções $x$ e $y$ respectivamente, então o termo difusivo pode ser escrito na forma $\Gamma \nabla \phi$, sendo $\phi$ agora a propriedade difundida. O componente do fluxo difusivo na direção de um vetor unitário $\vec{n}$ qualquer é dado por $\Gamma \nabla \phi \cdot \vec{n}$.

A equação para a taxa de variação de $\phi$ no volume de controle $V$ pode ser enunciada da seguinte forma: "A taxa de variação de $\phi$ em $V$ é igual à entrada líquida de $\phi$ em $V$ juntamente com a produção líquida de $\phi$ em $V "$.

A taxa de variação de $\phi$ em $V$ é dada pelas composições entre os fluxos convectivos e difusivos de $\phi$ que entram e saem de $V$. A entrada líquida de $\phi$ em $V$ juntamente com a produção líquida de $\phi$ em $V$ é a diferença entre a geração e o consumo de $\phi$ em $V$. 
Considerando a equação genérica transiente de transporte convecção-difusão conhecida na literatura, temos que na forma diferencial para o transporte de uma propriedade qualquer $\phi$ é dada por:

$$
\frac{\partial}{\partial t}(\rho \phi)+\nabla \cdot(\rho \phi \mathbf{u})=\nabla \cdot\left(\boldsymbol{\Gamma}_{\phi} \nabla \phi\right)+\mathbf{S}_{\phi}
$$

sendo $\Gamma_{\phi}$ o coeficiente de difusão e $S_{\phi}$ o termo fonte, ambos específicos para cada $\phi$.

A equação conservativa genérica acima será usada para ilustrar a aplicação da técnica de volumes finitos. Considerando uma situação simplificada de escoamento newtoniano incompressível tem-se que, se $\phi=\mathbf{u}$, então $S_{\phi}$ é igual a $-\nabla P$ (gradiente de pressão) e forças de campo e, $\Gamma_{u}=\mu$ (viscosidade dinâmica). Logo a Equação (2.2) se torna:

$$
\frac{\partial}{\partial t}(\rho \mathbf{u})+\nabla \cdot(\rho \mathbf{u u})=-\nabla \mathbf{P}+\nabla \cdot(\mu \nabla \mathbf{u})
$$

Além disso, para obter a equação da continuidade, basta considerar $\phi=1$ e $S_{\phi}=0$ na Equação (2.2), ou seja,

$$
\frac{\partial}{\partial t}(\rho)+\nabla \cdot(\rho \mathbf{u})=0
$$

Equações conservativas discretizadas são obtidas integrando-se a equação genérica (2.2) no tempo e num volume finito $V$. 


\subsection{Esquema de Discretização}

\subsubsection{Técnica de Volumes Finitos}

Para discretização das equações que modelam o escoamento bifásico gás-sólido bidimensional, será utilizado o método de volumes finitos. Este método está ligado ao conceito de fluxo entre regiões (ou volumes) adjacentes.

Segundo SYAMLAL [86], utiliza-se a técnica de volumes finitos para preservar o caráter conservativo das equações. Este método divide o domínio físico em volumes de controle discretos nos quais as equações que modelam o problema são integradas. Isto assegura a conservação global da massa, de momentum e de energia, independentemente da malha, PATANKAR [63].

Para demonstrar essa técnica, considera-se a Equação (2.2) descrita na seção anterior aplicada para um escoamento bifásico (gás-sólido). Assim, a Equação (2.2) fica da seguinte forma:

$$
\frac{\partial}{\partial t}\left(\alpha_{k} \rho_{k} \phi\right)+\frac{\partial}{\partial x_{j}}\left(\alpha_{k} \rho_{k} u_{k j} \phi\right)=\frac{\partial}{\partial x_{j}}\left(\Gamma_{\phi} \frac{\partial \phi}{\partial x_{j}}\right)+S_{\phi}
$$

sendo $k=g$ denotando a fase contínua de gás e $k=s$ denotando a fase dispersa de partículas sólidas. $\alpha_{k}$ é a fração volumétrica da fase $k$, tal que $\alpha_{g}+\alpha_{s}=1$.

Considere o volume de controle, $V$, mostrado na Figura 2.1 a seguir e que será utilizado para integração da Equação (2.5).

Logo, integrando a Equação (2.5) no volume de controle $V$, tem-se:

$\int_{t} \int_{V} \frac{\partial}{\partial t}\left(\alpha_{k} \rho_{k} \phi\right) d V d t+\int_{t} \int_{V} \frac{\partial}{\partial x_{j}}\left(\alpha_{k} \rho_{k} u_{k j} \phi\right) d V d t=\int_{t} \int_{V} \frac{\partial}{\partial x_{j}}\left(\Gamma_{\phi} \frac{\partial \phi}{\partial x_{j}}\right) d V d t+\int_{t} \int_{V} S_{\phi} d V d t$ 


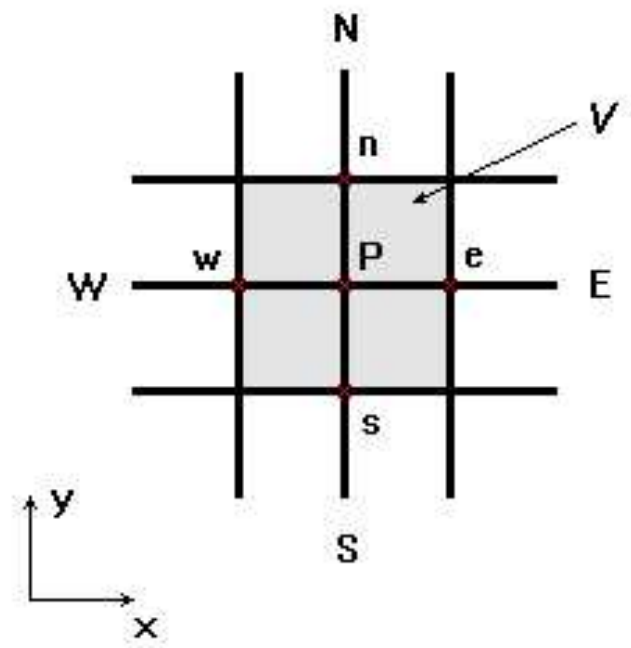

Figura 2.1: Volume de controle $(V)$ e localização das faces north $(n)$, west $(w)$, south $(s)$ e east $(e)$.

Portanto, os termos da Equação (2.6) são dados pelas seguintes expressões a seguir, integrando o termo transiente em $V$, e entre os instantes $t$ e $t+\Delta t$, tem-se

-Termo transiente,

$$
\begin{aligned}
\int_{t} \int_{V} \frac{\partial}{\partial t}\left(\alpha_{k} \rho_{k} \phi\right) d V d t & =\int_{w}^{e} \int_{s}^{n} \int_{t}^{t+\Delta t} \frac{\partial}{\partial t}\left(\alpha_{k} \rho_{k} \phi\right) d t d y d x \approx \Delta x \Delta y \int_{t}^{t+\Delta t} \frac{\partial}{\partial t}\left(\alpha_{k} \rho_{k} \phi\right) d t= \\
& =\Delta x \Delta y\left[\left(\alpha_{k} \rho_{k} \phi\right)_{p}^{n+1}-\left(\alpha_{k} \rho_{k} \phi\right)_{p}^{n}\right]
\end{aligned}
$$

Os termos convectivo e difusivo serão primeiramente integrados em $V$, para posteriormente serem também integrados no tempo.

-Termo Convectivo, 


$$
\begin{aligned}
\int_{V} \frac{\partial}{\partial x_{j}}\left(\alpha_{k} \rho_{k} u_{k j} \phi\right) d V= & \int_{s}^{n} \int_{w}^{e} \frac{\partial}{\partial x}\left(\alpha_{k} \rho_{k} u_{k} \phi\right) d x d y+\int_{w}^{e} \int_{s}^{n} \frac{\partial}{\partial y}\left(\alpha_{k} \rho_{k} v_{k} \phi\right) d y d x \approx \\
\approx & \int_{s}^{n}\left[\left(\alpha_{k} \rho_{k} \phi\right)_{e}\left(u_{k}\right)_{e}-\left(\alpha_{k} \rho_{k} \phi\right)_{w}\left(v_{k}\right)_{w}\right] d y+ \\
& +\int_{w}^{e}\left[\left(\alpha_{k} \rho_{k} \phi\right)_{n}\left(v_{k}\right)_{n}-\left(\alpha_{k} \rho_{k} \phi\right)_{s}\left(v_{k}\right)_{s}\right] d x= \\
= & \left(\alpha_{k} \rho_{k} \phi\right)_{e}\left(u_{k}\right)_{e} A_{e}-\left(\alpha_{k} \rho_{k} \phi\right)_{w}\left(u_{k}\right)_{w} A_{w}+ \\
& +\left(\alpha_{k} \rho_{k} \phi\right)_{n}\left(v_{k}\right)_{n} A_{n}-\left(\alpha_{k} \rho_{k} \phi\right)_{s}\left(v_{k}\right)_{s} A_{s}= \\
= & G(\phi(t))
\end{aligned}
$$

- Termo Difusivo,

$$
\begin{aligned}
\int_{V} \frac{\partial}{\partial x_{j}}\left(\Gamma_{\phi} \frac{\partial \phi}{\partial x_{j}}\right) d V & = \\
& =\int_{s}^{n} \int_{w}^{e} \frac{\partial}{\partial x}\left(\Gamma_{\phi} \frac{\partial \phi}{\partial x}\right) d x d y+\int_{w}^{e} \int_{s}^{n} \frac{\partial}{\partial y}\left(\Gamma_{\phi} \frac{\partial \phi}{\partial y}\right) d y d x \approx \\
& \approx \int_{s}^{n}\left[\left(\Gamma_{\phi} \frac{\partial \phi}{\partial x}\right)_{e}-\left(\Gamma_{\phi} \frac{\partial \phi}{\partial x}\right)_{w}\right] d y+\int_{w}^{e}\left[\left(\Gamma_{\phi} \frac{\partial \phi}{\partial x}\right)_{s}-\left(\Gamma_{\phi} \frac{\partial \phi}{\partial x}\right)_{s}\right] d x= \\
& =\left(\Gamma_{\phi} \frac{\partial \phi}{\partial x}\right)_{e} A_{e}-\left(\Gamma_{\phi} \frac{\partial \phi}{\partial x}\right)_{w} A_{w}+\left(\Gamma_{\phi} \frac{\partial \phi}{\partial x}\right)_{s} A_{s}-\left(\Gamma_{\phi} \frac{\partial \phi}{\partial x}\right)_{s} A_{s}= \\
& =F(\phi(t))
\end{aligned}
$$

Integrando também os termos convectivo e difusivo entre os instantes $t$ e $t+\Delta t$, e compondo todos os termos, tem-se:

$$
\int_{t}^{t+\Delta t} \int_{V} \frac{\partial}{\partial t}\left(\alpha_{k} \rho_{k} \phi\right) d V d t+\int_{t}^{t+\Delta t} G(\phi(t)) d t=\int_{t}^{t+\Delta t} F(\phi(t)) d t
$$

A discretização final dependerá agora de como se quer aproximar as duas integrais temporais dos fluxos convectivo e difusivo, respectivamente, da Equação (2.10). Nas 
integrações temporais pode-se considerar diferentes formulações: explícita, implícita e semi-implícita ou híbrida. Como pretende-se obter soluções transientes reais, aplica-se formulação implícita, ou seja,

$$
\int_{t}^{t+\Delta t} F(\phi(t)) d t \approx F\left(\phi^{n+1}\right) \Delta t: \text { Euler-Implícito. }
$$

Considerando o esquema de interpolação de diferenças centrais de segunda ordem para avaliar variáveis nas faces do volume de controle tem-se, para a face $e$, por exemplo:

$$
\left(\Gamma_{\phi} \frac{\partial \phi}{\partial x}\right)_{e}=\left(\Gamma_{\phi}\right)_{e}\left(\frac{\phi_{E}^{n+1}-\phi_{P}^{n+1}}{\Delta x_{e}}\right)+O\left(\Delta x_{e}^{2}\right)
$$

Com relação à aproximação do fluxo convectivo determinando $\phi$ nas faces do volume de controle, $V$, pode-se aplicar, por exemplo, diferenças centrais de segunda ordem. Dessa forma, a propriedade $\phi$ na face $e$ do volume de controle, por exemplo, é aproximada da seguinte maneira:

$$
\phi_{e}=\frac{\phi_{E}^{n+1}+\phi_{P}^{n+1}}{2}
$$

Na tentativa de garantir a estabilidade do esquema numérico, aplica-se aos termos convectivos o esquema de interpolação de primeira ordem denominado Upwind, onde

$$
\phi_{e}= \begin{cases}\phi_{P}, & \text { se } u \geq 0 \\ \phi_{E}, & \text { se } u<0 .\end{cases}
$$

Porém, sabe-se que este esquema de aproximação causa difusão numérica e, dessa forma, as soluções podem resultar tremendamente distorcidas por essa difusão numérica. 
A motivação para utilizar o esquema Upwind é a estabilidade numérica que propicia.

A partir do Upwind foram propostos procedimentos interpolativos mais realistas pela consideração de pesos convecção/difusão locais. Contudo, apesar de permitirem reduzir tal difusão numérica, estes procedimentos continuam com precisão de primeira ordem (ver, por exemplo, em LEONARD \& MOKHATARI [44]).

LEONARD e MOKHATARI [44] observam que é razoável esperar que métodos de discretização de alta ordem para aproximação do fluxo convectivo aumentam a precisão dos resultados.

Entretanto, esquemas de alta ordem também podem produzir oscilações no processo iterativo de solução, sobretudo perto de descontinuidades. Além disso, aumentam o tempo de convergência nas iterações, produzindo soluções intermediárias em desacordo com a física do problema.

Para contornar estas dificuldades foram propostas os denominados esquemas TVD (Total Variational Diminishing). Trata-se de esquemas de alta ordem que não produzem soluções espúrias, o que se consegue pela aplicação de limitadores para o valor da propriedade $\phi$ nas faces do volume de controle.

LEONARD e MOKHATARI [44] propuseram um método de discretização das quantidades calculadas nas faces de um volume de controle que impede oscilações sem introduzir difusão artificial. Este método foi denominado por eles por Down Wind Factor $(D W F)$ ou limitador universal. Baseado na notação e localização nas faces ao longo da direção do escoamento, Figura 2.2, tem-se que o $D W F$ é dador por:

$$
D W F=\frac{\phi_{f}-\phi_{C}}{\phi_{D}-\phi_{C}}=\frac{\tilde{\phi}_{f}-\tilde{\phi}_{C}}{1-\tilde{\phi}_{C}}
$$

sendo que $\tilde{\phi}$ representa valores normalizados de $\phi$ ao longo da direção do escoamento e dado por: 


$$
\tilde{\phi}=\frac{\phi-\phi_{U}}{\phi_{D}-\phi_{U}}
$$

Segundo LEONARD e MOKHATARI [44], uma das funcionalidades deste fator é simplificar a inserção de métodos de alta ordem em um código existente sem a necessidade de se alterar a estrutura matricial das equações discretizadas, por gerar um método implícito conveniente para obtenção das soluções das matrizes pentadiagoanal (no caso bidimensional) ou septadiagoanal (no caso tridimensional).

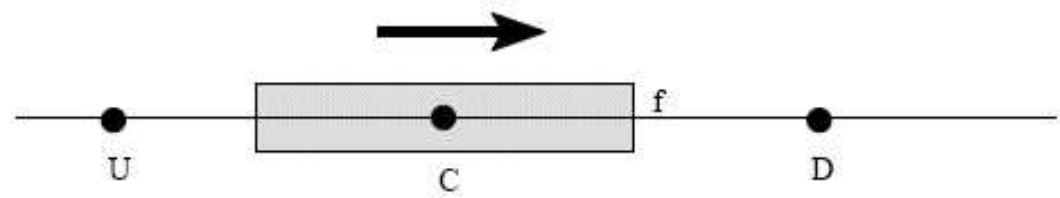

Figura 2.2: Notação e localização das faces ao longo da direção do escoamento (SYAMLAL [84]).

LEONARD e MOKHATARI [44] descrevem um procedimento para aplicação deste limitador em um esquema arbitrário de alta ordem. Segundo SYAMLAL [86], fórmulas explícitas para os DWFs podem ser obtidos avaliando $\frac{\phi_{f}-\phi_{C}}{\phi_{D}-\phi_{C}}$, onde $\phi_{f}$ é trocada pelo valor de sua interpolação.

Considerando a notação dada de localização das faces, se $\tilde{\phi}_{U}=0$ e $\tilde{\phi}_{D}=1$, então $\tilde{\phi}=\phi$.

A definição dada de uma distribuição local de $\phi$ monotônica é,

$$
0 \leq \phi \leq 1
$$


Sob está condição, $\phi_{f}$ está limitada no volume de controle estabelecido e nas faces desse volume, da seguinte maneira:

1. $\phi_{f}$ está entre $\phi_{C}$ e $\phi_{D}$, isto é, $\tilde{\phi}_{C} \leq \phi \leq 1$ para $0 \leq \tilde{\phi}_{C} \leq 1$, incluindo o caso em que $\phi_{C}=\phi_{D}$, ou seja, $\phi_{f}=\phi_{C}=\phi_{D}$ e $\tilde{\phi}_{f}=1$ para $\tilde{\phi}_{C}=1$.

2. Se $\phi_{C}=\phi_{U}$, segue que $\phi_{f}=\phi_{C}=\phi_{U}$, isto é, $\tilde{\phi}_{f}=0$ para $\tilde{\phi}_{C}=0$.

3. Se $\phi_{C}$ tende a zero, então $\phi_{f}=\frac{\tilde{\phi}_{C}}{c}$ para $0 \leq \tilde{\phi}_{C} \leq c$, sendo $c=u \frac{\Delta t}{\Delta x}$ (número de Courant) uma constante para simulação em regime estacionário.

4. Para comportamento fora da condição dada em (2.17), ou seja, $\tilde{\phi}<0$ ou $\tilde{\phi}>1$, a interpolação em $\phi_{f}$ deve ser contínua em relação à $\tilde{\phi}_{C}$, isto é, a curva $\phi_{f}$ deve passar nos pontos $(0,0)$ e $(1,1)$, em coordenadas cartesianas, com

$$
\frac{\partial \tilde{\phi}_{f}}{\partial \tilde{\phi}_{C}}>0 \text { e finito. }
$$

Uma região em que $\phi_{f}$ está normalizada pode ser, assim, representado por um diagrama denominado NVD (Normalized Variable Diagram), Figura 2.3, determinada pelas afirmações anteriores. Este diamagra, que se tratra de uma região triangular de valores permitidos para $\tilde{\phi}_{f}$. Os valores de $\phi$ calculados por qualquer método de alta ordem devem passar na região triangular do diagrama NVD, de forma a evitar a ocorrência de oscilações numéricas indesejáveis.

Para um esquema ser de segunda ordem a condição necessária e suficiente é que a curva dada pela representação funcional de $\phi_{f}$ passe no ponto $(0,5,0,75)$ pertencente à região triangular do diagrama NVD. Para um método ser de terceira ordem, a curva deve passar no ponto de ordenada 0,75 e com inclinação positiva.

Resumidamente, os passos para se aplicar a formulação para um método de discretização de ordem arbitrária são: 


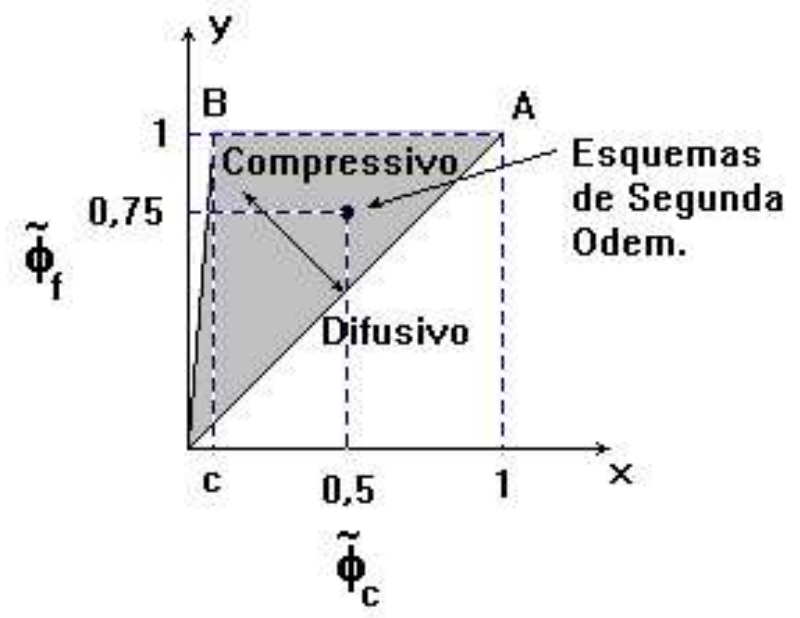

Figura 2.3: Diagrama de Variável Normalizada.

1. Computar $\phi_{f}$;

2. Computar o $D W F^{*}$ usando

$$
D W F^{*}=\frac{\phi_{f}-\phi_{C}}{\phi_{D}-\phi_{C}}=\frac{\tilde{\phi}_{f}-\tilde{\phi}_{C}}{1-\tilde{\phi}_{C}}=\frac{\tilde{\phi}_{f}}{-\tilde{\phi}_{C}}-\frac{\tilde{\phi}_{f}}{1-\tilde{\phi}_{C}}
$$

3. Limitar $D W F^{*}$ na região dada para o $D W F$;

4. Computar nova estimativa de $\phi_{f}$ por

$$
\phi_{f}=D W F \phi_{D}+(1-D W F) \phi_{C}=\phi_{C}+D W F\left(\phi_{D}-\phi_{C}\right)
$$

Para tornar a Equação (2.19) com notação conveniente nas faces do volume de controle, introduz-se o fator $\xi$ definido como 


$$
\xi= \begin{cases}D W F, & \text { se } u \geq 0 \\ 1-D W F, & \text { se } u<0\end{cases}
$$

Assim, o valor de $\phi_{e}$ é escrito, por exemplo, da seguinte forma:

$$
\phi_{e}=\xi_{e} \phi_{E}+\bar{\xi}_{e} \phi_{P}
$$

sendo $\bar{\xi}_{e}=1-\xi_{e}$.

Aplicando a Equação (2.21), por exemplo para o termo $\left(\alpha_{k} \rho_{k} \phi\right)_{e}$ que aparece no lado direito do fluxo convectivo descrito anteriormente, obtém-se:

$$
\begin{aligned}
\left(\alpha_{k} \rho_{k} \phi\right)_{e} & = \\
& =\left[\xi_{e}\left(\alpha_{k} \rho_{k} \phi\right)_{E}+\bar{\xi}_{e}\left(\alpha_{k} \rho_{k} \phi\right)_{P}\right]\left(u_{k}\right)_{e} A_{e}+ \\
& -\left[\xi_{w}\left(\alpha_{k} \rho_{k} \phi\right)_{P}+\bar{\xi}_{w}\left(\alpha_{k} \rho_{k} \phi\right)_{W}\right]\left(u_{k}\right)_{w} A_{w}+ \\
& +\left[\xi_{n}\left(\alpha_{k} \rho_{k} \phi\right)_{N}+\bar{\xi}_{n}\left(\alpha_{k} \rho_{k} \phi\right)_{P}\right]\left(u_{k}\right)_{n} A_{n}+ \\
& -\left[\xi_{s}\left(\alpha_{k} \rho_{k} \phi\right)_{P}+\bar{\xi}_{s}\left(\alpha_{k} \rho_{k} \phi\right)_{S}\right]\left(u_{k}\right)_{s} A_{s}
\end{aligned}
$$

De forma análoga, obtém-se as expressões para estes termos nas demais faces do volume de controle.

Vários outros esquemas de discretização podem ser obtidos a partir da Equação (2.19), que pode ser reescrita da seguinte forma:

$$
\phi_{f}-\phi_{C}=D W F\left(\phi_{D}-\phi_{C}\right)
$$


Considerando então a Equação (2.23) e fazendo, por exemplo, $D W F=0$, obtémse o esquema Upwind de primeira ordem (Foup), $\phi_{f}=\phi_{C}$. A Tabela 2.1 ilustra o $D W F$ em função de $r, r \equiv \frac{\tilde{\phi}_{C}}{1-\tilde{\phi}_{C}}$, para obtenção dos esquemas de discretização: (1) Diferenças Centrais (DC), (2) Upwind de segunda ordem, (3) MINMOOD, (4) SMART e (5) Superbee. Neste trabalho serão utilizados os esquemas Foup e Superbee.

\begin{tabular}{|c|c|}
\hline Esquema & $D W F$ \\
\hline \hline DC & 2 \\
\hline Upwind de segunda ordem & $\frac{2}{r}$ \\
\hline MINMOD & $\max [0, \min (1, r)]$ \\
\hline SMART & $\max [0, \min (4 r, 0,75+0,25 r, 2)]$ \\
\hline Superbee & $\max [0, \min (1,2 r), \min (2, r)]$ \\
\hline
\end{tabular}

Tabela 2.1: $D F W$ para Esquemas de Discretização.

\subsection{Formulação Euler-Euler para o Escoamento Bi- fásico Gás-Sólido}

Considerando condições isotérmicas, duas fases (gás e sólido), sem troca de massa entre fases, e propriedades físicas constantes obtém-se as equações da continuidade e de momentum dadas por:

- Equação da continuidade para a fase $\mathrm{k}$ :

$$
\frac{\partial}{\partial t}\left(\alpha_{k} \rho_{k}\right)+\nabla \cdot\left(\alpha_{k} \rho_{k} \mathbf{u}_{\mathbf{k}}\right)=0
$$

- Equação de momentum para a fase k: 


$$
\frac{\partial}{\partial t}\left(\alpha_{k} \rho_{k} \mathbf{u}_{k}\right)+\nabla \cdot\left(\alpha_{k} \rho_{k} \mathbf{u}_{k} \mathbf{u}_{k}\right)=\alpha_{k} \rho_{\mathbf{k}} \mathbf{F}_{\mathbf{k}}+\nabla \cdot \mathbf{T}_{\mathbf{k}}+\sum_{l} \beta\left(\mathbf{u}_{l}-\mathbf{u}_{k}\right)
$$

As Equações (2.24) e (2.25) tratam-se das mesmas já descritas no Capítulo 1, Seção 1.5.2, exceto que aqui os termos devidos as trocas de massas entre as fases são desconsiderados.

Nesta formulação, considerando uma superfície geométrica $r$ descrita num ponto $(\xi, \eta)$ e num instante $t$ dada por $\mathbf{r}=\mathbf{r}(x(\xi, \eta, t), y(\xi, \eta, t), z(\xi, \eta, t))$, tem-se que a função de indicação de fase pode ser definida da seguinte forma:

$$
\chi_{k}(\mathbf{r}, t)=\left\{\begin{array}{cc}
1, & \text { se } \mathbf{r} \in \mathrm{k} \\
0, & \text { se } \mathbf{r} \notin \mathrm{k}
\end{array}\right.
$$

A velocidade de $\mathbf{r}, \mathbf{u}_{r}$, pode ainda ser computada por:

$$
\mathbf{u}_{r}=\left(\frac{\partial \mathbf{r}}{\partial t}\right)_{\xi, \eta=\text { constante }}
$$

A fração volumétrica da fase $k, \alpha_{k}$, pode ser expressa como:

$$
\alpha_{k}=\left\langle\chi_{k}(\mathbf{r}, t)\right\rangle
$$

sendo que \langle\rangle representa uma média. 
Essa condição representa a restrição para a fração volumétrica de ambas as fases no escoamento global, dada por:

$$
\sum \alpha_{k}=1
$$

\subsection{Desenvolvimento do Modelo de Fases Separadas}

A modelagem matemática que consiste em um sistema de equações diferenciais parciais é então formulada utilizando um modelo de duas fases separadas, visto que é aplicado um sistema de equações de conservação de massa e de momentum para cada fase.

Segundo ENWALD et al. [21], o desenvolvimento dessa formulação inicia pelos balanços integrais de massa, quantidade de movimento e energia feitos considerando um volume de controle euleriano fixo no espaço contendo as duas fases, com interface móvel, conforme ilustrado na Figura 2.4.

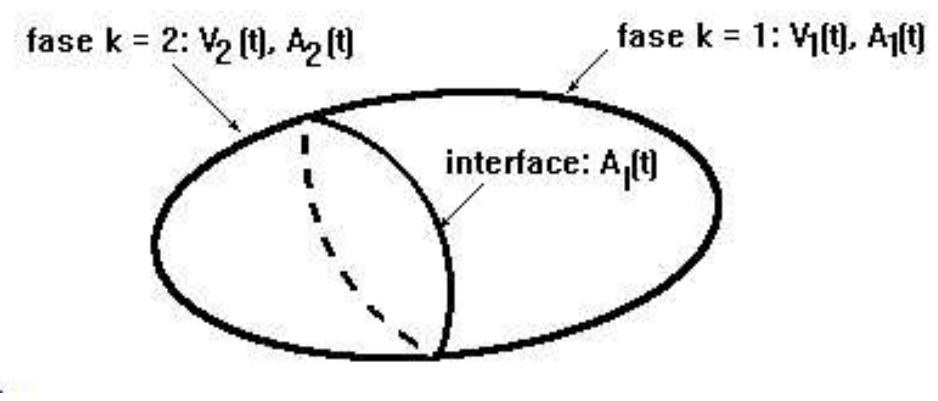

Figura 2.4: Volume de Controle fixo contendo duas fases, com interface móvel.

O volume de controle contém ambas as fases $(k=1$ denota o gás e $k=2$ denota o sólido) separadas pela interface, de área $A_{I}(t)$, que se move com velocidade $\mathbf{u}_{\mathbf{I}}$ ( $\mathbf{u}_{\mathbf{I}}$ pode ser diferente da velocidade da fase, $\left.\mathbf{u}_{\mathbf{k}}\right) . A_{k}$ é a superfície do volume de controle que separa a fase $k$ do meio externo. $V_{k}$ é o sub-volume do volume de controle ocupado pela fase $k$. $\mathbf{n}$ é o vetor unitário normal à interface do volume ocupado pela fase $k$.

Aplicando os teoremas de Leibniz e Gauss-Ostragradskii, descrito no Anexo A, estes balanços dão origem às equações diferenciais locais instantâneas para cada fase e equação 
de salto locais instantâneas que descrevem interações de interface entre as fases.

Após isso, aplica-se o procedimento de médias de Euler nas equações locais instantâneas afim de serem eliminadas as flutuações locais instantâneas do escoamento. Isto faz com que novas variáveis apareçam nas equações de campo relacionadas aos termos de interação na interface.

Para modelar os novos termos que aparecem na equação de momentum, a formulação necessita, conforme exposto no Capítulo 1, Seção 1.5.2, de modelos adicionais denominadas leis constitutivas ou de fechamento. Para completar o modelo são estabelecidas as condições iniciais e de contorno.

As equações conservativas e constitutivas aplicadas considerando escoamentos gássólido dão origem aos denominados modelos hidrodinâmicos $\mathbf{A}$ e $\mathbf{B}$ desenvolvidos por GIDASPOW [27]. Estes modelos foram utilizados em simulações de escoamento gássólido considerando a instalação de um LFC do grupo de pesquisa de Illinois Institute of Technology/Argone National Laboratory (IIT/ANL).

Basicamente o procedimento para obtenção das equações médias é dividido em duas etapas. Primeiro aplica-se as equações locais instantâneas previamente multiplicadas pela função indicador de fase $\chi_{k}(\mathbf{r}, t)$ e, em seguida, as médias de produtos são transformadas em produtos de médias aplicando a decomposição de Reynolds e médias ponderadas de variáveis dependentes.

\subsection{Leis Constitutivas}

As leis constitutivas serão utilizadas para modelar: (1) o tensor de tensões viscosas; (2) a viscosidade dinâmica; (3) a viscosidade volumétrica; (4) a pressão para ambas as fases; (5) o arrasto entre fases. Atualmente, a literatura apresenta duas formas de se obter tais modelos para essas propriedades. A primeira forma é denomindada procedimento tradicional e a segunda forma é chamada de Teoria Cinética de Escoamento 
Granular (TCEG).

O procedimento tradicional faz uso de modelos empíricos com base nas propriedades das partículas, na fração volumétrica de sólido e em outras propriedades do escoamento. A TCEG calcula essas propriedades a partir de analogias com a teoria cinéticas dos gases densos. Neste trabalho, será aplicado o procedimento tradicional.

\section{- Viscosidade Dinâmica}

A viscosidade dinâmica é considerada constante e determinada empiricamente para ambas as fases.

\section{- Viscosidade Volumétrica}

A viscosidade volumétrica para ambas as fases, $\lambda_{k}$, é fornecida pela hipótese de Stokes, ou seja,

$$
\lambda_{k}=-\frac{2}{3} \mu_{k}
$$

\section{- Tensões Viscosas}

O tensor das tensões viscosas para a fase $k, \overline{\bar{\tau}}_{k}$, é modelado assumindo a relação tensão/deformação para um fluido newtoniano, tendo em conta a hipótese de Stokes, ou seja,

$$
\left.\overline{\bar{\tau}}_{k}=\mu_{k}\left[\nabla \mathbf{u}_{k}+\left(\nabla \mathbf{u}_{k}\right)^{T}-\frac{2}{3}\left(\nabla \cdot \mathbf{u}_{k}\right) \overline{\bar{I}}\right)\right]
$$

O tensor das tensões, $\overline{\bar{T}}_{k}$ é determinado por:

$$
\overline{\bar{T}}_{k}=-P_{k} \overline{\bar{I}}+\overline{\bar{\tau}}_{k}
$$




\section{- Pressão do Gás}

A pressão do gás, $P_{g}$, é a pressão termodinâmica da fase contínua, ou seja,

$$
P_{g}=P
$$

\section{- Pressão do Sólido}

A pressão do sólido é algo mais complexo de se analisar, visto que não se tem uma definição única para este termo e o estudo de uma correlação que descreva corretamente a pressão do sólido é assunto ainda em aberto.

Uma definição de pressão do sólido que pode ser encontrada em BOEMER et al. [10] tem o seguinte enunciado: "Trata-se de uma força normal por unidade de área exercida sobre a fase sólida devido às interações entre partículas". Outra definição de pressão do sólido dada por CAMPBELL \& WANG [16] é a seguinte: "Trata-se de uma força por unidade de área exercida por uma fase sólida sobre uma superfície, refletindo o transporte total de quantidade de movimento que se pode atribuir ao movimento das partículas sólidas e as suas interações".

Considerando o procedimento tradicional de obtenção de modelos, três efeitos da pressão do sólido serão considerados, a saber:

1. Efeito causado pelas flutuações de velocidades das partículas;

2. Efeito causado pelas interações das partículas entre si (colisões), $P_{s}^{c o l}$;

3. Contribuição da pressão da fase gasosa $\left(P_{g}\right)$.

Geralmente despreza-se o efeito causado pelas flutuações de velocidades das partículas, de forma que o gradiente de pressão para a fase sólida, $\nabla\left(\alpha_{s} P_{s}\right)$, resulta: 


$$
\nabla\left(\alpha_{s} P_{s}\right)=\nabla\left(\alpha_{s} P_{s}^{c o l}\right)+\nabla\left(\alpha_{s} P_{g}\right)=-G\left(\alpha_{s}\right) \nabla \alpha_{s}+\nabla\left(\alpha_{s} P_{g}\right)
$$

onde o efeito colisional é descrito em termos do módulo de eslasticidade das colisões entre partículas, $G\left(\alpha_{s}\right)$, modelado empiricamente. Há várias correlações para o cálculo de $G\left(\alpha_{s}\right)$. GIDASPOW \& ETTEHADIEH [28], por exemplo, obtém uma correlação por meio de uma interpolação dos dados experimentais obtidos por RIETEMA \& MUTSERS apud GIDASPOW [26] dada por:

$$
G\left(\alpha_{s}\right)=10^{-8,76 \alpha_{s}+5,43}
$$

\section{- Arrasto na Interface}

Deve-se formular uma lei descrevendo o transporte de momentum na interface $\left(\vec{M}_{k I}\right)$.

Segundo GIDASPOW [27], esta lei pode ser aproximada pela força de arrasto generalizada por unidade de volume sobre uma suspensão de partículas de diâmetro médio na interface, obtida a partir da correlação para o coeficiente de arrasto sobre uma partícula numa suspensão, $\left(C_{D}\right)$, e a partir da queda de pressão por unidade de comprimento na suspensão.

Dessa forma, formula-se $\mathbf{M}_{k I}$ em função da velocidade relativa entre as fases, ou seja, $\mathbf{u}_{R}=\mathbf{u}_{g}-\mathbf{u}_{s}$, e do coeficiente de transferência de quantidade de movimento na interface, denominada função de arrasto $\beta$, é dado por:

$$
\mathbf{M}_{k I}=\beta \mathbf{u}_{R}=\beta\left(\mathbf{u}_{g}-\mathbf{u}_{s}\right)
$$

A Seção a seguir descreve os modelos hidrodinâmicos A e B formulados por GIDASPOW [27], bem como as equações de fechamento para estes modelos. 


\subsection{Modelos Hidrodinâmicos para Formulação Euler- Euler}

As Seções seguintes descrevem as equações para o escoamento bifásico dos modelos A e B em coordenadas cartesianas (GIDASPOW [27]) em conjunto com as equações da continuidade abaixo.

- Equação da continuidade

Fase sólida $(k=s)$ :

$$
\frac{\partial}{\partial t}\left(\rho_{s} \alpha_{s}\right)+\nabla \cdot\left(\rho_{s} \alpha_{s} \mathbf{u}_{s}\right)=0
$$

Fase gasosa $(k=g)$ :

$$
\frac{\partial}{\partial t}\left(\rho_{g} \alpha_{g}\right)+\nabla \cdot\left(\rho_{g} \alpha_{g} \mathbf{u}_{g}\right)=0
$$

\subsubsection{Modelo Hidrodinâmico A}

- Equação da Conservação da Quantidade de Movimento

Fase gasosa:

$$
\frac{\partial}{\partial t}\left(\alpha_{g} \rho_{g} \mathbf{u}_{g}\right)+\nabla \cdot\left(\rho_{g} \alpha_{g} \mathbf{u}_{g} \mathbf{u}_{g}\right)=-\alpha_{g} \nabla P-\beta_{A}\left(\mathbf{u}_{g}-\mathbf{u}_{s}\right)+\nabla \cdot\left(\alpha_{g} \overline{\bar{\tau}}_{g}\right)+\rho_{g} \alpha_{g} \mathbf{g}
$$

Fase sólida: 


$$
\frac{\partial}{\partial t}\left(\alpha_{s} \rho_{s} \mathbf{u}_{s}\right)+\nabla \cdot\left(\rho_{s} \alpha_{s} \mathbf{u}_{s} \mathbf{u}_{s}\right)=-\alpha_{s} \nabla P+\beta_{A}\left(\mathbf{u}_{g}-\mathbf{u}_{s}\right)-G\left(\alpha_{s}\right) \nabla \alpha_{s}+\nabla \cdot\left(\alpha_{s} \overline{\bar{\tau}}_{s}\right)+\rho_{s} \alpha_{s} \mathbf{g}
$$

\subsubsection{Modelo Hidrodinâmico B}

- Equação da Conservação da Quantidade de Movimento

Fase gasosa:

$$
\frac{\partial}{\partial t}\left(\alpha_{g} \rho_{g} \mathbf{u}_{g}\right)+\nabla \cdot\left(\rho_{g} \alpha_{g} \mathbf{u}_{g} \mathbf{u}_{g}\right)=-\nabla P-\beta_{B}\left(\mathbf{u}_{g}-\mathbf{u}_{s}\right)+\nabla \cdot\left(\alpha_{g} \overline{\bar{\tau}}_{g}\right)+\rho_{g} \mathbf{g}
$$

Fase sólida:

$$
\frac{\partial}{\partial t}\left(\alpha_{s} \rho_{s} \mathbf{u}_{s}\right)+\nabla \cdot\left(\rho_{s} \alpha_{s} \mathbf{u}_{s} \mathbf{u}_{s}\right)=-\beta_{B}\left(\mathbf{u}_{g}-\mathbf{u}_{s}\right)-G\left(\alpha_{g}\right) \nabla \alpha_{s}+\nabla \cdot\left(\alpha_{s} \overline{\bar{\tau}}_{s}\right)+\left(\rho_{s}-\rho_{g}\right) \alpha_{s} \mathbf{g}
$$

AGRAWAL [1] realizou simulações aplicando ambos os modelos, $\mathbf{A}$ e $\mathbf{B}$, obtendo resultados semelhantes. Neste trabalho utiliza-se o modelo hidrodinâmico B.

\subsubsection{Equações de Fechamento para o Modelo B}

- Equações de estado (Lei do Gás Ideal)

$$
\begin{gathered}
\rho_{g}=\frac{P}{R_{g} T} \\
\rho_{s}=\text { constante. }
\end{gathered}
$$




\section{- Fração volumétrica}

$$
\alpha_{g}+\alpha_{s}=1
$$

\section{- Função de Arrasto na Interface}

Se $\alpha_{g} \leq 0,8$, o procedimento de GIDASPOW considera a seguinte correlação para $\beta$ dada por ERGUN [22]:

$$
\beta=150 \frac{\alpha_{s} \mu_{g}}{\alpha_{g}\left(d_{p} \phi_{s}\right)^{2}}+1,75 \frac{\rho_{g} \alpha_{s}\left\|\mathbf{u}_{g}-\mathbf{u}_{s}\right\|}{\left(d_{p} \phi_{s}\right)}
$$

Se $\alpha_{g}>0,8$, a correlação para $\beta$ é a de WEN \& YU [99]:

$$
\beta=\frac{3}{4} C_{D_{S}} \frac{\rho_{g} \alpha_{s}\left\|\mathbf{u}_{g}-\mathbf{u}_{s}\right\|}{\left(d_{p} \phi_{s}\right)} \alpha_{g}^{-3,65}
$$

sendo $C_{D_{S}}$ dado por

$$
C_{D_{S}}= \begin{cases}\frac{24}{R e_{p}}\left(1+0,15 R e_{p}^{0,687}\right), & \text { se } R e_{p}<1000 \\ 0,44, & \text { se } R e_{p} \geq 1000\end{cases}
$$

A Equação (2.48) foi descrita por ROWE [70]. Re $e_{p}$ é o número de Reynolds da partícula dado por

$$
R e_{p}=\frac{\alpha_{g} \rho_{g}\left\|\mathbf{u}_{g}-\mathbf{u}_{s}\right\| d_{p}}{\mu_{g}}
$$


sendo $d_{p}$ o diâmetro da partícula.

- Tensor das tensões viscosas para ambas as fases $(k=s$ ou $k=g)$

$$
\overline{\bar{\tau}}_{k}=\mu_{k}\left[\nabla \mathbf{u}_{k}+\left(\nabla \cdot \mathbf{u}_{k}\right)^{T}-\frac{2}{3}\left(\left(\nabla \cdot \mathbf{u}_{k}\right) \overline{\bar{I}}\right)\right]
$$

- Módulo de elasticidade da fáse sólida

$$
G\left(\alpha_{s}\right)=10^{-8,76 \alpha_{s}+5,43}
$$

A Equação (2.51) foi descrita por GIDASPOW \& ETTEHADIEH [28].

\subsubsection{Condições de contorno}

\section{- Parede}

Com relação à fase gasosa pode ser adotada a condição de plena aderência devido à irregularidade inerente da superfície sólida. Sob o ponto de vista macroscópico esta condição implica na condição de não deslizamento na parede, ou seja, as componentes normal e tangencial do vetor velocidade são nulas, isto é,

$$
u_{g, \text { parede }}=v_{g, \text { parede }}=0
$$

Novamente aqui o caso da fase sólida é mais complicado, ou seja, para se estabelecer as condições de contorno para a fase sólida encontra-se a dificuldade de caracterização da interação das partículas com a parede. Trata-se de uma questão também em aberto e necessitando de estudos mais profundos tratando dessa interação partícula-parede e 
condicões de contorno apropriadas.

Assume-se que a velocidade na direção tangencial na parede oscila entre a condição de não deslizamento e deslizamento livre. TSUO e GIDASPOW [93] determinam para a componente tangencial a seguinte expressão:

$$
v_{s, \text { parede }}=L_{p}\left(\frac{\partial u_{s, \text { parede }}}{\partial y}\right)
$$

sendo

$$
L_{p}=\left(\frac{\pi}{6 \alpha_{s}}\right)^{\frac{1}{3}}
$$

o caminho livre médio das partículas.

Já DING e GIDASPOW [19] especificam uma condição de deslizamento parcial dada por:

$$
v_{s, \text { parede }}=-\lambda_{p}\left(\frac{\partial u_{s, \text { parede }}}{\partial y}\right)
$$

sendo

$$
\lambda_{p}=\frac{1}{\left(\alpha_{s}\right)^{\frac{1}{3}}} d_{p}
$$

Para a componente normal, a condição estabelecida é,

$$
u_{s, \text { parede }}=0
$$

Para as variáveis escalares $\alpha_{g}$ e $P$, tem-se

$$
\frac{\partial \alpha_{\text {g,parede }}}{\partial y}=\frac{\partial P_{\text {parede }}}{\partial y}=0
$$


Considerando o código MFIX de simulação para escoamento bifásico gás-sólido, temse que as condições de contorno na parede, para qualquer fase, são:

1. Deslizamento livre (Free-Slip Wall);

2. Não deslizamento (No-Slip Wall);

3. Deslizamento parcial (Partial-Slip Wall).

\section{- Entrada e Saída}

A simulação de uma instalação de um LFC considera na maior parte dos casos, apenas o tubo ascendente (riser), região de maior interesse em função das reações químicas ocorrerem nesta parte do leito fluidizado. Sendo assim, deve existir uma região de entrada e outra de saída. Numa instalação real de LFC, normalmente se tem uma saída lateral, conforme pode ser visto na Figura 2.5.

No caso do particulado sólido, adotar uma saída vertical é relativamente mais conveniente sob o ponto de vista computacional. Se o objetivo da simulação é investigar os efeitos hidrodinâmicos que ocorrem no interior do riser, então o tipo de geometria adotado na saída é a vertical. Mas se o objetivo é de fato investigar os efeitos da geometria de saída e/ou de entrada, então é interessante adotar a geometria de saída lateral, uma vez que a prática industrial utiliza este tipo de leito fluidizado.

A condição de contorno na saída amplamente utilizada, comumente denominada condição de continuidade, é dada por:

$$
\frac{\partial f}{\partial n}=0
$$




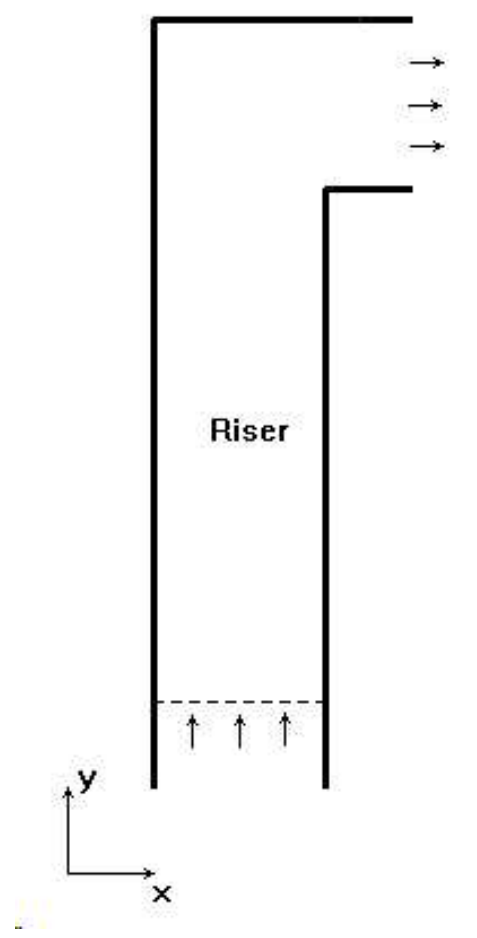

Figura 2.5: Tubo ascendente de um leito circulante com saída lateral

sendo que $f$ pode ser $\alpha_{g}, u_{g}$ ou $u_{s}$.

Na entrada, bastam as condições:

$$
\begin{gathered}
\rho_{g} \alpha_{g} u_{g}=\text { constante (fluxo mássico). } \\
v_{s}=\text { constante. } \\
\alpha_{s}=\text { constante. }
\end{gathered}
$$

O Capítulo seguinte apresenta o ambiente de simulação numérica MFIX (SYAMLAL [84]) utilizado neste trabalho. 


\section{Capítulo 3}

\section{Ambiente de Simulação Numérica}

\subsection{Introdução}

Neste Capítulo descrevem-se as características básicas do ambiente de simulação para escoamento multifásico gás-sólido bidimensional denominado MFIX (Multiphase Flow Interphase Exchanges). O ambiente de simulação MFIX, desenvolvido por SYAMLAL et al. do grupo da U.S. Department of Energy, Morgantown Energy Techonology Center, tem por objetivo simular a hidrodinâmica de escoamentos fluido-sólido (denso ou diluído) e pode ser utilizados na simulação de LFC.

\subsection{O Ambiente de Simulação do Código MFIX}

Em linhas gerais, o MFIX é um código para Dinâmica dos Fluidos Computacional (DFC) capaz de tratar problemas multifásicos envolvendo reações químicas e transferência de calor. Permite a análise da pressão, da temperatura, das frações volumétricas de cada fase e o campo de velocidades em função do tempo.

A precisão e o passo no tempo são calculados por um método semi-implícito com integração no tempo. O MFIX possui uma rotina para definição automática do passo no tempo, a qual permite que a restrição de estabilidade seja otimizada.

A discretização espacial se dá por volumes finitos utilizando uma malha deslocada que, segundo PATANKAR (1980), tem a vantagem de controlar possíveis oscilações no 
campo de velocidades. O domínio é dividido em uma quantidade de volumes de controle não sobrepostos de forma que exista um volume cercando cada nó da malha, tal como pode ser observado na Figura 3.1. É nesta configuração do domínio que é feita a integração da equações diferenciais parciais (EDP's), ou seja, as leis de conservação da massa, momentum e energia, que modelam escoamento em leito fluidizado.

Esta forma de discretização das EDP's por integração em volumes de controle assegura o caráter conservativo das equações, em qualquer volume de controle, bem como no domínio computacional. Esta propriedade se mantém em qualquer tipo de malha. Mesmo para as mais grosseiras, a solução exibe um balanço integral exato. Como em qualquer outra formulação, os termos convectivos na formulação por volumes finitos também requerem tratamento especial, uma vez que também aqui as soluções podem ser afetadas por oscilações de características não físicas.

Sabe-se que esquemas do tipo Upwind de primeira ordem são estáveis, porém causam forte difusão numérica exigindo o uso de malhas bem refinadas. O MFIX permite que se utilize esquemas de discretização de segunda ordem. Estes esquemas estão baseados nos métodos denominados TVD (Total Variation Dimention). Dentre os esquemas do tipo TVD, destaca-se o método de segunda ordem denominado Superbee que é largamente utilizado.

A discretização da equação de momentum é similar à efetuada na equação de transporte escalar descrita na Seção 2.2 do Capítulo 2. A diferença é que o volume de controle tem seus nós deslocados em relação ao nós do volume de contole original, isto é, utiliza-se uma malha uniforme deslocada para discretização das equações de conservação, Figura 3.1.

Este tipo de malha é utilizada para previnir campos de pressão fisicamente incorretos, fato que pode se tornar crítico com malhas grosseiras. As discretizações considerando todas as equações do modelo de dois-fluidos podem ser vistas na documentação do MFIX relativa à técnica numérica empregada, [84]. 


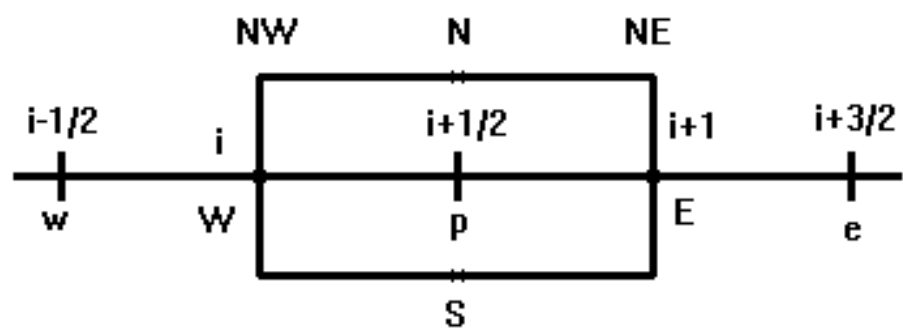

Figura 3.1: Volume de controle com malha deslocada na direção $x$ considerada para discretização da equação de Momentum.

Além disso, o guia referente à teoria empregada no código pode ser consultado em [85]. Versões atualizadas, grupos de discussão, bem como todo o material disponível do MFIX pode ser consultado, acessando a página eletrônica oficial do MFIX (www.mfix.org) na rede mundial de computadores.

\subsection{Procedimento Iterativo}

Escoamentos multifásicos são inerentemente instáveis sob o ponto de vista físico. Cálculos em estado estacionário são possíveis, mas para alguns poucos casos, como por exemplo em transporte pneumático de sólidos. Para a outra grande maioria de escoamentos gás-sólido, o problema tem de ser simulado de forma transiente, sendo médias no tempo calculadas a partir dos resultados.

Simulações transientes divergem se o passo-no-tempo escolhido é muito grande. Por outro lado, pequeno passo-no-tempo faz com que o processamento seja lento. O MFIX faz, então, o ajuste automático do passo-no-tempo reduzindo o tempo computacional da simulação.

Segue abaixo procedimentos básicos do algoritmo computacional do MFIX.

1. Inicia o passo no tempo. Calcula as propriedades físicas e coeficientes;

2. Calcula os campos de velocidades $u_{k}^{*}$ e $v_{k}^{*}$ baseados na pressão corrente. 
3. Calcula a correção da pressão do fluido, $P^{\prime}$, pelo método SIMPLE.

4. Atualiza o campo de pressão aplicando sub-relaxação: $P_{g}=P_{g}^{*}+\omega_{p g} P_{g}^{\prime}$; Calcula a correção da velocidade a partir de $P_{g}^{\prime}$ e atualiza o campo de velocidade $u_{k}=u_{k}^{*}+u_{k}^{\prime}$;

5. Calcula o gradiente de pressão, $\frac{\partial P_{k}}{\partial \epsilon_{k}}$, para usar na correção da fração volumétrica do sólido. Calcula a correção da fração volumétrica do sólido $\epsilon_{s}$.

6. Atualiza a fração volumétrica do sólido $\epsilon_{k}=\epsilon_{k}^{*}+\omega_{p s} \epsilon_{k}^{\prime}\left(\epsilon_{k} \rho_{k}\right.$ no MFIX); Usa-se sub-relaxação somente onde $\epsilon_{0}<\epsilon_{c p}$ e $\epsilon_{k}>0$, ou seja, onde os sólidos estão densamente concentrados e a fração volumétrica está aumentando; Calcula a correção da velocidade para a fase sólida e atualiza o campo de velocidades $u_{k}=u_{k}^{*}+u_{k}^{\prime}$

7. Calcula a fração volumétrica $\epsilon_{0}=\epsilon_{v}-\sum_{k \neq 0} \epsilon_{k}\left(\epsilon_{v}\right.$ é usualmente igual a 1$)$;

8. Calcula a pressão do sólido da equação de estado $P_{k}=P_{k}\left(\epsilon_{k}\right)$;

9. Calcula a temperatura e a fração mássica de espécie.

10. Usa o resíduo normalizado calculado em 2, 3, 5 e 9 para checar a convergência. Se o critério de convergência não é satisfeito, continuar as interações (passo 2), senão atualizar o passo-no-tempo (passo 1);

\subsection{Técnica Numérica}

A essência do método numérico foi desenvolvida por HARLOW e AMSDEN [31] em 1975 e implementada no KFIX (versão anterior ao MFIX). O método foi mais tarde adaptado por GIDASPOW [27] do Illinois Institute of Technology para descrever escoamento gás-sólido. O MFIX 2.0 utiliza o método baseado no SIMPLE (SemiImplicit Method for Pressure Linked Equation) desenvolvida por PATANKAR e SPALDING [63].

No MFIX 2.0, foram feitas duas modificações no SIMPLE. A primeira delas é o uso da correção da fração volumétrica do sólido auxiliando a convergência quando há regiões muito densas de partículado sólido. Além disso, estão incorporados os efeitos da pressão do sólido que se trata de uma característica nova na implementação do MFIX que também auxilia na estabilização em regiões densas de particulas sólidas. A segunda 
modificação foi o ajuste automático do passo-no-tempo assegurando que o processo de simulação fique de três a trinta vezes mais rápido que a versão anterior sem este $\Delta t$ ajustável.

Na malha numérica bidimensional utilizada pelo MFIX (Figura 3.2) a variável escalar $\alpha_{k}$ e também a pressão $P$ são armazenadas no ponto $i j$. Por sua vez, a velocidade $\mathbf{u}$ é armazenada no ponto $i+\frac{1}{2}$ e a velocidade $v$ no ponto $j+\frac{1}{2}$.

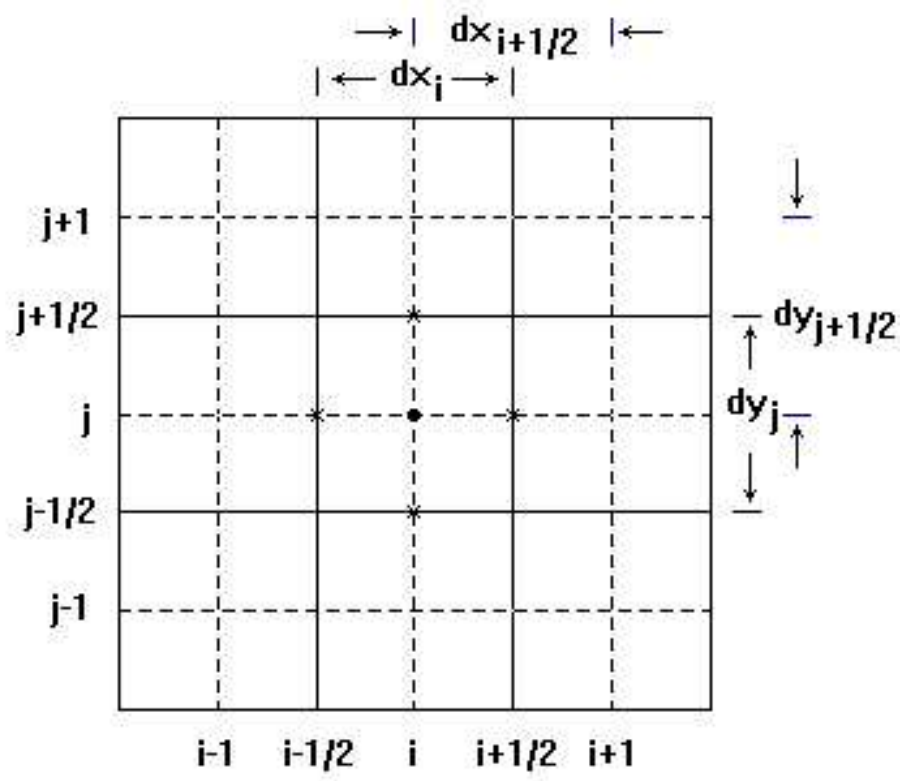

Figura 3.2: Malha numérica utilizada no código MFIX (SYAMLAL [84]).

\subsection{Arquitetura Computacional utilizada para as Si- mulações}

A arquitetura computacional que está sendo utilizada para realizar as simulações é baseada em PC's (Computadores Pessoais) utilizando o sistema operacional MANDRAKE - LINUX versão 10.1.

Para compilar o código MFIX, escrito na linguagem de programação FORTRAN, gerando o executável que dá início ao processo iterativo da simulação, utiliza-se o compilador Intel Fortran Compiler (IFC) compatível com a versão do FORTRAN 90. A 
escolha da versão 10.1 do MANDRAKE (atualmente denominado MANDRIVA) foi pautada na compatibilidade desta distribuição com o compilador $I F C$ do FORTRAN 90.

A Tabela 3.1 resume a configuração dos microcomputadores utilizados nas simulações. O funcionamento desses computadores com relação aos seus processadores é serial.

\begin{tabular}{|c|c|c|c|c|}
\hline Computador & Processador & Memória RAM & HD & Sitema Operacioanal \\
\hline \hline mfix1 & Intel Pentium $41.4 \mathrm{GHz}$ & $512 \mathrm{MB}$ & $40 \mathrm{~GB}$ & Mandrake Linux 10.1 \\
\hline mfix2 & AMD Athlon (TM) $2.17 \mathrm{GHz}$ & $1 \mathrm{~GB}$ & $60 \mathrm{~GB}$ & Mandrake Linux 10.1 \\
\hline mfix3 & Intel Pentium $43.4 \mathrm{GHz}$ & $1 \mathrm{~GB}$ & $200 \mathrm{~GB}$ & Mandrake Linux 10.1 \\
\hline
\end{tabular}

Tabela 3.1: Configuração dos Microcomputadores utilizados nas simulações. 


\section{Capítulo 4}

\section{Resultados Numéricos de Simulação}

\subsection{Introdução}

Neste Capítulo são apresentados os resultados numéricos computacionais de escoamento bifásico gás-sólido em LFC. Estabelece-se domínios de dimensões em escalas re-

duzidas. Aplica-se malhas bidimensionais refinadas de até $0,25 \mathrm{~mm}$ de resolução e 25600 elementos computacionais para o domínio.

\subsection{Domínio Computacional e Condições de Con- torno para o Tubo Ascendente}

Nos experimentos computacionais, os seguintes aspectos são variados:

(a) Tamanho do domínio computacional;

(b) Esquemas de interpolação para os termos advectivos;

(c) Refinamento de malha.

Avalia-se, assim, os efeitos desses parâmetros sobre os resultados de simulação. Considera-se primeiramente um domínio $2 \mathrm{~cm} \times 8 \mathrm{~cm}$, conforme ilustrado na Figura 4.1.

Na Tabela 4.1 são mostrados os parâmetros numéricos considerados para os experimentos computacionais levando-se em conta os aspectos (b) e (c) descritos anteriormente. 
As propriedades físicas e as condições de contorno utilizadas na entrada do domínio podem ser vistas nas Tabelas 4.2 e 4.3, respectivamente.

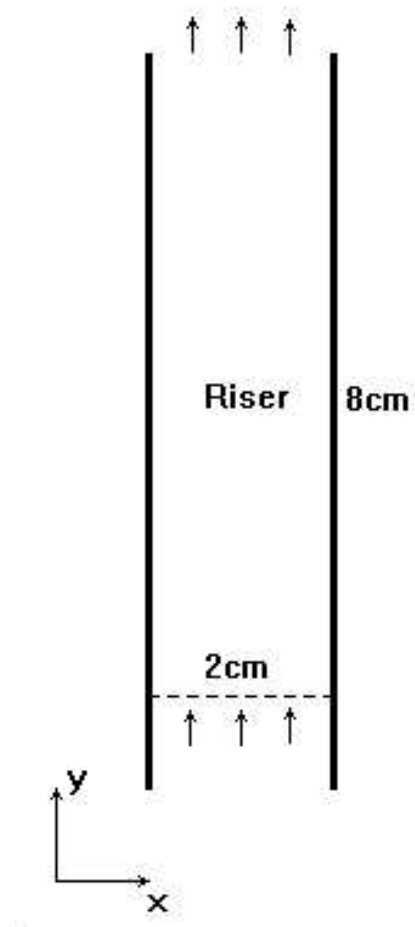

Figura 4.1: Domínio para o tubo ascendente considerado para a simulação do escoamento gás-sólido. 


\begin{tabular}{|c|c|c|c|c|}
\hline Experimento & $\Delta t(\mathrm{~s})$ & $\Delta x=\Delta y(\mathrm{~mm})$ & Número de Células & Esquemas de Interpolação \\
\hline \hline B1 & $10^{-4}$ & $4 \times 4$ & 100 & Superbee \\
\hline B2 & $10^{-4}$ & $2 \times 2$ & 400 & Superbee \\
\hline B3,A1 & $10^{-4}$ & $1 \times 1$ & 1600 & Superbee \\
\hline B4 & $10^{-4}$ & $0,5 \times 0,5$ & 6400 & Superbee \\
\hline A2 & $10^{-4}$ & $1 \times 1$ & 1600 & Foup \\
\hline
\end{tabular}

Tabela 4.1: Parâmentos numéricos de simulação para os experimentos computacionais no domínio de $2 \mathrm{~cm} \times 8 \mathrm{~cm}$

\begin{tabular}{|c|c|}
\hline Diâmetro da partícula & $d_{p}=520 \mu \mathrm{m}$ \\
\hline Densidade do Sólido & $\rho_{s}=2620 \mathrm{~kg} / \mathrm{m}^{3}$ \\
\hline Viscosidade do Sólido & $\mu_{s}=0,509$ Pas \\
\hline Viscosidade do gás & $\mu_{g}=1,8 \times 10^{-5}$ Pas \\
\hline Densidade do gás & $\rho_{g}=1,2 \mathrm{~kg} / \mathrm{m}^{3}$ \\
\hline
\end{tabular}

Tabela 4.2: Propriedades físicas do gás e do sólido utilizadas nas simulações.

\begin{tabular}{|c|c|}
\hline Fluxo mássico da fase sólida & $G_{s}=24,9 \mathrm{~kg} /\left(\mathrm{m}^{2} \mathrm{~s}\right)$ \\
\hline Velocidade do sólido & $V_{s}=0,386 \mathrm{~m} / \mathrm{s}$ \\
\hline Velocidade do gás & $V_{g}=4,979 \mathrm{~m} / \mathrm{s}$ \\
\hline Fração Volumétrica do sólido & $\alpha_{s}=0,0246$ \\
\hline Pressão & $P=120,6639 \mathrm{kPa}$ \\
\hline
\end{tabular}

Tabela 4.3: Condições de contorno na entrada. 
Como condição inicial considera-se o tubo ascendente sem partículas sólidas e uma pressão inicial de $P=101,325 \mathrm{kPa}$. As condições de contorno na saída obedecem a condição da continuidade (4.1).

$$
\frac{\partial f}{\partial n}=0
$$

sendo que $f$ pode ser $\alpha_{g}, \mathbf{u}_{g}, \mathbf{u}_{s}$. Na saída, assume-se $P=117,2049 \mathrm{kPa}$.

Nas paredes as condições de contorno são: Equação (2.52), para a fase gasosa; Equações (2.53), (2.54) e (2.57), para a fase sólida, descritas no Capítulo 2, Secão 2.6.

A técnica numérica implementada no modelo hidrodinâmico do código MFIX foi utilizada para obtenção dos resultados reportados aqui, considerando os parâmetros numéricos da Tabela 4.2 .

Vale ressaltar que para simulação de escomento bifásico existem diversos códigos computacionais classificados como "acadêmicos" e "comerciais". Na tese de CABEZASGÓMEZ et al. [12] foram utilizadas duas versões anteriores do código acadêmico MFIX, a saber o MULTIFIX e o MICEFLOW. Na linha de pacotes comerciais para simulação de escoamento multifásico tem-se, por exemplo, o código CFX utilizado por MILIOLI [58]. Basicamente, a essência desses códigos difere quanto: (1) ao tipo de modelo numérico utilizado; (2) procedimento de solução das equações do modelo e (3) condições de contorno utilizadas.

\subsection{Influência do Esquema de Interpolação nos Re- sultados Numéricos}

A Tabela 4.4 indica os parâmentros de simulação para os experimentos computacionais A1 e A2 levando-se em conta os esquemas de interpolação Upwind de primeira ordem (Foup) e o esquema de segunda ordem (Superbee). 


\begin{tabular}{|c|c|c|c|c|}
\hline Experimento & $\Delta t(\mathrm{~s})$ & $\Delta x=\Delta r(\mathrm{~mm})$ & Número de Células & Esquemas de Interpolação \\
\hline A1 & $10^{-4}$ & $1 \times 1$ & 1600 & Superbee \\
\hline A2 & $10^{-4}$ & $1 \times 1$ & 1600 & Foup \\
\hline
\end{tabular}

Tabela 4.4: Parâmentos Numéricos para as simulações computacionais.

\section{- Experimento Computacional A1:}

Para este experimento foram necessários o total de 380942,93 segundos, aproximadamente, 105,8 horas ou 4 dias de processamento, para se obter cinquenta segundos de simulação de escoamento real.

\section{- Experimento Computacional A2:}

Neste experimento foram necessários 109976.68 segundos de processamento, aproximadamente, ou 30,6 horas (1 dias) para processar o tempo de cinquenta segundos de escoamento real.

A diferença nos resultados de simulação se dá em função da ordem dos esquemas de interpolação utilizados (primeira ordem e segunda ordem, respectivamente). Tal diferença ocorre, sobretudo, nas regiões próximas à parede, conforme pode ser visto na Figura 4.2. Esta figura mostra os perfis radiais instantâneos na seção transversal da coluna a 4,8 cm acima da entrada, para (a) $V_{s}$, (b) $\alpha_{g}$ e (c) $\alpha_{s}$.

Conclui-se que o esquema Superbee apresenta melhores resultados numéricos, uma vez que quantitativamente apresenta os resultados esperados quando se considera regiões próximas às paredes do riser. Estas regiões apresentam as maiores instabilidades hidrodinâmicas e numéricas exigindo que métodos de maior precisão numéricas sejam preferidos nestes casos. O esquema Superbee será, então, escolhido para as simulações que consideram: refinamento de malha e ajuste do domínio computacional, descritos nas seções seguintes. 


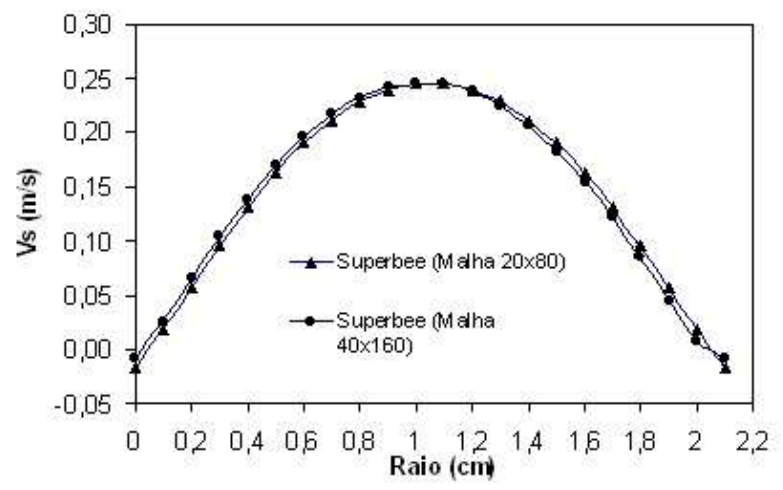

(a)

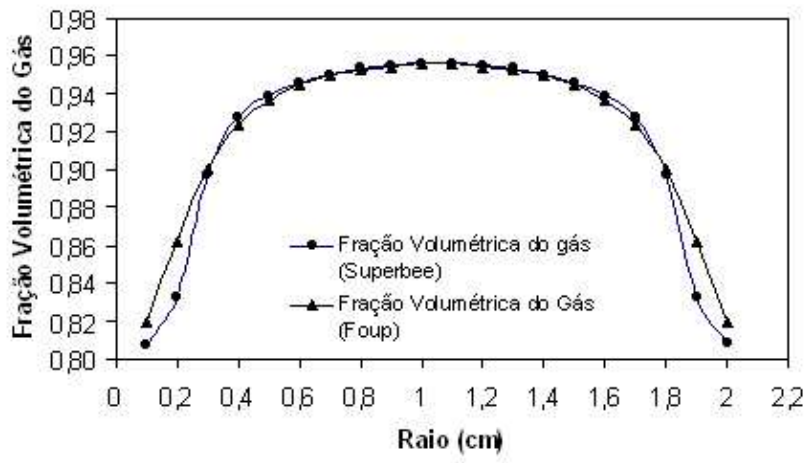

(b)

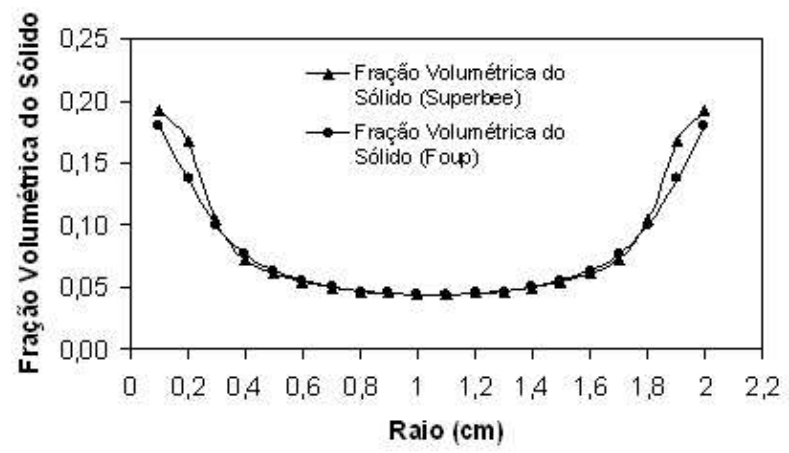

(c)

Figura 4.2: Comparação entre os perfis radiais das velocidades e frações volumétricas para ambas as fases em $t=50 \mathrm{~s}$ a $4,8 \mathrm{~cm}$ acima da entrada. Métodos Foup e Superbee. Malha: $40 \times 160$; Resolução: $0,5 \mathrm{~mm} \times 0,5 \mathrm{~mm}$. 


\subsection{Influência da Malha Computacional nos Resul- tados de Simulação}

São descritos aqui, os resultados computacionais obtidos utilizando-se diferentes tamanhos de malhas bidimensionais, conforme descreve a Tabela 4.5.

\begin{tabular}{|c|c|c|c|c|}
\hline Experimento & Domínio & Número de células & $\Delta x=\Delta y(\mathrm{~mm})$ & $\Delta t$ \\
\hline \hline B1 & $5 \times 20$ & 100 & $4 \times 4$ & $10^{-4}$ \\
\hline B2 & $10 \times 40$ & 400 & $2 \times 2$ & $10^{-4}$ \\
\hline B3 & $20 \times 80$ & 1600 & $1 \times 1$ & $10^{-4}$ \\
\hline B4 & $40 \times 160$ & 6400 & $0,5 \times 0,5$ & $10^{-4}$ \\
\hline
\end{tabular}

Tabela 4.5: Malhas Numéricas para os experimentos computacionais considerando refinamento da malha.

\section{- Dados finais da simulação B1}

Para todos estes experimentos, o tempo real de simulação foi também de cinquenta segundos e o tempo total de processamento foi pouco mais de 2,3 horas. A Figura 4.3 mostra em (a) o perfil radial da velocidade axial da fase sólida, e em (b) a fração volumétrica para a fase sólida, ambos em $t=50 \mathrm{~s}$. 


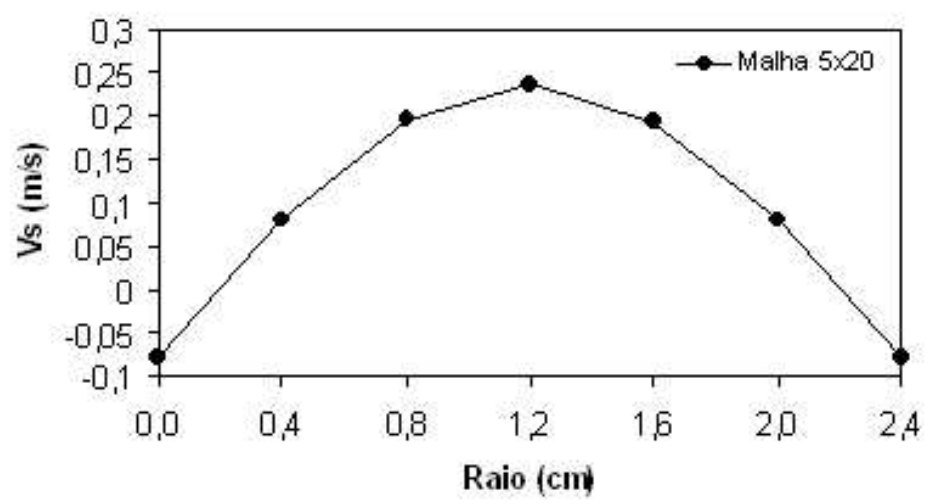

(a) Velocidade axial da fase Sólida

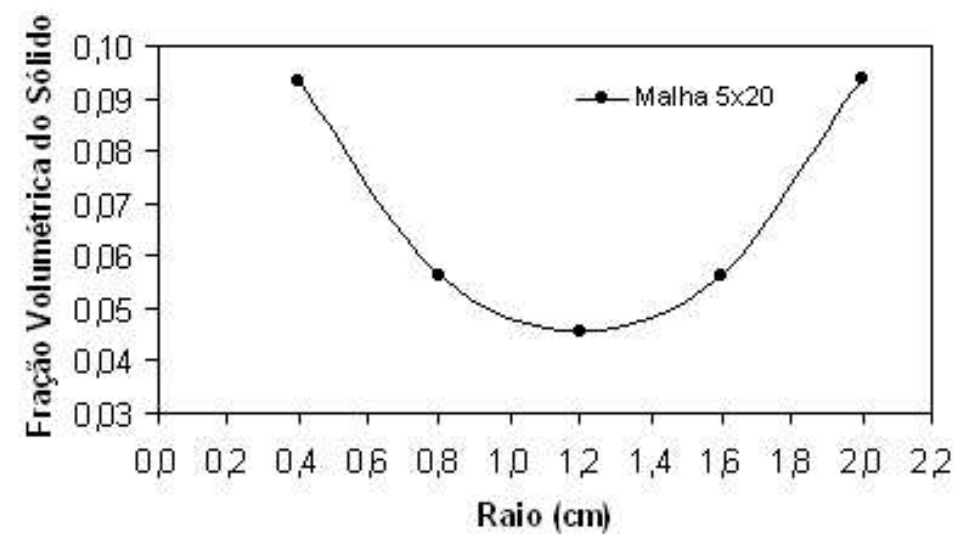

(b) Fração volumétrica da fase sólida

Figura 4.3: Perfis radiais da velocidade axial e fração volumétrica da fase sólida em $t=50 \mathrm{~s}$ avaliadas a $0,4 \mathrm{~cm}$ acima da entrada. Malha $5 \times 20$; Resolução: $4 \mathrm{~mm} \times 4 \mathrm{~mm}$. 


\section{- Dados finais da simulação B2}

Neste caso o tempo de processamento para ciquenta segundos de escoamento real foi de 60668.6 segundos, ou quase 17 horas de duração. A Figura 4.4 mostra os perfis radiais da velocidade axial (a) e fração volumétrica (b), ambas da fase sólida e avaliadas no tempo $t=50 \mathrm{~s}$.

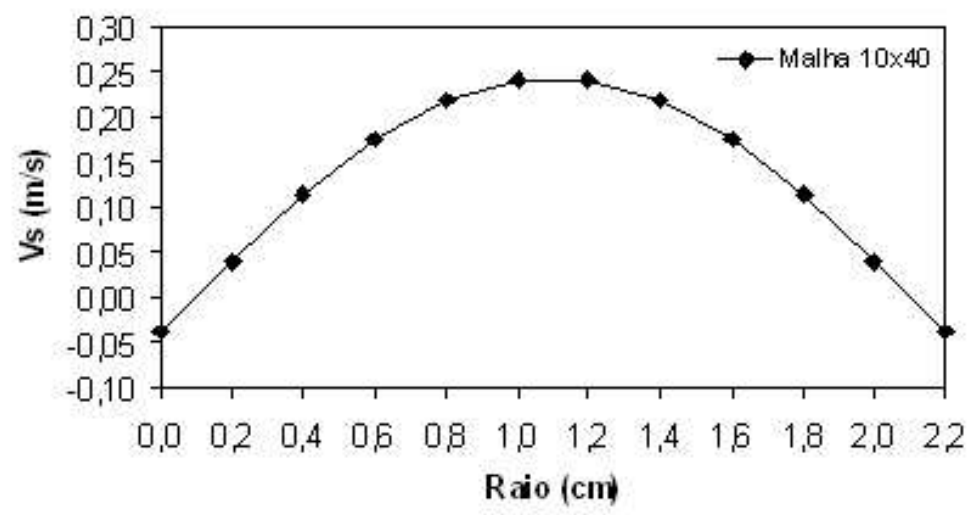

(a) Velocidade axial da fase Sólida

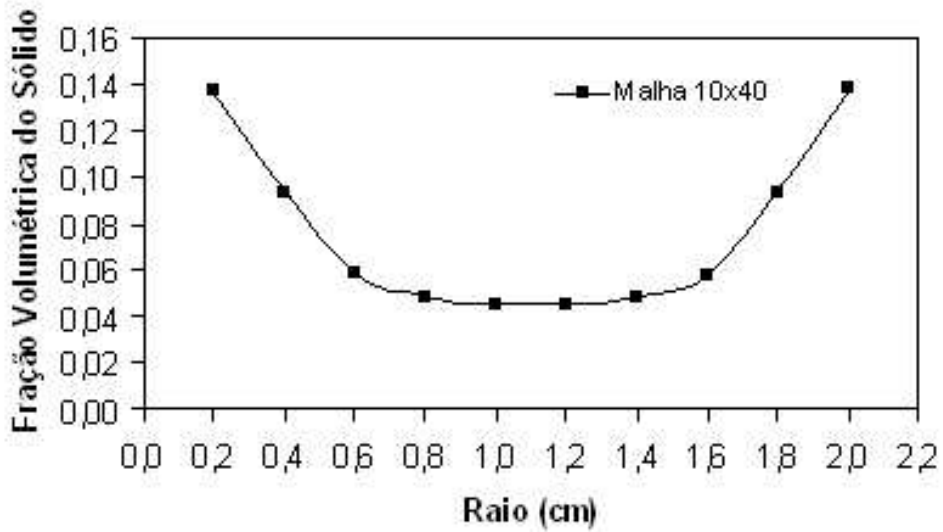

(b) Fração volumétrica da fase sólida

Figura 4.4: Perfis radiais da velocidade axial e fração volumétrica da fase sólida em $t=50 \mathrm{~s}$ avaliadas a $0,4 \mathrm{~cm}$ acima da entrada. Malha $10 \times 40$. Resolução: $2 \mathrm{~mm} \times 2 \mathrm{~mm}$. 
- Dados finais da simulação B3

Os perfis de velocidade axial e fração volumétrica são mostrados na Figura 4.5 (a) e (b), respectivamente.

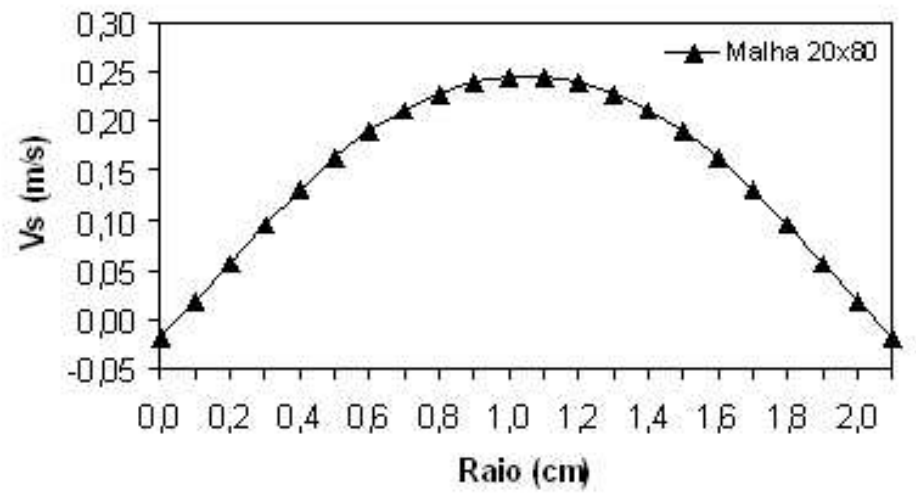

(a) Velocidade axial da fase gasosa

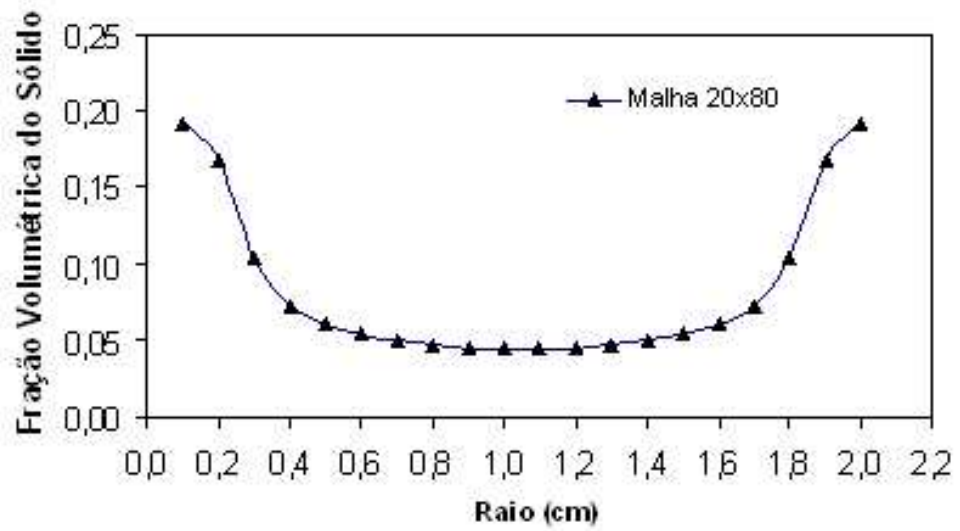

(b) Fração Volumétrica da fase sólida

Figura 4.5: Perfis radiais da velocidade axial e fração volumétrica para a fase sólida em tempo $t=50 \mathrm{~s}$ avaliadas a $0,4 \mathrm{~cm}$ acima da entrada. Malha $20 \times 80$. Resolução: $1 \mathrm{~mm} \times$ $1 \mathrm{~mm}$. 
- Dados finais da simulação B4

Neste experimento utiliza-se uma malha de $6400(40 \times 160)$ células. Os perfis de velocidades e fração volumétrica para ambas as fases no tempo $t=50 \mathrm{~s}$ podem ser vistos nas Figuras 4.6 e 4.7, respectivamente.

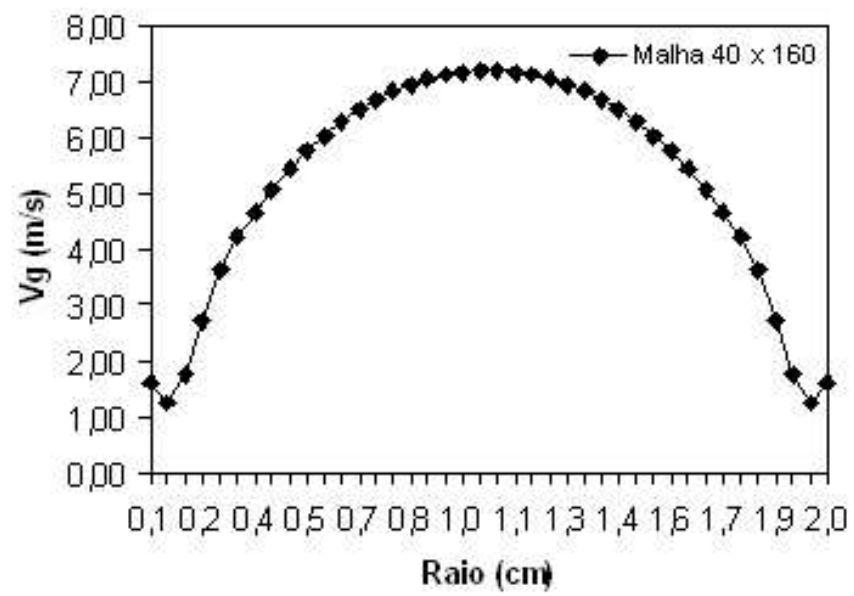

(a) Velocidade axial da fase gasosa

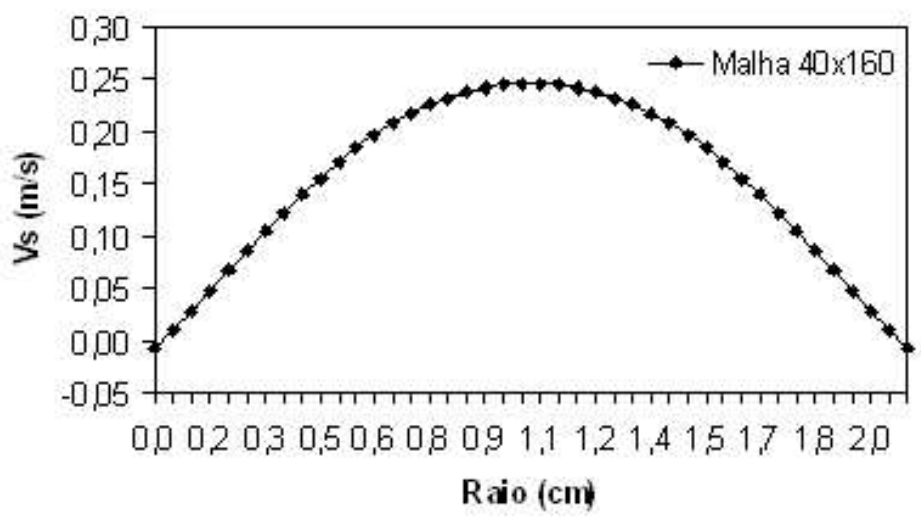

(b) Velocidade axial da fase sólida

Figura 4.6: Perfis radiais da velocidade axial para ambas as fases avaliadas a 0,4cm, acima da entrada, no tempo $t=50 \mathrm{~s}$. Malha $40 \times 160$. Resolução: $0,5 \mathrm{~mm} \times 0,5 \mathrm{~mm}$. 


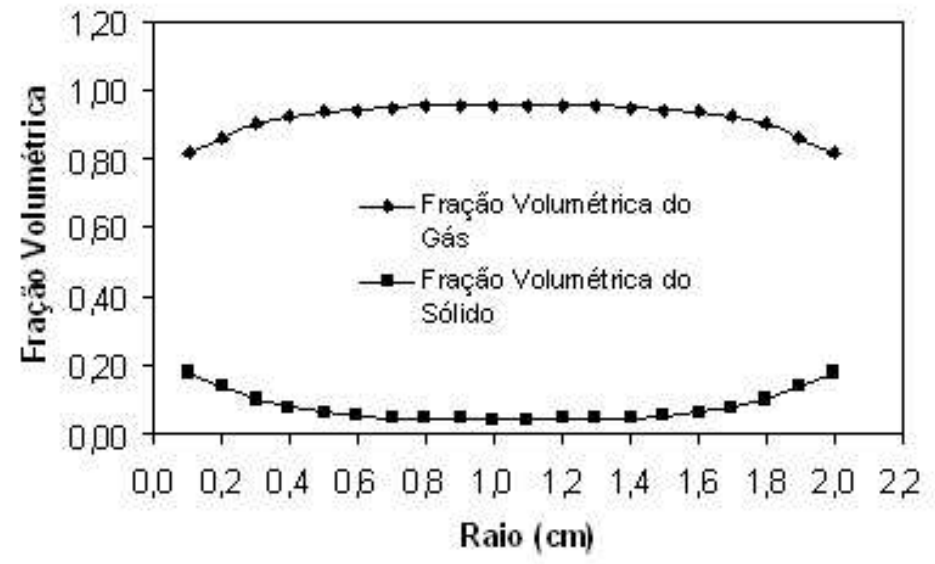

Figura 4.7: Perfis radiais da fração volumétrica para ambas as fases avaliadas a 0,4cm, acima da entrada, no tempo $t=50 \mathrm{~s}$. Malha $40 \times 160$. Resolução: $0,5 \mathrm{~mm} \times 0,5 \mathrm{~mm}$.

\subsection{Comparação dos Resultados considerando as Di- versas Malhas Computacionais}

A Figura 4.8 mostra a comparação qualitativa dos perfis de velocidades para a fase gasosa no tempo $t=50 \mathrm{~s}$, considerando as malhas de $100(5 \times 20), 400(10 \times 40), 1600$ $(20 \times 80)$ e $6400(40 \times 160)$ células computacionais, respectivamente. Nota-se variações significativas para as diferentes malhas. Porém, as diferenças se tornam menores para as malhas mais refinadas, conforme esperado.

Observa-se que o escoamento no tubo de dimensões $2 \mathrm{~cm} \times 8 \mathrm{~cm}$ resultou homogêneo no seu aspecto hidrodinâmico. A formação de clusters comum em escoamento gás-sólido em LFC não ocorreu, como visto nas Figuras 4.9 e 4.10. Pode-se notar, observando a variação da fração volumétrica do sólido no escoamento, mostrada na Figura 4.11, que mesmo a malha mais fina, de $6400(40 \times 160)$ pontos, não foi capaz de capturar o comportamento hidrodinâmico instável esperado. Avaliando-se novamente a variação da fração volumétrica do sólido, vê-se na Figura 4.12 apenas uma fina camada de partículas (linhas brancas) distribuídas ao logo da parede, e o acúmulo de partículas nos dois cantos (esquerdo e direito) na região de saída.

Nestes casos, tanto a malha quanto as dimensões do domínio computacional po- 


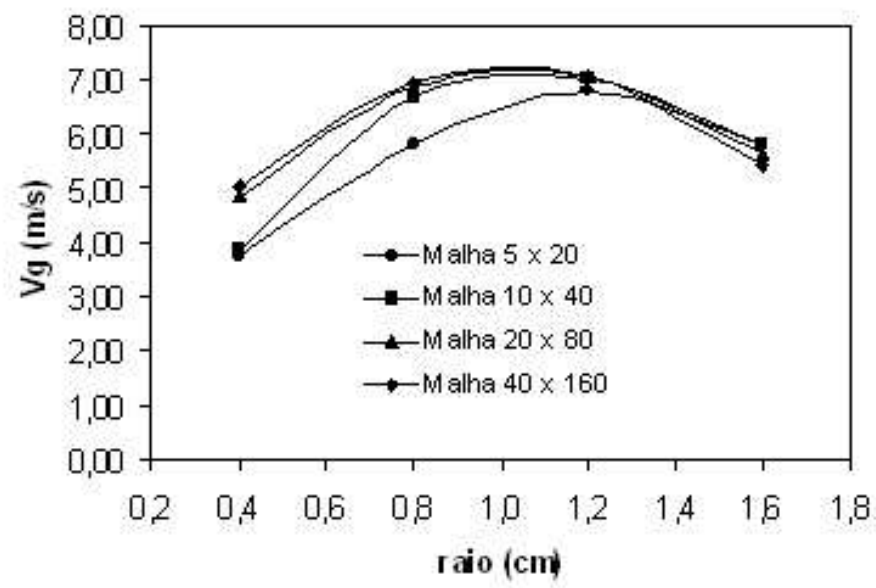

Figura 4.8: Perfis radiais da velocidade axial para a fase gasosa $\mathrm{emt}=50 \mathrm{~s}$ avaliadas a 0,4cm acima da entrada. Malhas: $5 \times 20 ; 10 \times 40 ; 20 \times 80$ e $40 \times 160$.

dem não estar permitindo capturar as interações hidrodinâmicas esperadas. Parece improvável que um possível refinamento insuficiente de malha seja a causa da homogeneidade do escoamento, já que a literatura mostra simulações onde clusters são capturados mesmo em malhas muito grosseiras (por exemplo, em CABEZAS-GÓMEZ [12]).

Quanto às dimensões do domínio, a altura pode não ter sido suficiente para formar um acúmulo significativo de partículas nas paredes ou, ainda, que não se conseguiu uma região do escoamento livre dos efeitos de entrada/saída. Aparentemente, a altura do domínio não foi suficiente para o desenvolvimento do escoamento no padrão heterogêneo esperado. Conclui-se que o domínio $2 \mathrm{~cm} \times 8 \mathrm{~cm}$ mostra-se inadequado para descrever o comportamento do escoamento.

Em vista dos resultados obtidos, decidiu-se aumentar a altura da coluna na busca de configurações de escoamento mais realistas. Na próxima seção apresenta-se os resultados obtidos com esta modificação. 


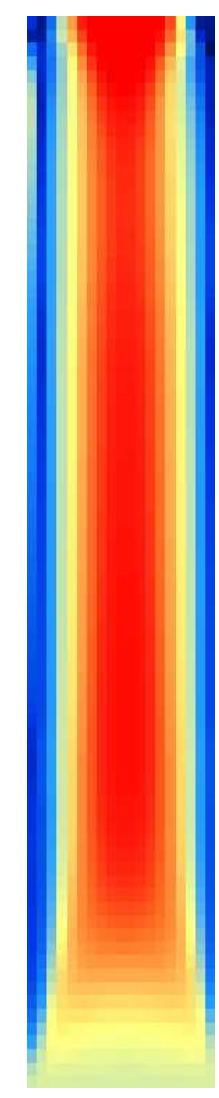

(a)

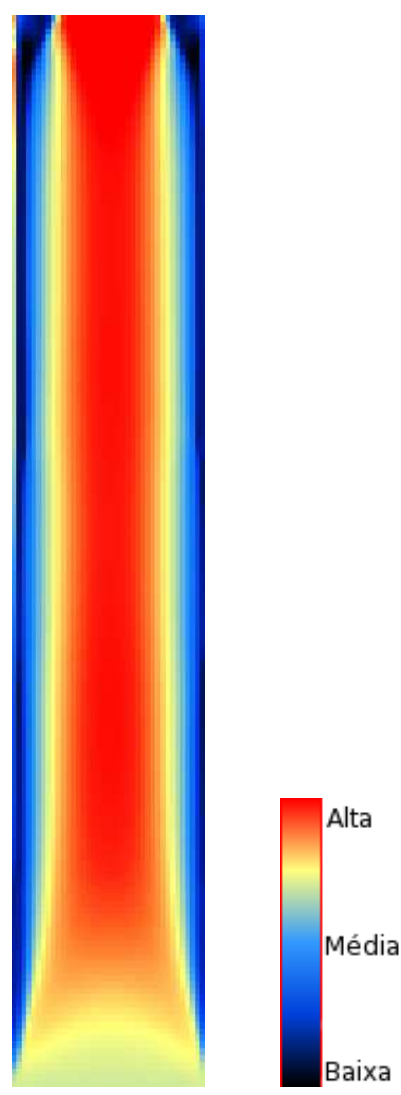

(b)

Figura 4.9: Comportamento da velocidade axial da fase gás no domínio, no tempo $t=1,0$ s. Malhas: (a) $20 \times 80$; (b) $40 \times 160$. 


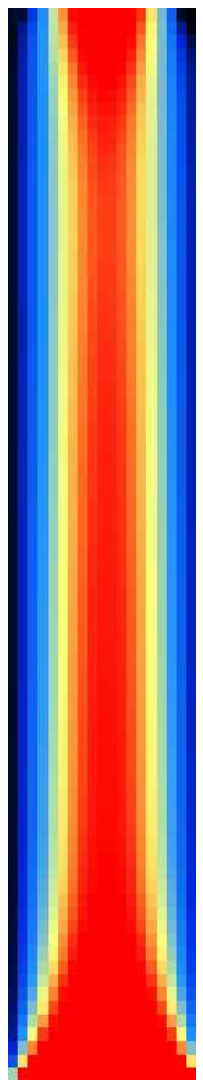

(a)
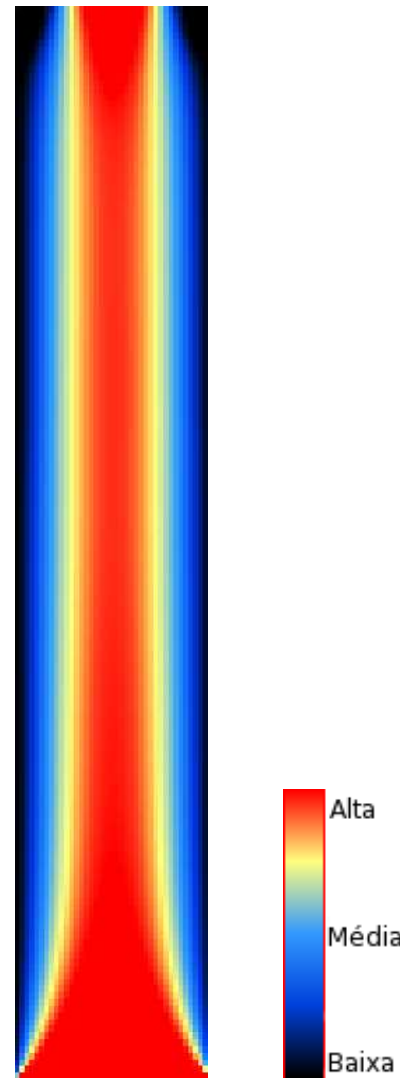

(b)

Figura 4.10: Comportamento da velocidade axial da fase sólida no domínio, no tempo $t=1.0 s$. Malhas: (a) $20 \times 80$; (b) $40 \times 160$. 


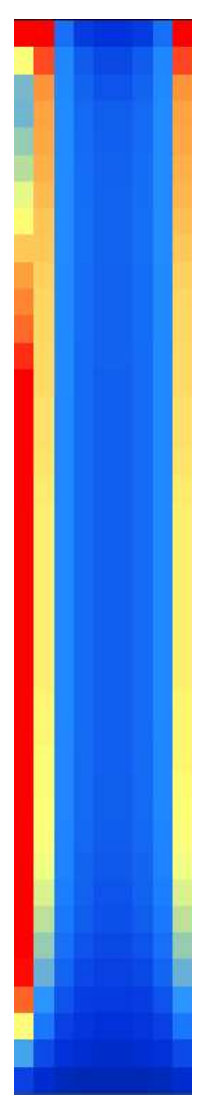

(a)

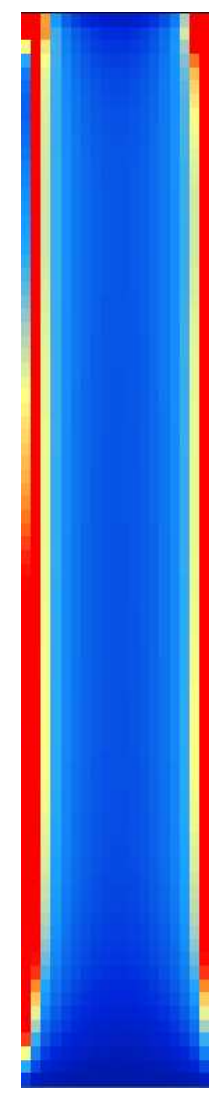

(b)

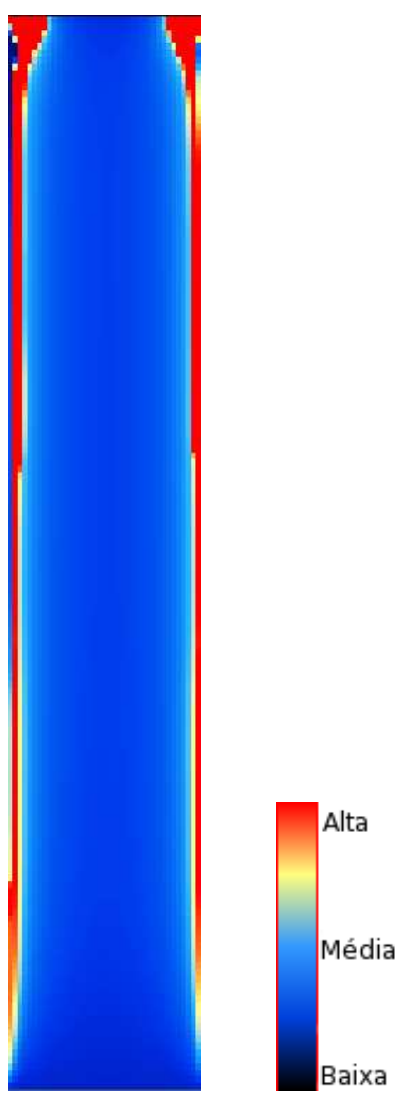

(c)

Figura 4.11: Evolução da Fração Volumétrica da fase sólida no domínio, no tempo $t=1,0$ s. Malhas: (a) $10 \times 40$; (b) $20 \times 80$; (c) $40 \times 160$. 


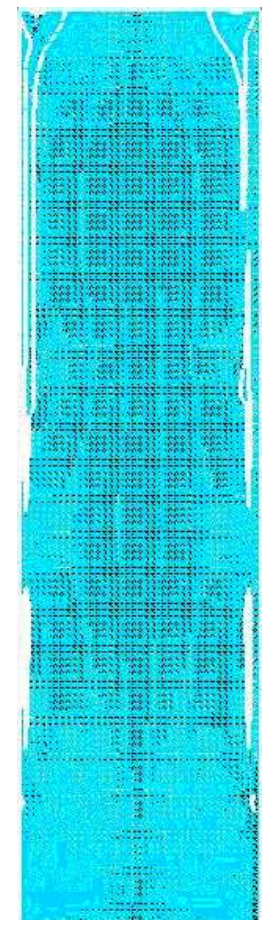

(a)

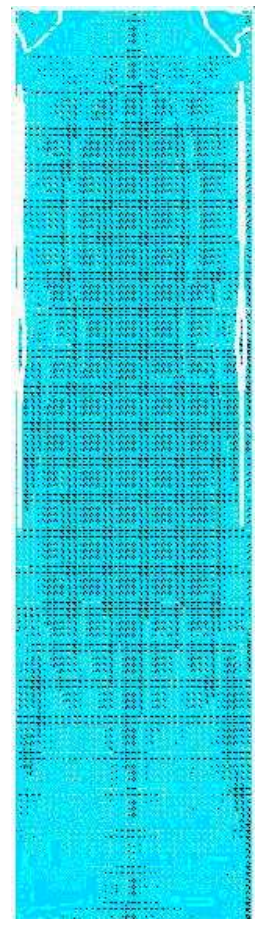

(b)

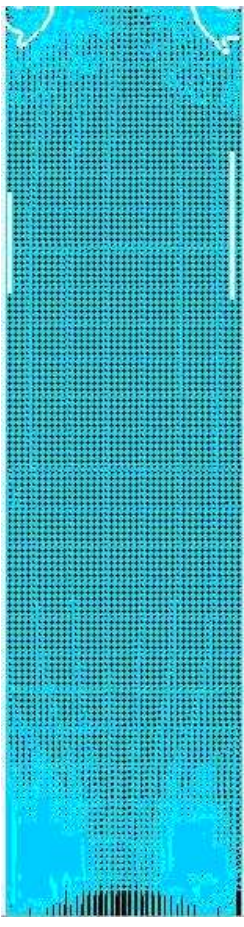

(c)

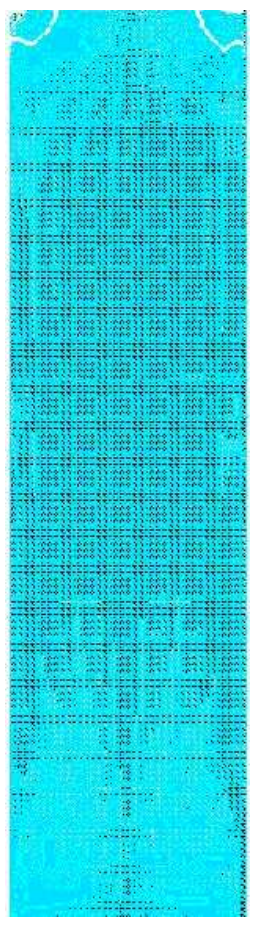

(d)

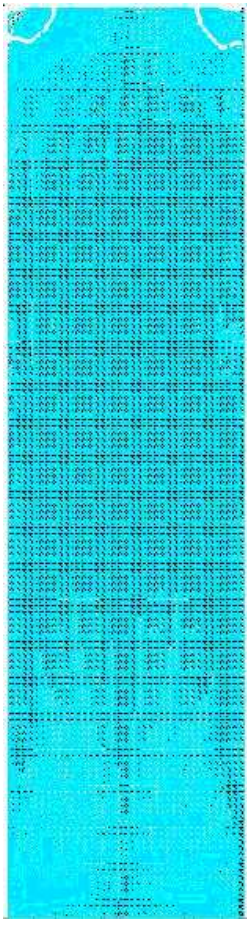

(e)

Figura 4.12: Evolução da Fração Volumétrica da fase sólida nos primeiros cinco segundos de simulação para malha $40 \times 160$. Resolução $0,5 \mathrm{~mm} \times 0,5 \mathrm{~cm}$; (a) $t=1 \mathrm{~s}$; (b) $t=2 \mathrm{~s}$; (c) $t=3 \mathrm{~s}$; (d) $t=4 \mathrm{~s}$; (e) $t=5 \mathrm{~s}$. Contornos com linhas brancas indicam a região com alta concentração da fase sólido no escoamento. 


\subsection{Resultados obtidos com o Ajuste da Coluna As- cendente e Refinamento da Malha}

Resultados com a malha de 6400 células $(40 \times 160)$ aplicadas no domínio $2 \mathrm{~cm} \times$ 8cm parecem não favorecer o aparecimento das interações hidrodinâmicas. Esta seção descreve resultados computacionais obtidos fazendo-se os seguintes ajustes nas escalas do domínio computacional e na respectiva malha bidimensional:

(a) Domínio: $2 \mathrm{~cm} \times 24 \mathrm{~cm}$; Malha: $80 \times 320$ células $(0,25 \mathrm{~mm} \times 0,25 \mathrm{~mm})$.

(b) Domínio: $4 \mathrm{~cm} \times 72 \mathrm{~cm}$; Malha: $20 \times 80$ células $(1 \mathrm{~mm} \times 1 \mathrm{~mm})$;

(c) Domínio: $4 \mathrm{~cm} \times 72 \mathrm{~cm}$; Malha: $40 \times 160$ células $(0,5 \mathrm{~mm} \times 0,5 \mathrm{~mm})$;

(d) Domínio: $2 \mathrm{~cm} \times 144 \mathrm{~cm}$; Malha: $20 \times 80$ células $(1 \mathrm{~mm} \times 1 \mathrm{~mm})$;

(e) Domínio: $4 \mathrm{~cm} \times 144 \mathrm{~cm}$; Malha: $40 \times 160$ células $(0,5 \mathrm{~mm} \times 0,5 \mathrm{~mm})$.

\subsubsection{Resultados numéricos de simulação para domínio de $2 \mathrm{~cm}$ $\times 24 \mathrm{~cm}$}

A Figura 4.13 ilustra o domínio $2 \mathrm{~cm} \times 24 \mathrm{~cm}$ para a realização de novas simulações computacionais. O intuito é verificar possíveis efeitos de dependência de malha e altura da coluna no desenvolvimento do escoamento.

A malha considerada para as dimensões $2 \mathrm{~cm} \times 24 \mathrm{~cm}$ foi refinada passando de 6400 para 25600 células computacionais, ou seja, utiliza-se uma malha de $80 \times 320$ células computacionais e resolução $0,25 \mathrm{~mm}$ x $0,25 \mathrm{~mm}$. Vale destacar que nos experimentos computacionais de CABEZAS-GOMÉZ [12] a malha mais fina utilizada possui pouco mais de 6500 células $(22 \times 297)$ aplicada em um riser de dimensões $0,76 \mathrm{~m} \times 5,5 \mathrm{~m}$, tendo resolução de 7,62mm × 76,2mm. Em AGRAWAL [1] a malha mais fina utilizada para o domínio $2 \mathrm{~cm} \times 8 \mathrm{~cm}$ foi de $50 \times 200$ (10000 elementos computacionais) com resolução $0,625 \mathrm{~mm} \times 0,606 \mathrm{~mm}$.

A Figura 4.14 mostra os contornos de fração volumétrica de sólidos no tubo ascendente de dimensões $2 \mathrm{~cm} \times 24 \mathrm{~cm}$. A fração volumétrica da fase sólida é maior para 


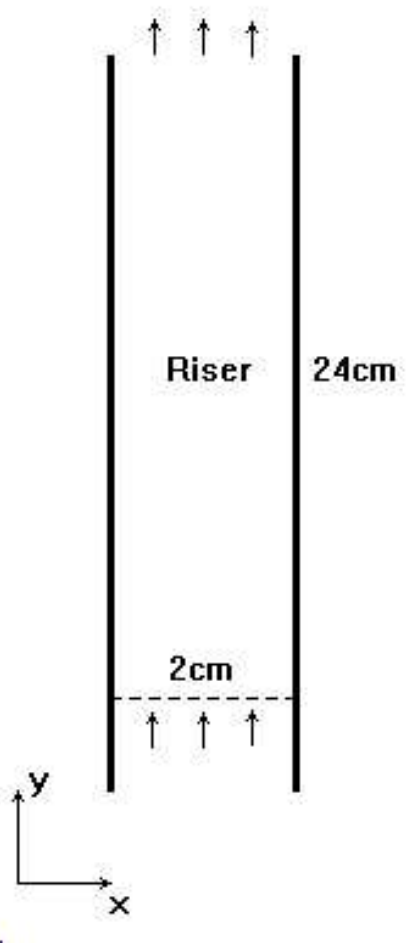

Figura 4.13: Tubo ascendente $2 \mathrm{~cm} \times 24 \mathrm{~cm}$ para simulação

tonalidades próximas do vermelho. Nota-se que nesta simulação já é possível verificar a formação e dissipação de clusters, o que até o momento não havia sido possível visualizar nos resultados anteriores utilizando o domínio $2 \mathrm{~cm} \times 8 \mathrm{~cm}$. Isto indica que esta malha e dimensões do domínio são adequadas para capturar a física do escoamento bifásico gás-sólido.

As Figuras 4.15 a 4.19 mostram os resultados para vários parâmetros relevantes. Nota-se na Figura 4.15 o padrão heterogêneo e instável do escoamento, com campos de $V_{g}$ bastante não uniformes. Nas Figuras 4.16 e 4.17 apresentam-se resultados médios temporais na seção transversal $12 \mathrm{~cm}$ acima da entrada. Observa-se que, após cerca de 12 segundos de simulação, os parâmetros tendem a um valor médio bem estabelecido, tal como em regime estácionário.

Nas Figuras 4.18 e 4.19 mostra-se a evolução temporal das frações de gás e sólido no domínio. Nota-se que ocorrem formação de clusters nas paredes, com posterior desenvolvimento e dissipação. 

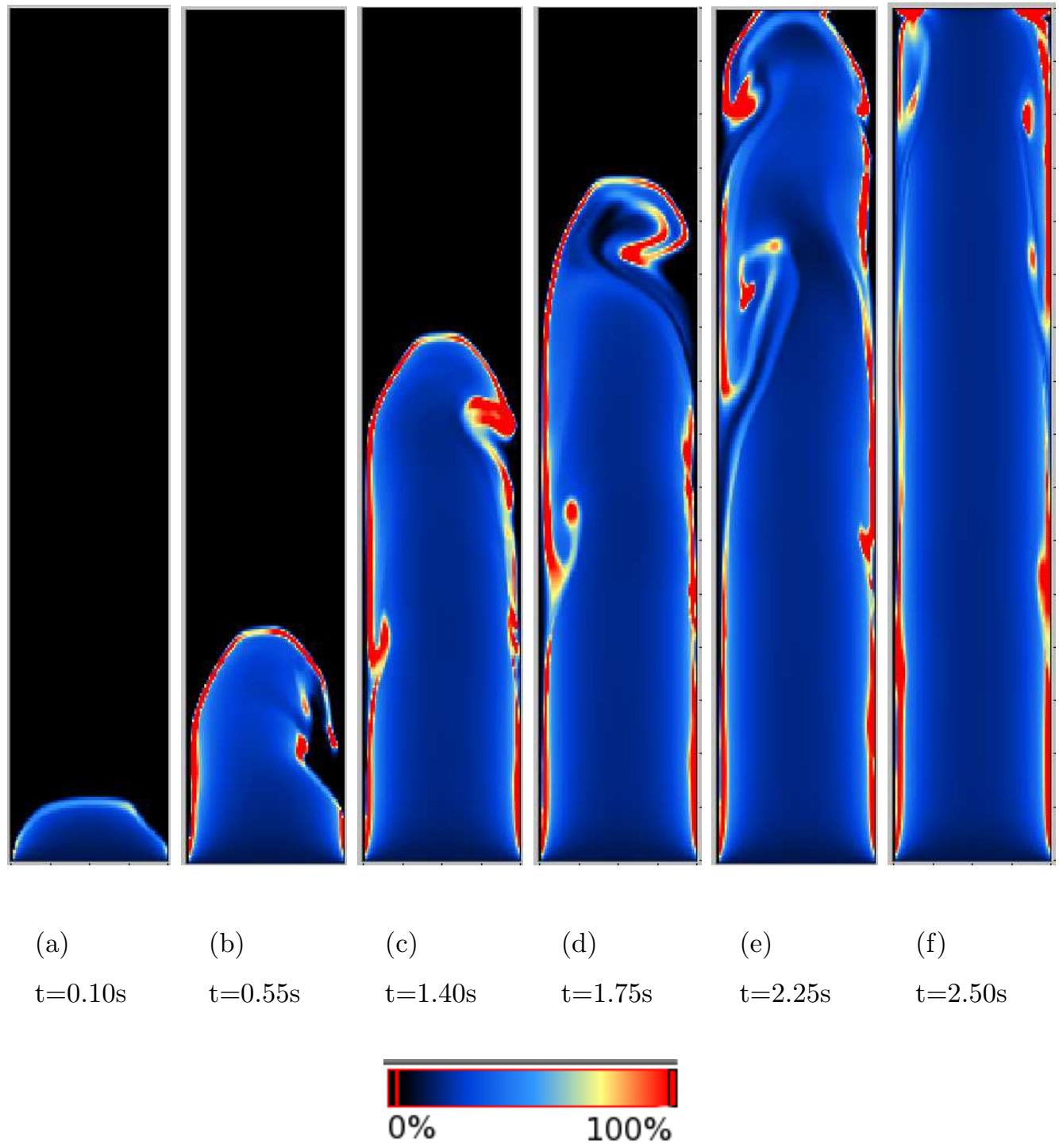

Figura 4.14: Variação da fração volumétrica da fase sólida ao longo do tubo ascendente. Domínio: $2 \mathrm{~cm} \times 24 \mathrm{~cm}$. Malha computacional: $80 \times 320$. Resolução: $0,25 \mathrm{~mm} \times 0,25 \mathrm{~mm}$. 

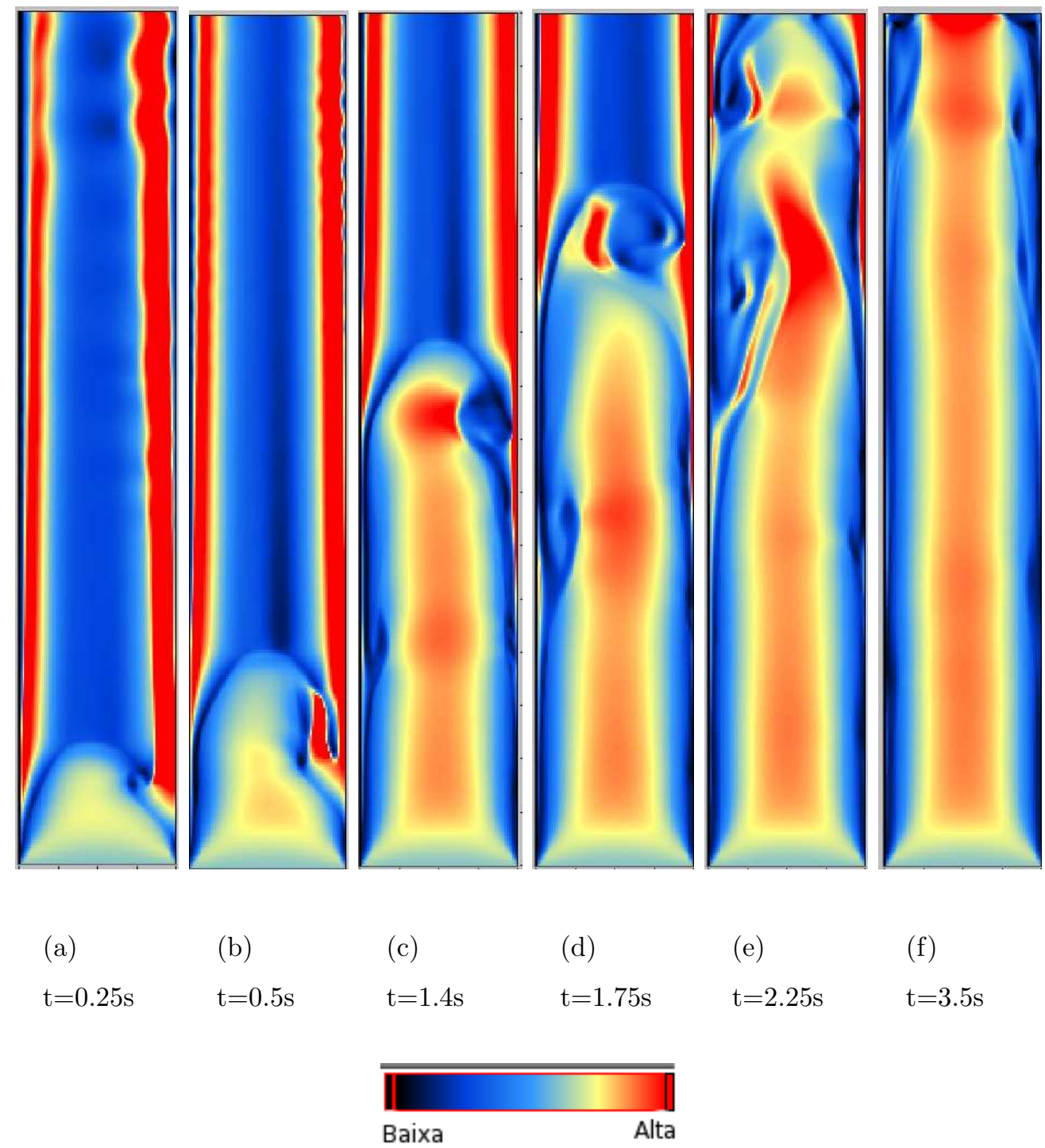

(e)

$\mathrm{t}=2.25 \mathrm{~s} \quad \mathrm{t}=3.5 \mathrm{~s}$

Figura 4.15: Variação temporal da velocidade axial da fase gasosa. Domínio: $2 \mathrm{~cm} \times$ 24cm; Malha computacional: $80 \times 320$; Resolução: $0,25 \mathrm{~mm} \times 0,25 \mathrm{~mm}$. 


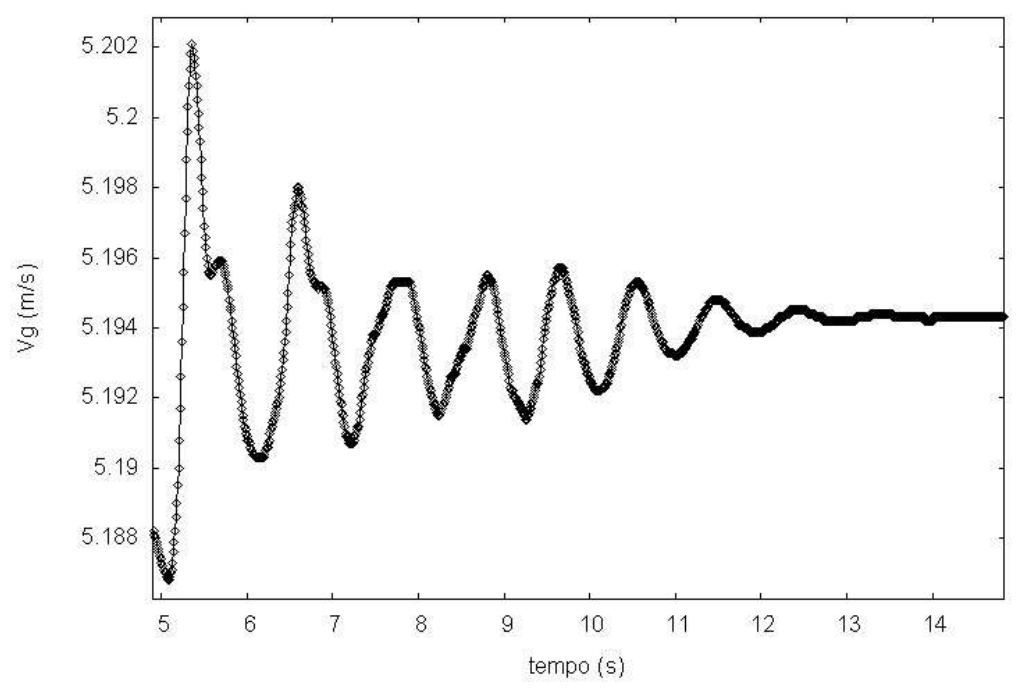

(a) Variação temporal da velocidade axial do gás

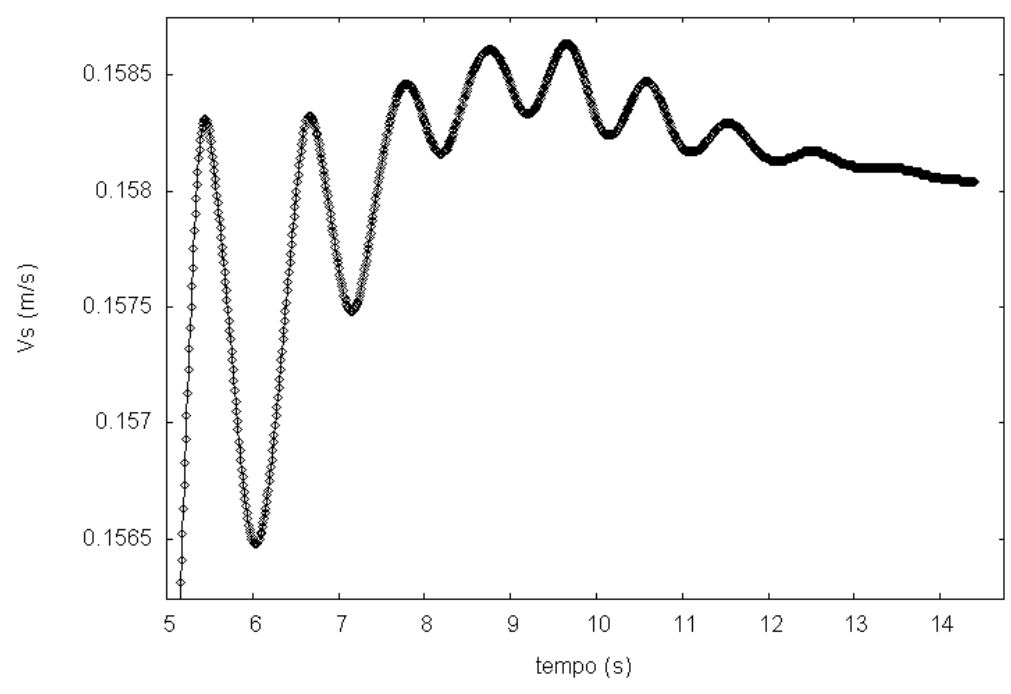

(b) Variação temporal da velocidade axial do sólido

Figura 4.16: Variações temporais médias das velocidade axiais de ambas as fases na seção $12 \mathrm{~cm}$ acima da entrada. Domínio: $2 \mathrm{~cm} \times 24 \mathrm{~cm}$; Malha computacional: $80 \times 320$; Resolução: $0,25 \mathrm{~mm} \times 0,25 \mathrm{~mm}$. 


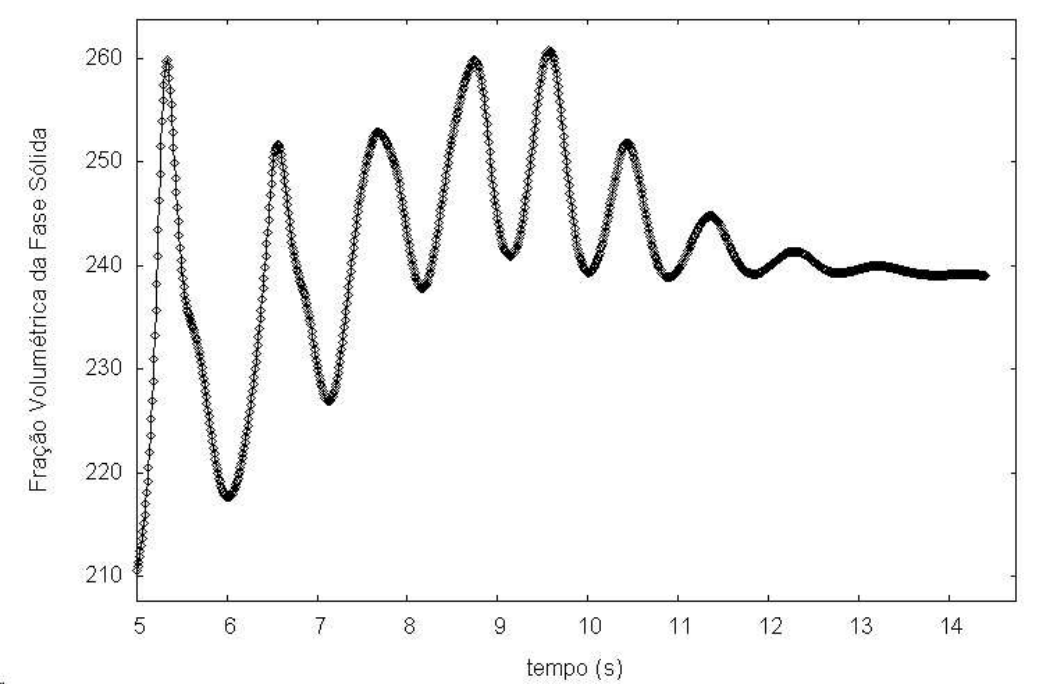

(a) Variação temporal da fração volumétrica da fase sólida

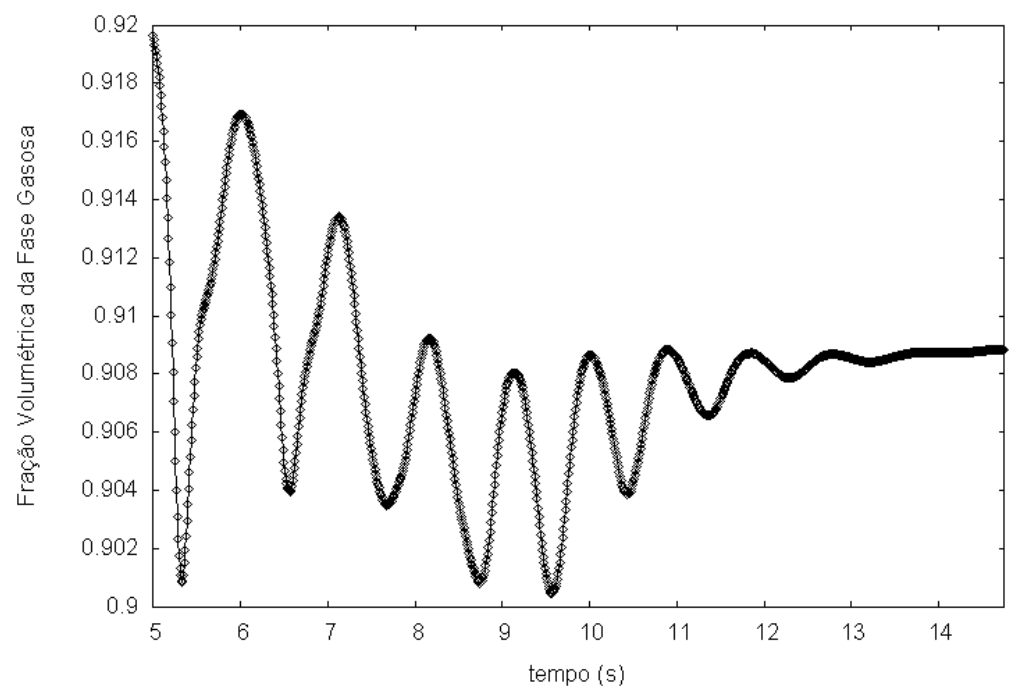

(b) Variação temporal da fração volumétrica da fase gasosa

Figura 4.17: Variações temporais médias das frações volumétricas de ambas as fases na seção $12 \mathrm{~cm}$ acima da entrada. Domínio: $2 \mathrm{~cm} \times 24 \mathrm{~cm}$; Malha computacional: $80 \times 320$; Resolução: $0,25 \mathrm{~mm} \times 0,25 \mathrm{~mm}$. 

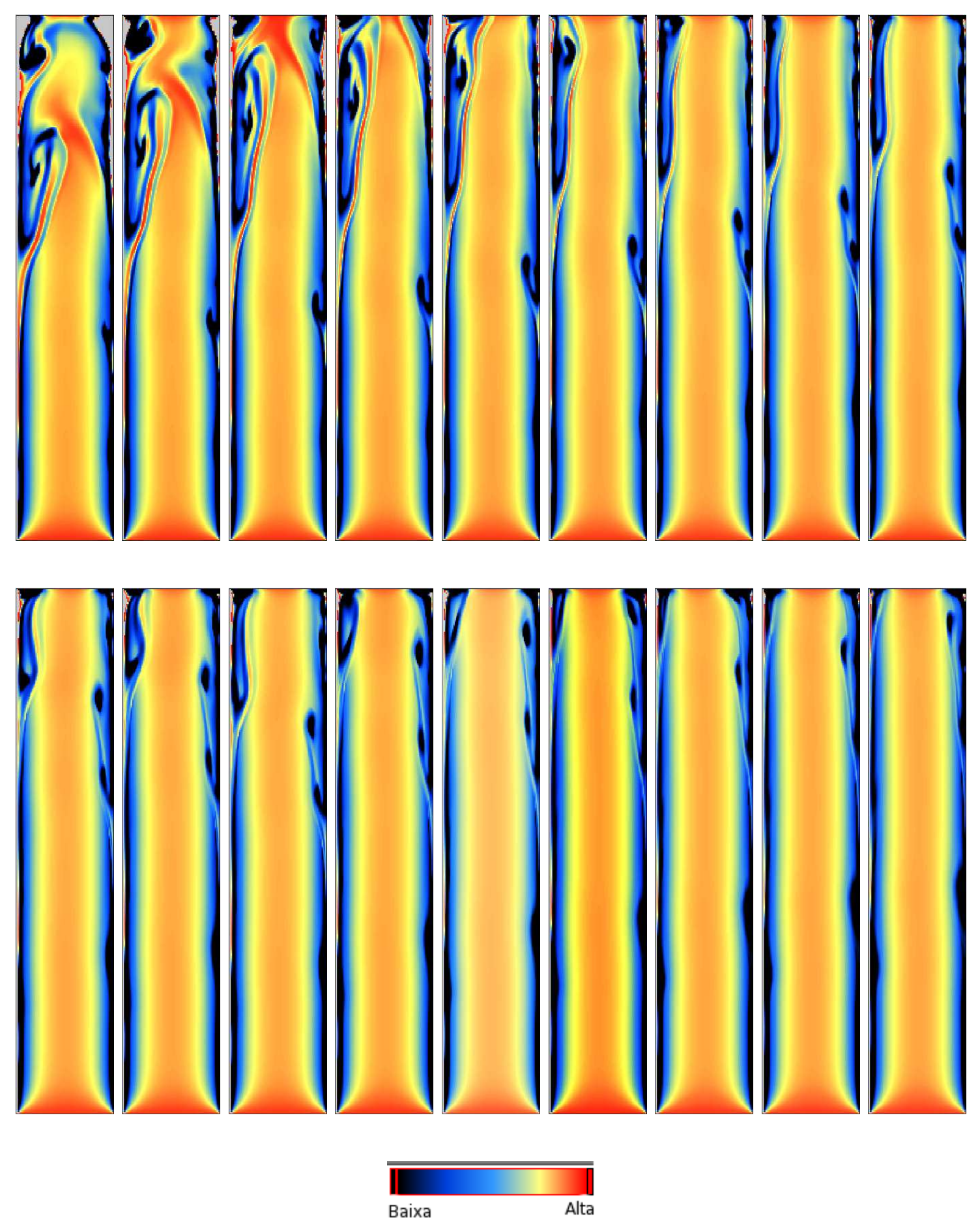

Figura 4.18: Variação temporal da fração volumétrica da fase gasosa no domínio. Domínio: $2 \mathrm{~cm} \times 24 \mathrm{~cm}$; Malha computacional: $80 \times 320$; Resolução: $0,25 \mathrm{~mm} \times 0,25 \mathrm{~mm}$; Intervalo de $0,1 \mathrm{~s}$ do instante $t=2,3 \mathrm{~s}$ até $t=4,0 \mathrm{~s}$ entre os sucessivos quadros. 

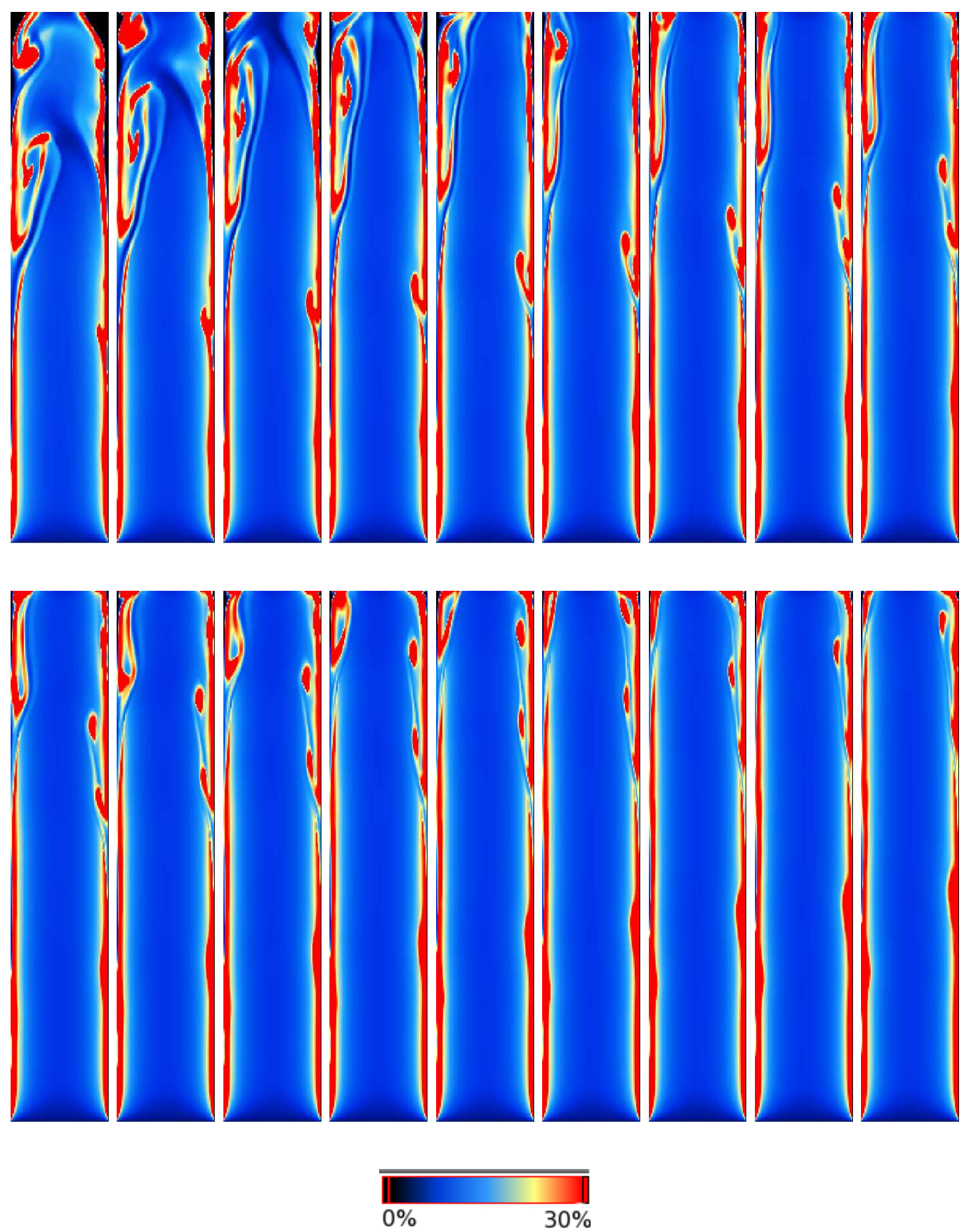

Figura 4.19: Variação temporal da fração volumétrica da fase sólida no domínio. Domínio: $2 \mathrm{~cm} \times 24 \mathrm{~cm}$; Malha computacional: $80 \times 320$; Resolução: 0,25mm × 0,25mm; Intervalo de $0,1 s$ do instante $t=2,3 s$ até $t=4,0 s$ entre os sucessivos quadros. 
Na Figura 4.20 segue uma comparação qualitativa dos presentes resultados com resultados obtidos por AGRAWAL [1], utilizando um domínio $5 \mathrm{~cm} \times 20 \mathrm{~cm}$ com resolução $2 \mathrm{~mm} \times 2 \mathrm{~mm}$. Compara-se frações volumétricas de sólido ao longo da altura da coluna. No resultado de AGRAWAL, tonalidades escuras apontam mais de $25 \%$ de fração de sólido no escoamento. Em (b) mostra-se o resultado de simulação da variação da fração volumétrica do sólido, obtido no presente trabalho, no domínio $2 \mathrm{~cm} \times 24 \mathrm{~cm}$ e resolução $0,25 \mathrm{~mm} \times 0,25 \mathrm{~mm}$. Tonalidades próximas do vermelho também apontam mais de $25 \%$ da fração de sólido no escoamento.

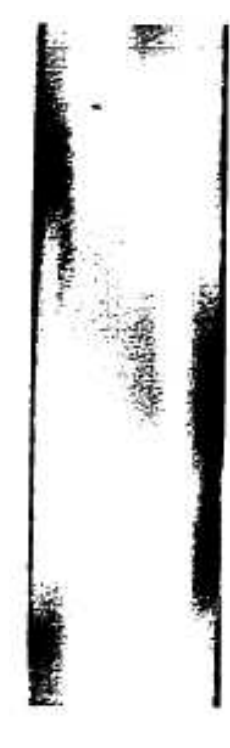

(a)

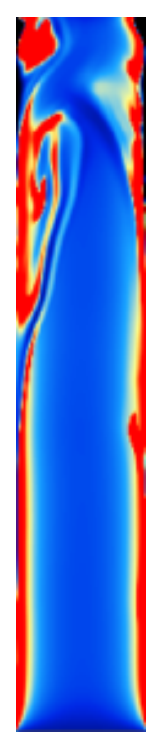

(b)

Figura 4.20: Compararação qualitativa da fração volumétrica da fase sólida. (a) AGRAWAL [1] (Tonalidade preta indica altas frações de sólido, o branco baixas frações de sólido); Domínio: $5 \mathrm{~cm} \times 20 \mathrm{~cm}$; Resolução: $2 \mathrm{~mm} \times 2 \mathrm{~mm}$. (b) Presente Trabalho (Tonalidade vermelha indica altas frações de sólido, o azul baixas frações de sólido); Domínio: $2 \mathrm{~cm} \times 24 \mathrm{~cm}$; Resolução $0,25 \mathrm{~mm} \times 0,25 \mathrm{~mm}$.

Nota-se que a presente simulação captura um padrão de escoamento detalhado em vista da resolução de malha aplicada. 


\subsubsection{Resultados numéricos para domínio de $4 \mathrm{~cm} \times 72 \mathrm{~cm}$}

O domínio adotado para as simulações computacionais descritas a seguir está ilustrado na Figura 4.21. Para este domínio aplica-se inicialmente uma malha $20 \times 80$ (resolução $1 \mathrm{~mm} \times 1 \mathrm{~mm}$ ) cujos resultados de simulação podem ser vistos na Figura 4.22 mostrando a variação da fração volumétrica da fase gasosa ao longo da coluna. A Figura 4.23 mostra a variação da fração volumétrica da fase gasosa nas regiões (a) entrada, (b) centro e (c) saída da coluna com os vetores apontando a direção da velocidade do gás. Após isso, aplica-se uma malha mais fina $40 \times 160$ (resolução 0,5mm × 0,5mm) sobre este mesmo domínio. A variação temporal da fração volumétrica do gás obtida com aplicação dessa malha mais fina é mostrada na Figura 4.24. A avaliação da variação das velocidades das fases (a) gasosa, (b) sólida e (c) fração volumétrica da fase gasosa no centro da coluna pode ser visualizada na Figura 4.25 com vetores apontando o direcionamento da velocidade de cada fase.

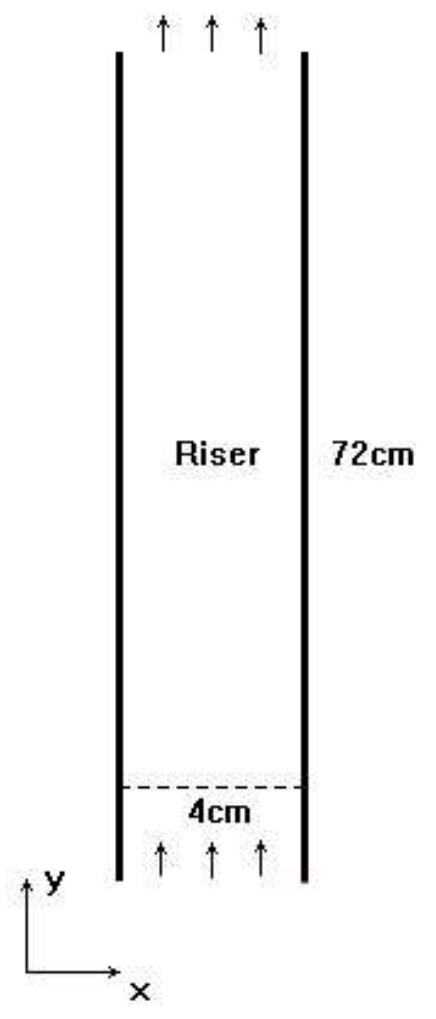

Figura 4.21: Tubo ascendente $4 \mathrm{~cm} \times 72 \mathrm{~cm}$ para simulação 


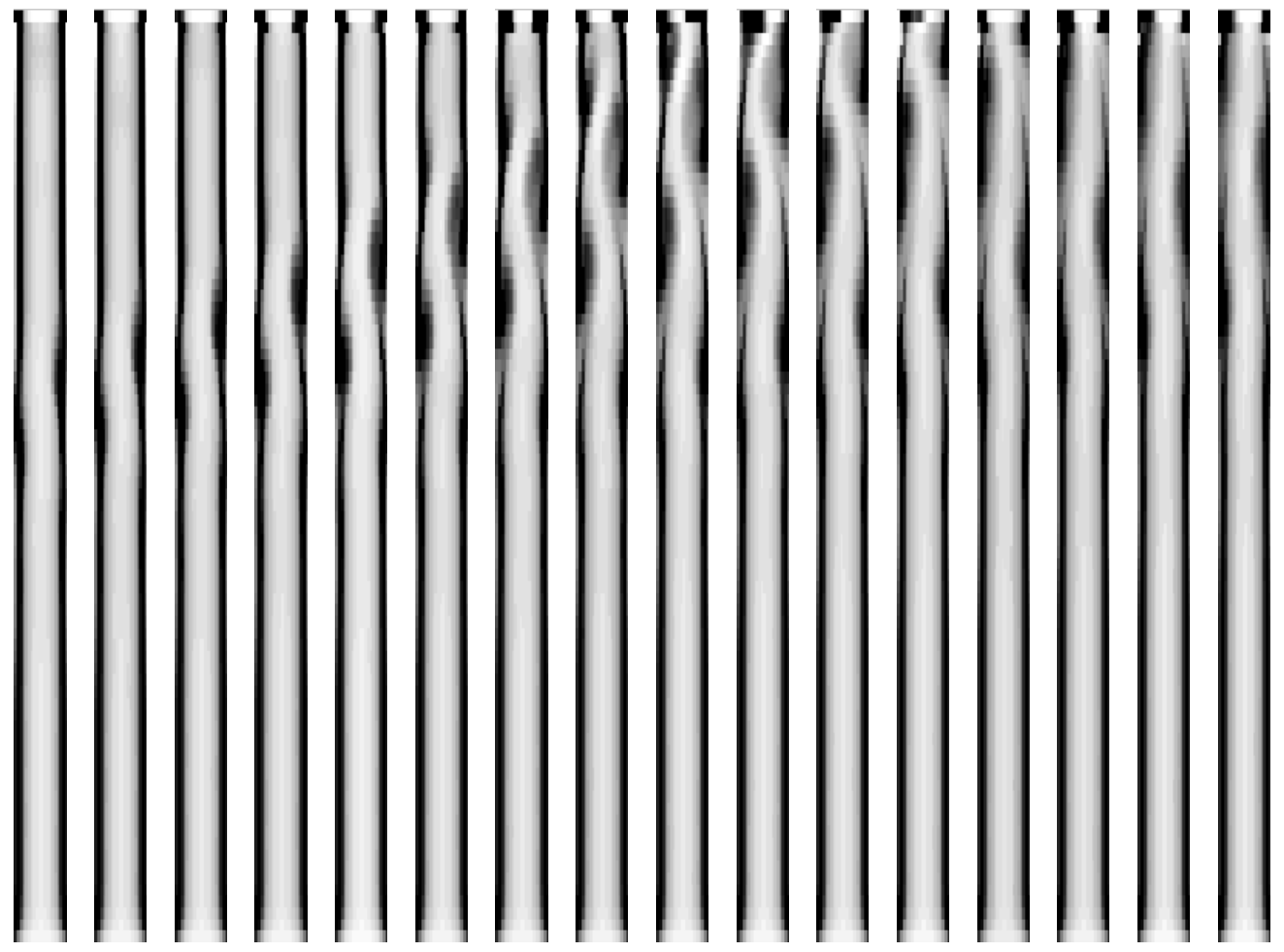

Figura 4.22: Variação temporal da fração volumétrica da fase gasosa ao longo da coluna. Domínio: $0,04 \mathrm{~m} \times 0,72 \mathrm{~m}$; Malha computacional: $20 \times 80$; Resolução: $1 \mathrm{~mm} \times 1 \mathrm{~mm}$; Intervalo de $0,1 s$ do instante $t=3,7 s$ até $5,2 s$ entre os sucessivos quadros; A tonalidade cinza claro indica altas frações de gás, o preto indica baixas frações de gás.

O efeito do refinamento de malha é evidente em todas as figuras, onde detalhes mais refinados do escoamento são observados para a malha mais refinada. 


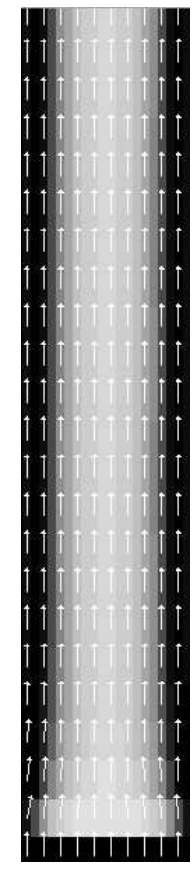

(a)

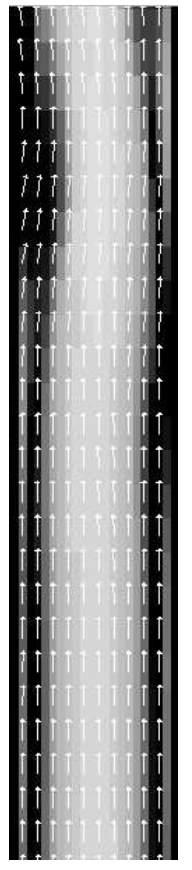

(b)

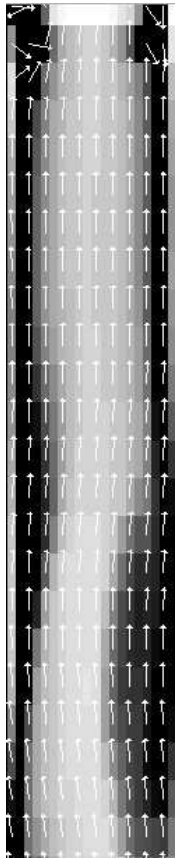

(c)

Figura 4.23: Variação da fração volumétrica da fase gasosa nas regiões (a) entrada, (b) centro e (c) saída da coluna. Vetores apontam o direcionamento da velocidade do gás nas três regiões do riser. Tempo: $t=4,2 s$. Domínio: $0,04 \mathrm{~m} \times 0,72 \mathrm{~m}$; Malha computacional: $20 \times$ 80; Resolução: $1 \mathrm{~mm} \times 1 \mathrm{~mm}$. A tonalidade cinza clara indica altas frações de gás, o preto indica baixas frações de gás. 


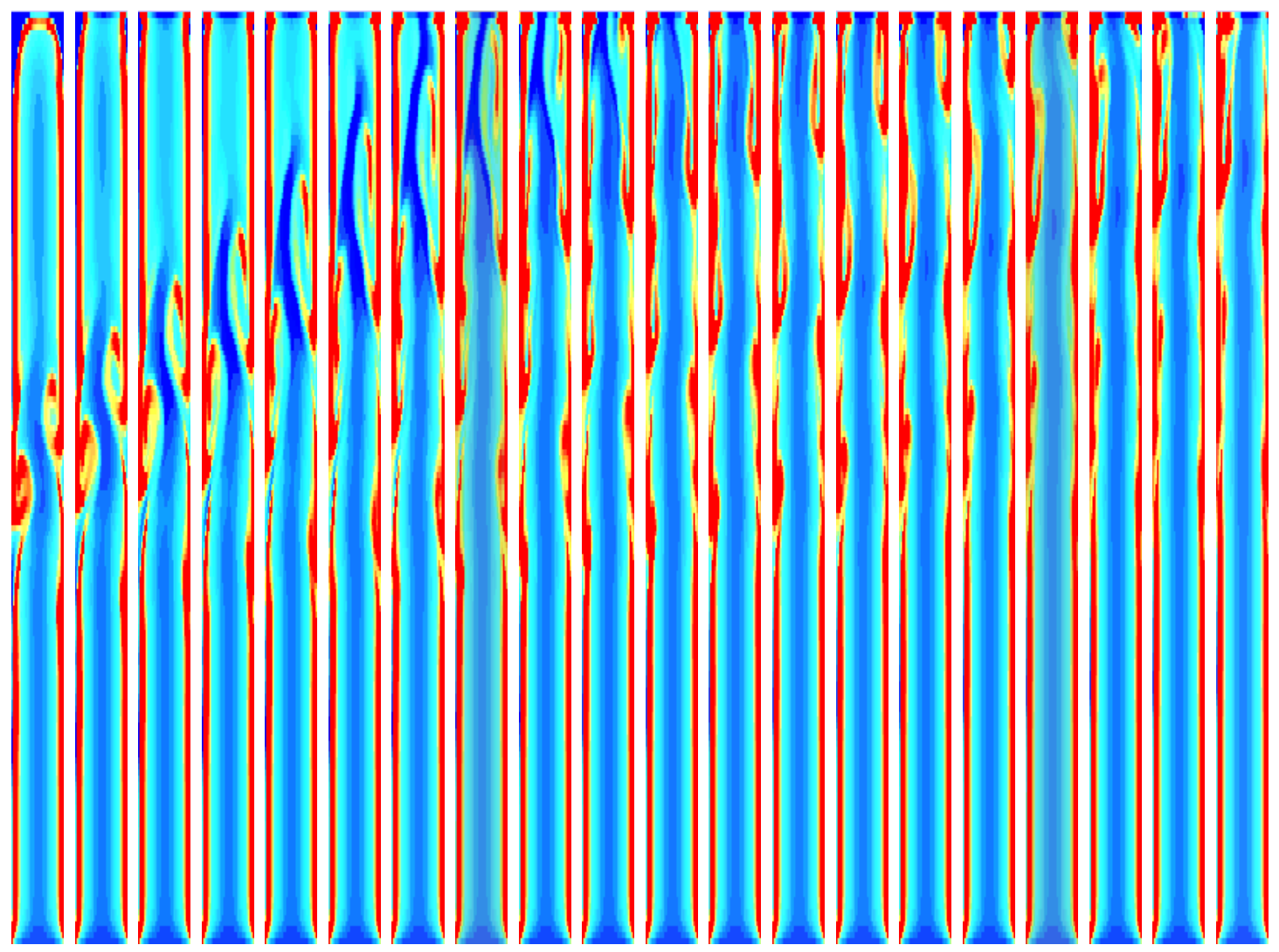

Figura 4.24: Variação temporal da fração volumétrica da fase gasosa ao longo da coluna. Domínio: $4 \mathrm{~cm} \times 72 \mathrm{~cm}$; Malha computacional: $40 \times 160$. Resolução: 0,5mm × 0,5mm; Intervalo de $0,1 s$ do instante $t=4,0 s$ até $5,9 s$ entre os sucessivos quadros. A tonalidade azul indica altas frações de gás, o vermelho indica baixas frações de gás. 


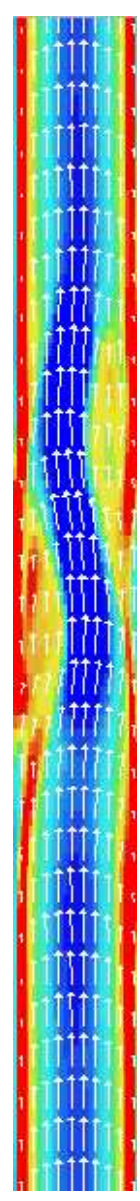

(a)

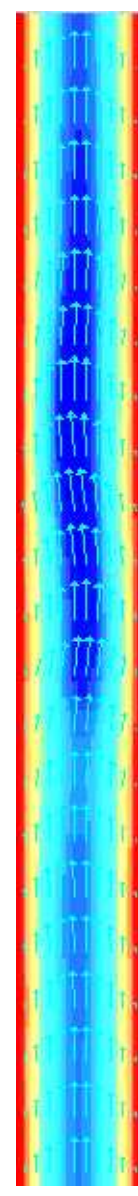

(b)

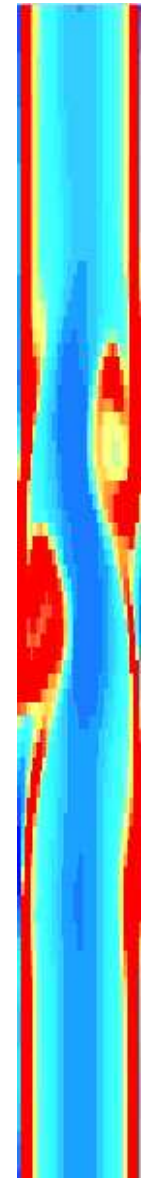

(c)

Figura 4.25: Variação das velocidades das fases (a) gasosa, (b) sólida e (c) fração volumétrica da fase gasosa avaliadas no centro da coluna no tempo $t=4 \mathrm{~s}$. Domínio: $0,04 \mathrm{~m}$ $\times$ 0,72m; Malha computacional: $40 \times 160$; Resolução: $0,5 \mathrm{~mm} \times 0,5 \mathrm{~mm}$; A tonalidade azul indica altas velocidades (a) gás e (b) sólido e (c) altas frações de gás, o vermelho indica baixas velocidades (gás e sólido) e baixas fração de gás; Vetores apontam a direção da velocidade de cada fase. 


\subsubsection{Resultados numéricos para domínio de $2 \mathrm{~cm} \times 144 \mathrm{~cm} \mathrm{e}$ $4 \mathrm{~cm} \times 144 \mathrm{~cm}$}

A Figura 4.26 ilustra a configuração utilizada para a simulação em domínio $2 \mathrm{~cm} \times$ $144 \mathrm{~cm}$.

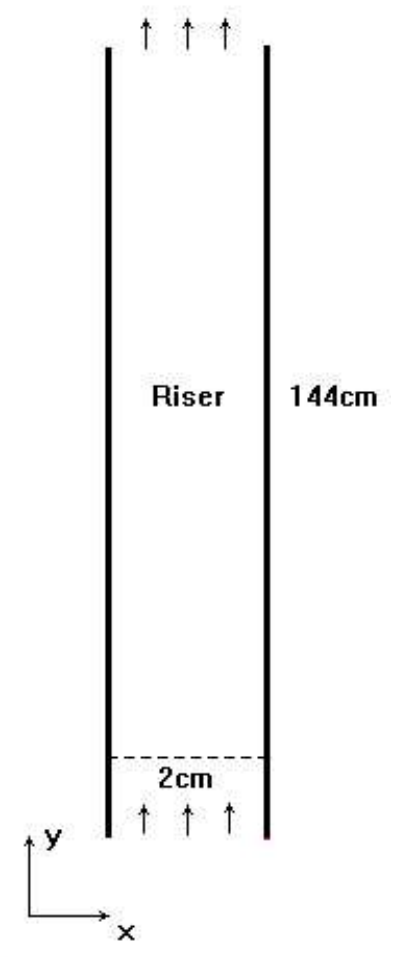

Figura 4.26: Tubo ascendente $2 \mathrm{~cm} \times 144 \mathrm{~cm}$ para simulação

A malha numérica considerada tem $20 \times 80$ células computacionais, com resolução de $1 \mathrm{~mm} \times 1 \mathrm{~mm}$.

Os campos de velocidades axiais de ambas as fases e a fração volumétrica da fase gasosa ao longo da coluna são mostrados na Figura 4.27. Nota-se que o comportamento hidrodinâmico apresenta-se ainda bastante homogêneo. Vetores apontam o direcionamento das velocidades de cada fase no escoamento ao longo da coluna. Pode-se perceber o formato parabólico dos perfís de velocidades axiais em ambas as fases. 


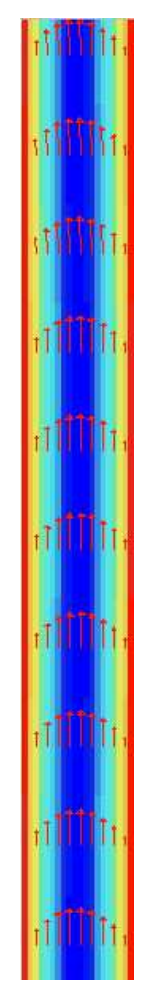

(a)

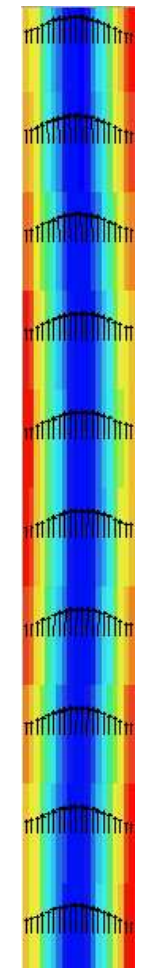

(b)

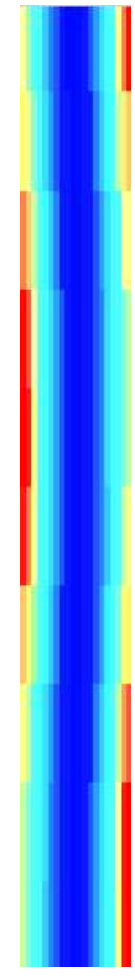

(c)

Figura 4.27: Variação das velocidades das fases (a) sólida, (b) gasosa e (c) variação da fração volumétrica dos gás. Tempo: $t=38 \mathrm{~s}$; Domínio: 0,02m $\times$ 1,44m; Malha computacional: $20 \times 80$; Resolução: $1 \mathrm{~mm} \times 1 \mathrm{~mm}$. A tonalidade azul indica altas velocidades (gás e sólido) e altas frações de gás, o vermelho indica baixas velocidades (gás e sólido) e baixas fração de gás; Vetores apontam o direcionamento das velocidades na direção de saída.

A Figura 4.28 mostra a configuração utilizada para simulação em domínio de 4cm x $144 \mathrm{~cm}$.

Neste caso, aumentando-se o diâmetro da coluna de $2 \mathrm{~cm}$ para $4 \mathrm{~cm}$ e mantendo-se a altura de $144 \mathrm{~cm}$ com resolução de $0,5 \mathrm{~mm} \times 0,5 \mathrm{~mm}$. Percebeu-se um comportamento hidrodinâmico semelhante àquela obtido com a malha fina $80 \times 320$ (resolução 0,25mm $\times 0,25 \mathrm{~mm})$, conforme mostrado nas Figuras 4.29 e 4.30. Observou-se nas simulações anteriores que a malha $40 \times 160$ (resolução $0,5 \mathrm{~mm} \times 0,5 \mathrm{~mm}$ ) quando aplicada na coluna de dimensões $2 \mathrm{~cm} \times 8 \mathrm{~cm}$ não captava o comportamento heterogêneo do escoamento bifásico. Neste conjunto de simulações evidência-se os efeitos da altura do domínio, per- 
mitindo o desenvolvimento do escoamento no padrão esperado. Ficam também evidentes os efeitos no desenvolvimento do escoamento causados pela dependência de malha nos resultados de simulação. Quanto mais refinada a malha, mais detalhes do escoamento são capturados.

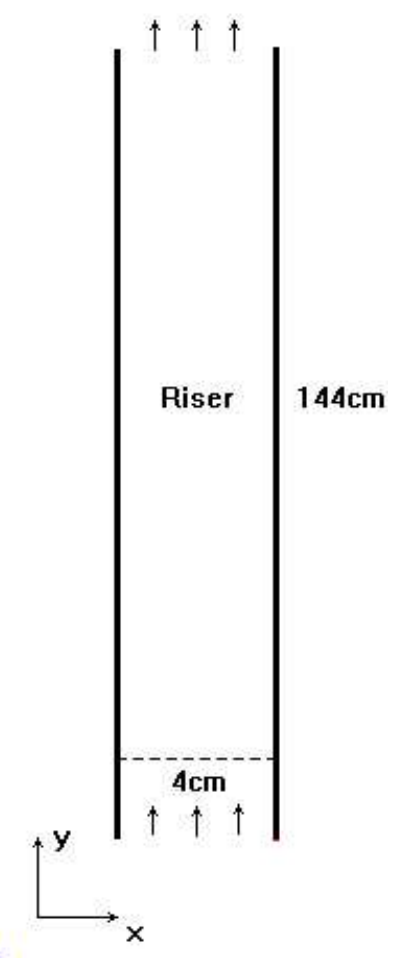

Figura 4.28: Tubo ascendente $2 \mathrm{~cm} \times 144 \mathrm{~cm}$ para simulação 


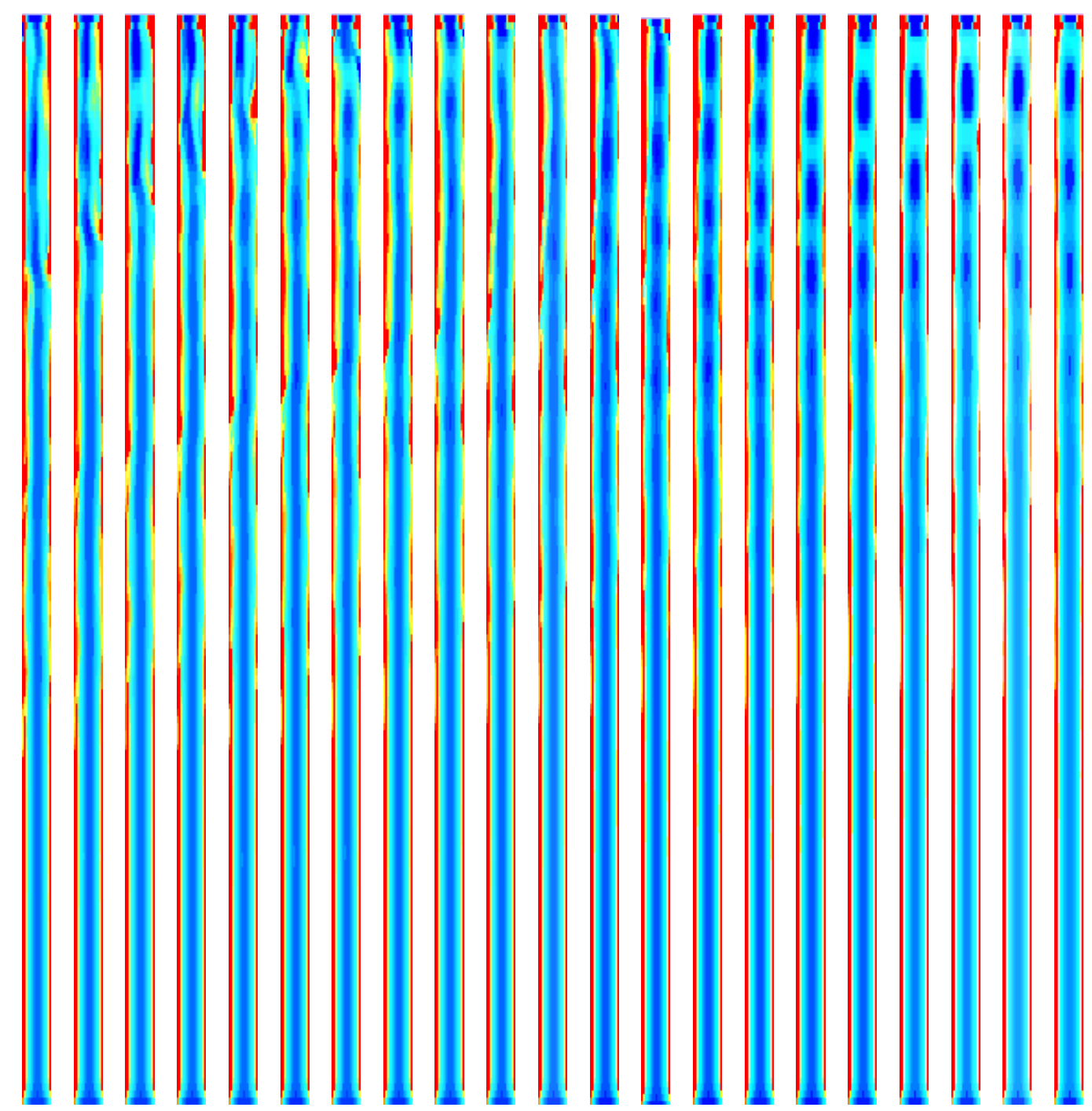

Figura 4.29: Variação temporal da fração volumétrica da fase gasosa ao longo da coluna. Domínio: $4 \mathrm{~cm} \times 144 \mathrm{~cm}$; Malha computacional: $40 \times 160$; Resolução: 0,5mm × 0,5mm; Intervalo de $0,2 s$ do instante $t=7,8 s$ até $11,8 s$ entre os sucessivos quadros. A tonalidade azul indica altas frações de gás, o vermelho indica baixas frações de gás. 


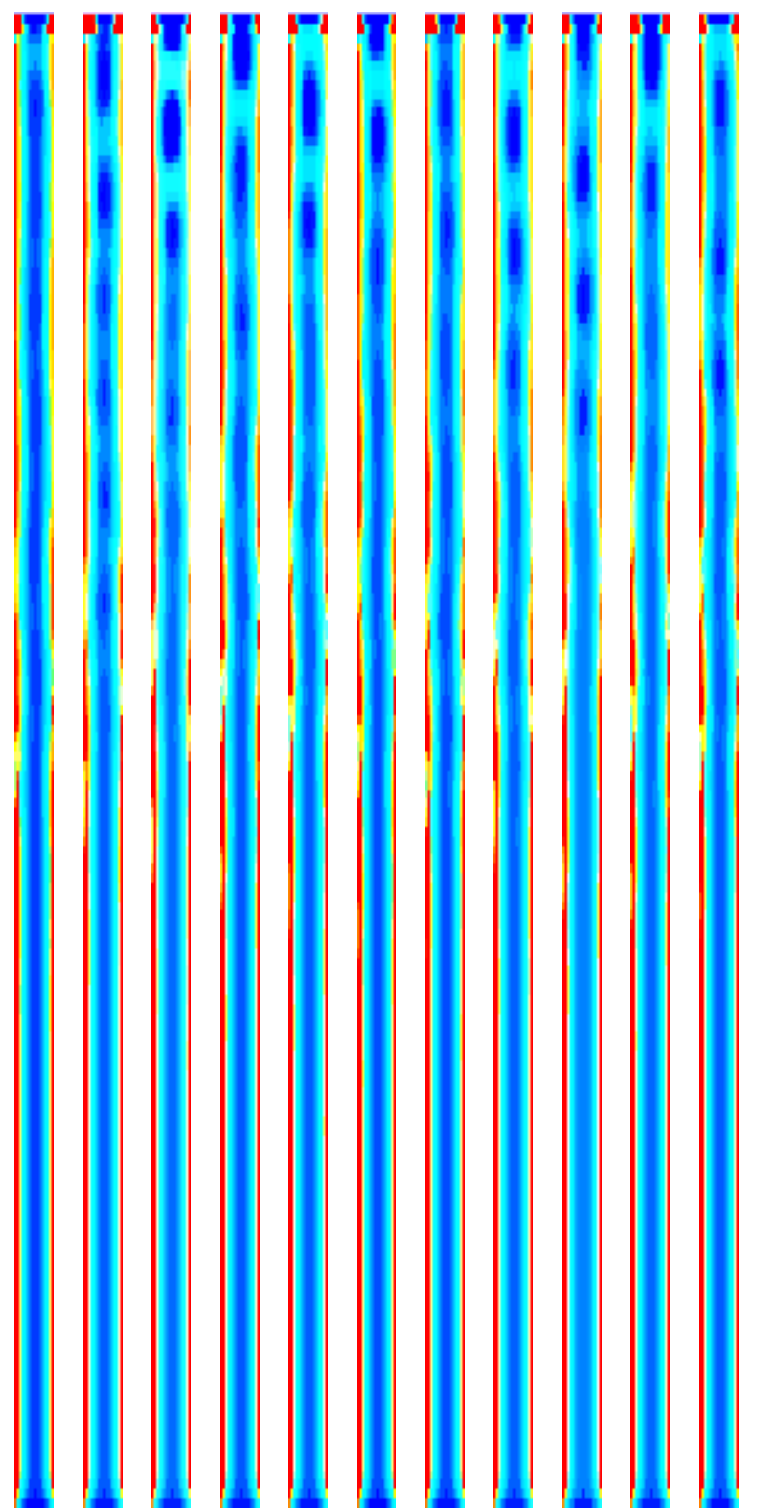

Figura 4.30: Variação temporal da fração volumétrica da fase gasosa ao longo da coluna. Domínio: $4 \mathrm{~cm} \times 144 \mathrm{~cm}$; Malha computacional: $40 \times 160$; Resolução: 0,5mm × 0,5mm; Intervalo de $1 s$ do instante $t=20 s$ até $30 s$ entre os sucessivos quadros; A tonalidade azul indica altas frações de gás, o vermelho indica baixas frações de gás. 


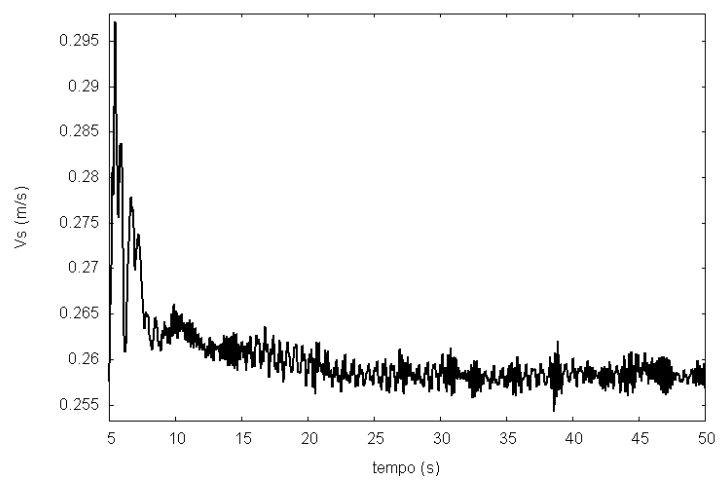

(a) Variação temporal da velocidade do sólido entre os instantes $t=5 \mathrm{~s}$ e $t=50 \mathrm{~s}$.

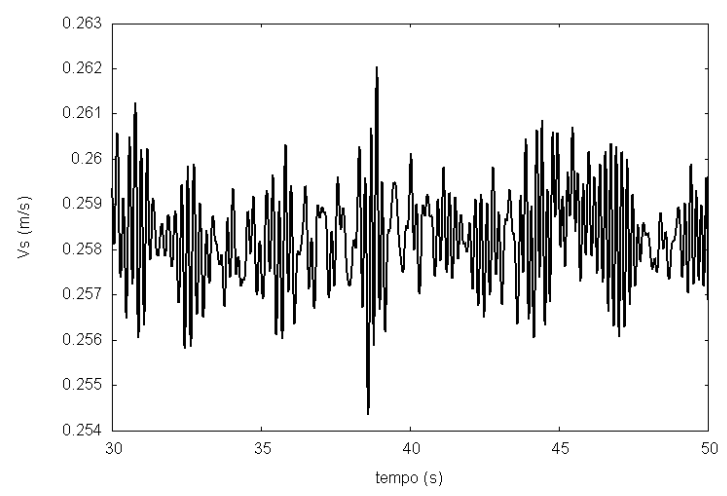

(c) Variação temporal da velocidade do sólido entre os instantes $t=30 \mathrm{~s}$ e $t=50 \mathrm{~s}$.

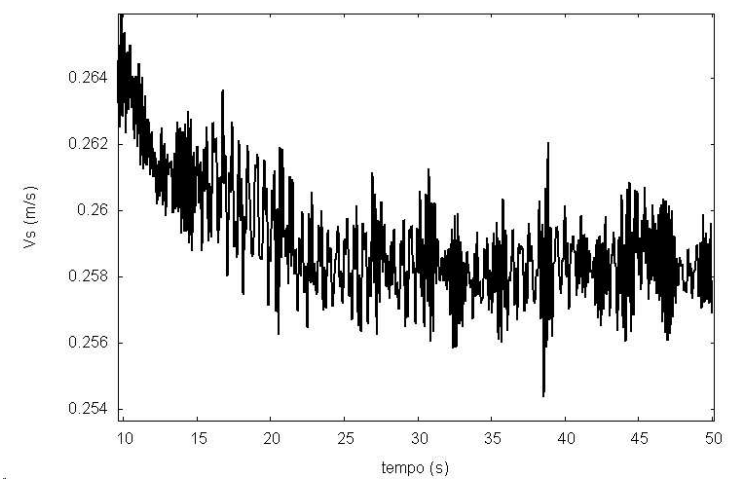

(b) Variação temporal da velocidade do sólido entre os instantes $t=10 \mathrm{~s}$ e $t=50 \mathrm{~s}$.

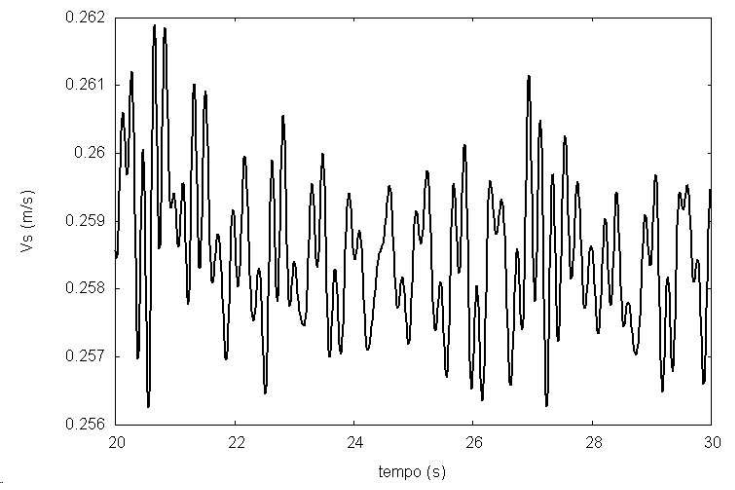

(d) Variação temporal da velocidade do sólido entre os instantes $t=20 \mathrm{~s}$ e $t=30 \mathrm{~s}$.

Figura 4.31: Variação temporal da velocidade da fase sólida em vários intervalos de tempo avaliada a $72 \mathrm{~cm}$ da entrada da coluna. Domínio: $4 \mathrm{~cm} \times 144 \mathrm{~cm}$; Malha computacional: $40 \times 160$; Resolução: $0,5 \mathrm{~mm} \times 0,5 \mathrm{~mm}$. 


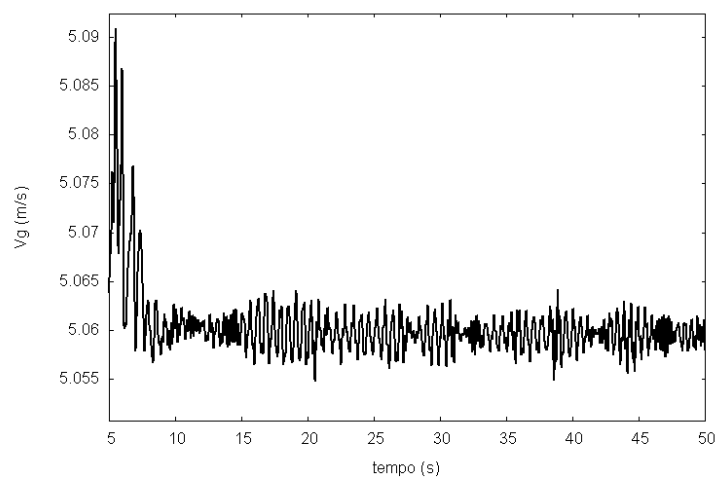

(a) Variação temporal da velocidade do gás entre os instantes $t=5 \mathrm{~s}$ e $t=50 \mathrm{~s}$.

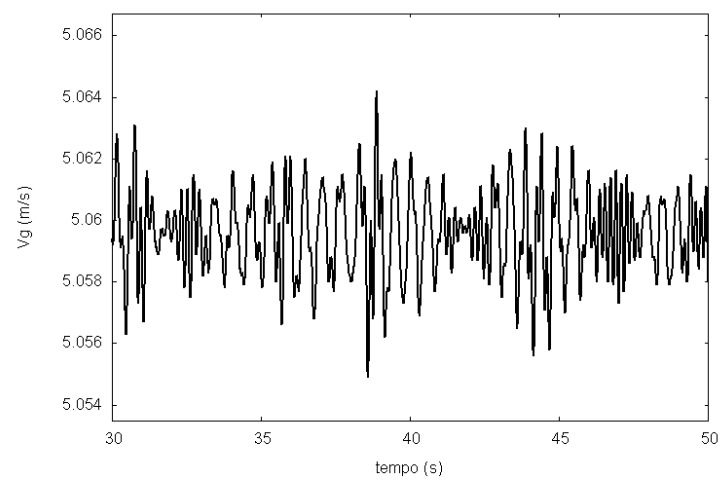

(c) Variação temporal da velocidade do gás entre os instantes $t=30 \mathrm{~s}$ e $t=50 \mathrm{~s}$.

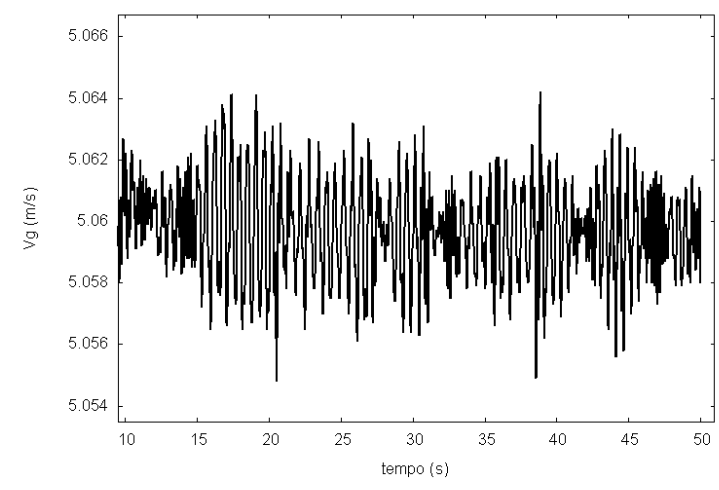

(b) Variação temporal da velocidade do gás entre os instantes $t=10 \mathrm{~s}$ e $t=50 \mathrm{~s}$.

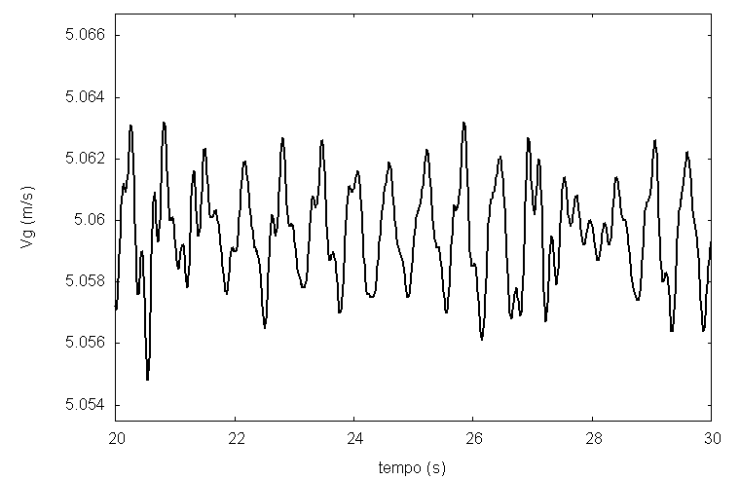

(d) Variação temporal da velocidade do gás entre os instantes $t=20 \mathrm{~s}$ e $t=30 \mathrm{~s}$.

Figura 4.32: Variação temporal da velocidade da fase gasosa em vários intervalos de tempos avaliada a $72 \mathrm{~cm}$ da entrada da coluna. Domínio: $4 \mathrm{~cm} \times 144 \mathrm{~cm}$; Malha computacional: $40 \times 160$; Resolução: $0,5 \mathrm{~mm} \times 0,5 \mathrm{~mm}$.

Foram feitas tentativas de simulações utilizando-se o domínio de $2 \mathrm{~cm} \times 144 \mathrm{~cm}$ e malha $40 \times 160$ (resolução $0,5 \mathrm{~mm} \times 0,5 \mathrm{~mm})$. Neste caso, contudo, não houve convergência por causas até o momento desconhecidas. O mesmo ocorreu em tentativas de simulações utilizando-se o domínio $4 \mathrm{~cm} \times 144 \mathrm{~cm}$ com malha de $80 \times 320$ (resolução $0,25 \mathrm{~mm} \times$ $0,25 \mathrm{~mm})$.

Reatores de leitos fluidizados operam em regime estatísticamente permanente. Uma discussão relativa pode ser encontrada em MILIOLI \& MILIOLI [59]. As Figuras 4.31 e 4.32 mostram que, para o caso do domínio $4 \mathrm{~cm} \times 144 \mathrm{~cm}$ em malha $40 \times 160$ (resolução 
$0,5 \mathrm{~mm} \times 0,5 \mathrm{~mm})$, regime estatisticamente permanente foi alcançado a partir de, aproximadamente, $25 \mathrm{~s}$ de simulação real.

Para o caso do domínio $2 \mathrm{~cm} \times 24 \mathrm{~cm}$, com malha computacional $80 \times 320$ (resolução $0,25 \mathrm{~mm} \times 0,25 \mathrm{~mm})$, o regime estatisticamente permanente foi alcançado em cerca de 12s de simulação real, como visto nas Figuras 4.16 e 4.17. Evidencia-se que domínios menores e/ou malhas mais refinadas permitem alcançar mais rapidamente o regime estatisticamente permanente. Estima-se que a altura do domínio seja o fator preponderante, pois permite que o escoamento desenvolva-se mais rapidamente (nota-se, contudo, que domínios demasiadamente baixos não permitem capturar um padrão hidrodinâmico correto). 


\section{Capítulo 5}

\section{Conclusões e Recomendações para Futuros Trabalhos}

Neste trabalho foram realizadas simulações de escoamento gás-sólido em LFC observando os aspectos: (1) domínio computacional reduzido e (2) malhas numéricas refinadas. Considerando-se resolução de malha desde $4 \mathrm{~mm} \times 4 \mathrm{~mm}$ até $0,25 \mathrm{~mm} \times 0,25 \mathrm{~mm}$. Não se encontrou na literatura simulações de escoamentos gás-sólido com modelos de dois fluidos aplicando malhas com resolução igual ou inferior a $0,25 \mathrm{~mm} \times 0,25 \mathrm{~mm}$. As malhas mais refinadas encontradas na literatura são devidas a AGRAWAL [1] e ANDREWS et al. [4], com dimensões em torno de 0,6mm. Aplicou-se o modelo de fases separadas. Os resultados numéricos foram obtidos utilizando o código computacional MFIX. Apresenta-se, a seguir, uma síntese das conclusões obtidas a partir das simulações efetuadas, bem como as recomendaçãos para trabalhos futuros.

\subsection{Conclusões}

Simulação numérica de escoamento bifásico gás-sólido em reatores de LF tem trazido significativas colaborações tanto na melhoria de um esquema completo de LFC, quanto no esclarecimento do processo hidrodinâmico altamente instável deste escoamento. Contudo, há ainda muitas questões envolvidas neste complexo fenômeno hidrodinâmico que necessitam de maiores discussões e esclarecimentos. Os atuais modelos matemáticos ainda não são capazes de descrever toda a física do processo hidrodinâmico. O modelo hidrodinâmico utilizado neste trabalho, por exemplo, incorpora correlações de origem 
empírica para o fechamento das equações e não modela a turbulência. A literatura não apresenta modelos de turbulência adequadas para escoamentos gás-sólidos, e não há correlações sub-malha adequadas para simulações de grandes escalas (MILIOLI [58]). Simulações numéricas com soluções independentes do tamanho de malha ainda não foram viabilizadas. Neste sentido, este trabalho teve por objetivo colaborar com a discussão sobre questões relacionadas com os efeitos sobre os resultados de simulação do tamanho do domínio computacional e com o refinamento de malha.

Conforme descrito no Capítulo anterior sobre resultados numéricos, foi possível utilizar uma malha fina de resolução $0,25 \mathrm{~m} \times 0,25 \mathrm{~mm}$ com 25600 células computacionais para um domínio de dimensões bastante reduzidas $(2 \mathrm{~cm} \times 24 \mathrm{~cm})$ comparando-se com as escalas reais de um LFC ou com escalas normalmente descritas na literatura sobre o assunto. Esta configuração para domínio e malha produziu bons resultados qualitativos. Os corretos padrões de escoamento foram capturados, evidenciando seu aspecto heterogêneo, com intensa formação e dissipação de clusters próximos das paredes e ao longo do escoamento.

A seguir, descreve-se resumidamente conclusões finais acerca dos resultados obtidos com as simulações numéricas efetuadas:

- A redução do domínio computacional permitiu o uso de malhas finas para a resolução do modelo hidrodinâmico B de GIDASPOW [27]. Este mesmo modelo hidrodinâmico foi aplicado em diversos trabalhos de GIDASPOW [27], [29] e [25], bem como nos trabalhos de TSUO [92], CABEZAS-GÓMEZ [12], CABEZAS-GÓMEZ et. al. [13], [14], [15]. Todos estes autores consideraram domínio computacional de $0,76 \mathrm{~m} \times 5,5 \mathrm{~m}$, e malhas extremamente grosseiras, com resolução de 7,62mm $\times 76,2 \mathrm{~mm}$. AGRAWAL [1] considera domínios reduzidos $(1 \mathrm{~cm} \times 1 \mathrm{~cm}, 1 \mathrm{~cm} \times 8 \mathrm{~cm}$ e $5 \mathrm{~cm} \times 20 \mathrm{~cm})$. A sua malha mais fina tem apenas 2048 células computacionals $(16 \times 128)$ e resolução de $1 \mathrm{~mm} \times 1 \mathrm{~mm}$. ANDREW IV et al. [4] praticou malhas de 0,625mm $\times 0,625 \mathrm{~mm}$. Sobre este aspecto, destaca-se o uso neste trabalho das malhas com resoluções $0,5 \mathrm{~mm} \times 0,5 \mathrm{~mm}$ e $0,25 \mathrm{~mm}$ $\times 0,25 \mathrm{~mm}$. 
- Foi possível realizar simulações com malhas refinadas encontrando-se soluções numéricas convergidas utilizando computação em processamento serial. O tempo computacional de processamento resultou bastante elevado em apenas um caso (apenas quando aplicou-se a malha 80 x 360). Porém, recomenda-se fortemente que uma estrutura de computação paralela seja viabilizada para se obter soluções convergidas em menor tempo de processamento, afim de que se possa tomar decisões mais rápidas acerca dos melhores ajustes dos parâmetros para o início de um novo teste. Computação paralela será também crucial para implementações tri-dimensionais.

- A malha com resolução de $0,25 \mathrm{~mm} \times 0,25 \mathrm{~mm}$ aplicada no domínio computacional $2 \mathrm{~cm} \times 24 \mathrm{~cm}$ permitiu capturar as estruturas coerentes que geralmente são formadas em LFC. Foi possível visualizar inclusive regiões de recirculação, semelhantes a vórtices típicos de escoamentos turbulentos, embora nenhum modelo de turbulência tenha sido utilizado neste trabalho.

- A altura da coluna afetou significativamente os resultados de simulação. Em pequenas alturas obteve-se escoamento homogêneo irreal, enquanto nas maiores alturas obteve-se o esperado padrão de escoamento instável com a evolução de clusters.

- Os resultados de simulação efetuados mostraram-se qualitativamente dependentes do tamanho de malha utilizado. Malhas mais refinadas produziram escoamentos com estrutura mais refinada. 


\subsection{Recomendações para Futuros Trabalhos}

Com base nas conclusões sintetizadas anteriormente, faz-se a seguir recomendações para trabalhos futuros, nos seguintes aspectos:

\section{- Processamento em Paralelo}

Processamento em paralelo permite acelerar o processo de solução e, consequentemente, diminuir o tempo de processamento. É altamente recomendável quando se trata de simulação de natureza bastante instável e de grande complexidade hidrodinâmica tal como escoamento bifásico gás-sólido em reatores de LFC. O processo finalizado e convergido em pouco tempo permite que sejam feitas simulações para ajustes de parâmetros (condições de contorno apropriadas, refinamento de malha, etc.) cujos resultados possam servir para a simulação definitiva. Além disso, viabiliza-se simulações tri-dimensionais.

\section{- Escolha de Parâmetros e Equação de Fechamento}

Com processamento em paralelo e com a possibilidade de se trabalhar com um código aberto tal como o MFIX, é possível viabilizar testes que realizam mudanças sistemáticas, por exemplo, no modelo hidrodinâmico implementado no código, nas condições de contorno e nas formulações das equações de fechamento.

\section{- Esquemas de Interpolação}

Desenvolvimento de técnicas numéricas para tratamento dos termos convectivo/advectivo que permitam estabelecer previamente a ordem do método e avaliar os respectivos erros de origem numérica. O mesmo poderia ser incoporando no ambiente de simulação que estivesse sendo desenvolvido, conforme proposto no ítem anterior.

\section{- Modelagem Matemática}

Efetuar estudos de novos modelos matemáticos incorporando aperfeiçoamentos nos já existentes, tais como modelos de turbulência. 


\section{Referências Bibliográficas}

[1] AGRAWAL, K. The Role of Meso-Scale Strutucture in Rapid Granular \& Gas-Solid Flows. Tese (Doutorado), Faculty of Princeton Univerty, 2000.

[2] AGResar, G.; Linderman, J. J.; TRYGGVASON, G.; POWELl, K. G. An Adaptative, Cartesian, Front-Tracking Method for the Motion, Deformation and Adhesion of Circulating Cells. Journal of Computational Physics, V.143, pp. 346380, 1998.

[3] AMASDEN, A.; HARLOW, F. H. The SMAC Method: A Numerical Techique for Calculating Incompressible Fluid Flows, Los Alamos Scientific Laboratory LA-4370, Los Alamos, New Mexico, 1970.

[4] ADREWS IV, A. T.; LOEZOS, P. N.; SUNDARESAN, S. Coarse-Grid Simulation of Gas-Particle Flows in Vertical Risers. Ind. Eng. Chem., V.44, pp. 6022-6037, 2005.

[5] ARMENIO, V. An Improvided MAC Method (SIMAC) for Unstead High-Reynolds Free Surfaces Flows. International Jornal for Numerical Methods in Fluids, V.24, pp. 185-214, 1996.

[6] BAI, D.; ISSANGYA, S.; GRACE, J. R. Characteristics of Gas-Fludized Beds in Different Flow Regimes. Ind. Eng. Chem., V.38, pp. 803-811, 1999.

[7] BAI, D.; MASUDA, Y.; NAKAGAWA, N.; KATO, K. Flow Structure in a Fast Fluidized Bed. Chemical Engineering Science, V.51, pp. 957-966, 1996.

[8] BAI, D.-R; JIN, Y.; YU, Z.-Q.; ZHU, J.-X. The Axial Distribution of the CrossSectionally Average Voidage in Fast Fluidized Beds. Powder Technology, V.71, pp. $51-58,1992$. 
[9] BI, H. T.; ELLIS, N.;ABBA, I. A., GRACE, J. R. A State-of-the-Art Review of GasSolid Turbulent Fluidization. Chemical Engineering Science, V.55, pp. 4789-4825, 2000.

[10] BOEMER, A; QI, H.; RENZ, U; VASQUEZ, S.; BOYSAN, F. Eulerian Computation of Fluidized Hydrodynamics: A Comparison of Physical Models. In: Proc. 13th Int. Conf. on Fluidized Bed Combustion. V.2, pp. 775-787, 1995.

[11] BRACKBILL, J. U.; KOTHE, D. B.; ZEMACH, C. A Continuum Method for Modeling Surface Tension, Journal of Computational Physics, V.100, pp. 335-354, 1992.

[12] CABEZAS-GÓMEZ, L. C., Modelagem Matemática e Simulação Numérica do Escoamento Bifásico Gás-Sólido em Coluna de Leito Fluidizado Circulante. Tese (Doutorado), Escola de Engenharia de São Carlos, Universidade de São Paulo, 2003.

[13] CABEZAS-GÓMEZ, L. C.; MILIOLI, F. E. Modelagem Matemática e Simulação numérica do Escoamento Bifásico Gás-Sólido num Leito Fluidizado Circulante. XV Congresso Brasileiro de Engenharia Mecânica - COBEM, Águas de Lindóia-SP, 1999.

[14] CABEZAS-GÓMEZ, L., MiLiOLI, F. E. Numerical Study on the Influence of Various Physical Parameters over the Gas-solid Two-phase Flow in the 2D Riser of a Circulating Fluidized Bed, A Powder Technology. V. 132, pp. 216-225, 2003.

[15] CABEZAS-GÓMEZ, L., MiLiOLI, F. E. Gas-solids Two-Phases Flow in the Riser of Circulating Fluidized Bed: Mathematical Modelling and Numerical Simulation. Journal of the Brazilian Society of Mechanical Sciences, V.XXIII, n.2, pp. 179-200, 2001.

[16] CAMPBELL, C. S.; WANG, D. G. Particle Pressures in Gas-Fluidized Beds. Journal of fluid Mechanics. V.227, pp.495-508, 1991.

[17] CHENG Y.; WEI, F.; YANG, G.; JIN, Y. Inlet and Outlet Effects on Flow Patterns in Gas-Solid Risers. Powder Technology, V.98, pp. 151-156, 1998.

[18] CHO, S. H.; CHOI, H. G.; YOO, J. Y. Direct Numerical Simulation of Fluid Flow Laden with Many Particles. International Journal of Multiphase Flow. V.31, pp. 435-451, 2005. 
[19] DING, J., GIDASPOW, D., A Bubbling Model using Kinetic Theory of Granular Flow. AIChE Journal, V.36, n.4, pp. 523-538, 1990.

[20] ENWALD, H., ALMSTEDT, A.-E., Fluid Dynamics of a Pressurized Fluidized Bed: Compararison Between Numerical Solution from Two-Fluid Models and Experimental Results. Chem. Eng. Sci., V.54, pp. 329-342, 1999.

[21] ENWALD, H., PEIRANO, E., ALMSTEDT, A.-E., Eulerian Two-phase Flow Theory Applied to Fluidization. International Journal of Multiphase Flow, V.22, pp. 21-66, 1996.

[22] ERGUN, S., Fluid Flow Through Packed Columns, Chemical Engineering Progress, Vol 8, n.2, p.89-94, 1952.

[23] ESMAEELI, A.; TRYGGVASON, G. Direct Numerical Simulations of Bubbly Flows. Part 1. Low Reynolds Number Arrays. Journal Fluid Mech., V.377, pp.313345, 1998.

[24] FORTUNA, A. O. Técnicas Computacionais para Dinâmica dos Fluidos. V.1, EDUSP, 2000.

[25] GIDASPOW, D., Computation and Measurement of Structure and Turbulence in Risers and Bubbling Beds. Multiphase Fluid Dynamics Research Consortium, SemiAnnual Meeting and Review, Apr. 12-14, Albuquerque, New Mexico, 2000.

[26] GIDASPOW, D., Hydrodynamics of Fluidization and Heat Transfer: supercomputing Modeling. Applied Mechanical Reviews, V.39, n.1, pp. 1-23, 1986.

[27] GIDASPOW, D., Multiphase Flow and Fluidization: Continuum and Kinetic Theory Descriptions, Academic Press Inc., Bostom, 1994.

[28] GIDASPOW, D., ETTEHADIEH, B. Fluidization in Two-Dimensional Beds with a Jet - Part. II: Hydrodynamic Modelling. Industrial Engineering Chem. Fundamentals, V.22, pp. 193-201, 1983.

[29] GIDASPOW, D., HUILIN, H. L. , Equation of state and radial distribution functions of FCC particles in a CFB, AIChE Journal, V.44, n.2, pp. 279-293, 1998. 
[30] GUENTHER, C.; SYAMLAL, M., The effect of Numerical Diffusion on Simulation of Isolated Bubles in a Gas-solid Fluidized Bed. Powder Technology, V.116, pp. 142-154, 2001.

[31] HARLOW, F. H.; AMSDEN, A. A. Numerical Calculation of Multiphase Fluid Flow. Journal of Computational Physics, V.17, pp. 19-52, 1975.

[32] HARLOW, F. H.; WELCH, J. E. Numerical Calculation of Time-Dependent viscous Incompressible flow of Fluid with Free Surface. The Physics of fluids, V.8, n.1, pp. 2182-2189,1965.

[33] HARRIS, A. T.; DAVIDSON, J. F.; THORPE, R. B. The Influence of the Riser Exit on the Particle Residence Time Distribution in a Circulating Fluidised Bed Riser. Chemical Engineering Science, V.58, pp. 3669-3680, 2003.

[34] HELLAND, E.; OCCELLI, R.; TRADIST, L. Numerical Study of Cluster Formation in a Gas-Particle Circulating Fluidized Bed. Powder Technology, V.110, pp. 210-221, 2000.

[35] HISHIDA, K.; ANDO, A.; MAEDA, M. Experiments on Particle Dispersion in a Turbulent Mixing Layer. Int. J. Multiphase Flow, V.18, pp. 181-194, 1992.

[36] HO, C. A.; SOMMERFELD, M. Modelling of Micro-Particle Agglomeration in Tubulent Flow. Chem. Eng. Sci, V.57, pp. 3073-3084,1999.

[37] HUILIN, L., GIDASPOW, D. Hydrodynamic Simulation of Binary Fluidization in a Riser: CFD Simulation using Two Granular Temperatures. Chemical Engineering Journal, V.58, pp. 3777-3792, 2003.

[38] HUILIN, L.; GIDASPOW, D. Hydrodynamic Simulation of Gas-Solid Flow in a Riser, Ind. Eng. Chem. Res., V. 42, pp. 2390-2398, 2003.

[39] HUILIN, L., GIDASPOW, D., BOUILlARD, J., WENTIE, L. Hydrodynamic Simulation of Gas-Solid Flow in a Riser using Kinetic Theory of Granular Flow, Chemical Engineering Journal, V. 95, pp. 1-13, 2003.

[40] HUBER, N.; SOMMERFELD, M., Modelling and Numerical Calculation of Dilutephase Pneumatic Conveying in Pipe Systems. Powder Technology, V. 99, pp. 90-101, 1998. 
[41] ISHII, M. Thermo-Fluid Dynamic Theory of Two-phase Flow. Eyrolles, Paris, 1975.

[42] JAYASWAL, U., Hydrodynamics of Multiphase Flows: Separation, Dissemination and Fluidization, Illinois Institute of Technology, Chicago, Tese de Doutorado, 1991.

[43] JIA, W. Transport Coordinate (TC) Method for the Dynamics of Multiple Materials. Journal of Fluids Engineering., V.122, pp.125-133, 2000.

[44] LEORNARD, B.; MOKHATARI, S. Beyond First Ordem Upwinding: The Ultra Sharp Alternative for Non-Oscillatory Steady-State Simulation of Convection, International Journal Numeric Methods Engineering, V. 30, pp. 729-766, 1990.

[45] LING, W.; LIU, J. CHUNG, J. N.; CROWE, C. T. Parallel Algorithms for ParticlesTurbulence Two-Way Interation Direct Numerical Simulation. Journal of Parallel and Distributed Computing, V.62, pp. 38-60, 2002.

[46] LIU C. High Performance Computation for DNS/LES. Applied Mathematical Modelling, 2005

[47] LIU, C.-H.; WOO, C.-M.; LEUNG, D. Y. C. Performance Analysis of a Parallel Finite Element Solution to the Direct Numerical Simulation of Fluid Turbulence on Linux PC Cluster. Applied of Fluid Turbulence, V.172, pp. 731-743, 2006.

[48] LOEZOS, P. N. An Investigation into Dense and Dilute Phase Gas-Particle Flow. Tese de Doutorado, Tese de Doutorado Faculty of Princeton Univerty, 2003.

[49] LUO, K. M. Dilute, Dense-Phase and Maximum Solids-Gas Transport. Tese de Doutorado, Illinois Instituto of Technology, Chicago, 1987.

[50] MAHESH, K. HOU, Y. A Robust, Colocated, Implicitit Algorithm for Direct Numerical Simulation of Compressible Turbulent Flows. Journal of Computational Physics, V.205, pp. 205-221, 2005.

[51] MANGIAVACCHI, N.; CASTELO, A.; TOMÉ, M. F.; CUMinATO, J. A.; FORTUNA, A. O.; FERREIRA V.G.; NONATO, L. G.; MCKEE, S. Numerical Simulation of Surface Tension Dominated Axisymetric Free Surface Flows, ENCIT, 2000. 
[52] MANSOORI, Z. SAFFAR-AVVAL, M.; TABRIZI, H. B.; AHMADI, G. Experimental Study of Turbulent Gas-Solid Heat Transfer at Different Particles Temperature. Experimental Thermal and Fluid Science, V.28, pp. 655-665, 2004.

[53] MARKHAM, G.; PROCTOR, M.V. C.E.G.B. Report TPRD/l/0063/M82, 1983.

[54] MAThieSEN, V.; SOLBERG, T.; HJERTAGER, B. H. Experimental and Computational Study of Multiphase Gas/Particle Flow in a CFB Riser. AIChE Journal, V.45, pp. 2503-2518, 1999.

[55] Mathiesen, V.; SOlBeRG, T.; HJERTAGeR, B. H. Prectitions of Gas/Particle Flow with an Eulerian Model Including a Realistic Particle Size Distribution. Powder Technology, V.112, pp. 34-45, 2000.

[56] MATONIS, D., GIDASPOW, D., BAHARY, M., CFD simulation of flow and turbulence in a slurry bubble column, AIChE Journal, Vol 48, n.7, pp. 1413-1429, 2001.

[57] MELO, J. R. C.; NIECKELE, A. O. An Advection and Interface Reconstructing Scheme for Incompressible Flow Calculations. Fluids Engineering Conference. V.3, pp. 385-390, 1996.

[58] MiLioli, C. C. Simulação de Escoamentos Gás-Sólido Reativos em Leitos Fluidizados Circulantes. Tese (Doutorado) - Escola de Engenharia de São Carlos, Universidade de São Paulo, 101 p., São Paulo, 2006.

[59] Milioli, C. C.; MiLIOLI, F. E. Reaching the Statistical Steady State Regime in Two-Fluid Simulation of Risers. Powder Technology, Vol. 167, pp. 26-32, 2006.

[60] NERI, A., GIDASPOW, D., "Riser Hydrodynamic: Simulation using kinetic theory", AIChE Journal, Vol 46, n.1, pp. 52-67, 2000.

[61] OLIVEIRA, P. J.; ISSA, R. I. Numerical Aspects of an Algorithm for the eulerian Simulation of Two-Phase Flows. Int. J. Math Fluids, V. 43, pp. 1177-1198, 2003.

[62] OSHER, S.; MULDER, W.; SETHIAN, J. A. Computing Interface Motion in Compressible Gas Dynamics. Journal of Computational Physics, V.100, pp. 209-228, 1992. 
[63] PATANKAR, S., Numerical heat Transfer and Fluid Flow, Hemisphere Publishing, New York, 1980.

[64] PEIRANO, E., DELloume, V., LECKNER, B., Two-or three-dimensional Simulations of Turbulent Gas-Solid flows Applied to Fluidization, Chemical Engineering Science, V. 56, pp. 4787-4799, 2001.

[65] PEIRANO, E., LECKNER, B., Fundamentals of Turbulent Gas-Solid Flows Applied to Circulating Fluidized Bed Combustion. Progress in Energy and Combustion Science, Vol 24, n.4, pp. 259-296, 1998.

[66] PORTELA, L. M.; COTA, P.; OLIEMANS, R. V. A. Numerical Study of the NearWall Behaviour of Particle in Turbulent Pipe Flows. Powder Technology, V. 125, pp. 149-157, 2002.

[67] PORTELA, L. M.; OLIEMANS, R. V. A. Eulerian-Lagrangian DNS/LES of Particle-Turbulence Interations in Wall-Bounded flows. International Journal for Numerical Methods in Fluids, V. 43, pp. 1045-1065, 2003.

[68] PORTELA, L. M.; OLIEMANS, R. V. A. Possibilities and Limitations of Computer Simulations of Industrial Turbulent Dispersed Multiphase Flows. Flow turbulent Combust, pp. 381-403, 2006.

[69] PUCKETT, E. G.; AlmGREN, A. S.; BELL, J. B.; MARCUS, D. L.; RIDER, W. J. A High-Order Projetion Method for Tracking Fluid Interfaces in Variable Density Incompressible Flows. Journal of Computational Physics, V.130, pp. 269-282, 1997.

[70] ROWE, P. N. Dray Forces in a Hydraulic Model of a Fluidized Bad: Part II. Transactions of the IChemE, V. 39, pp. 175-180, 1961.

[71] SAmUElBERG, A.; HJERTAGER, B. H. An Experimental and Numerical Study of Flow Patterns in a Circulating Fluidized Bed Reactor. Int. J. Multiphase Flow, V. 22, pp. 575-591, 1966.

[72] SANTOS, F. L. P. "Simulação Numérica de Escoamentos Multifásicos utilizando o Sistema FreeFlow2D”, Dissertação (Mestrado), ICMC/USP, São Carlos-SP, 2001. 
[73] SANTOS, F. L. P; MANGIAVACCHI, N. Numerical Simulation of Multiphase Flows using the FreeFlow2D System, COBEM, Uberlândia-MG, 2002.

[74] SETHIAN, J. A. Numerical Algorithms for Propagating Interfaces: Hamilton-Jacobi Equation and Conservation Laws. J. Differential Geom., V.31, pp. 131-161, 1990.

[75] SETHiAn, J. A. Theory, Algorthms and Applications of Level Sets Methods for Propagating Interfaces. Cambridge University Press, Cambridge - UK, 1995.

[76] SHARMA, N. PATANKAR, N. A. A Fast Computation Technique for the Direct Numerical Simulation of Rigid Particulate Flows. Journal of Computational Physics, V.205, pp. 439-457, 2005.

[77] SILVA, R. C. Modelagem Euleriana do Escoamento Gás-Sólido em Leitos Fluidizado Circulante: Análise da Influência de Parâmetros Físicos e Numéricos nos Resultados de Simulação. Tese (Doutorado) - Escola de Engenharia de São Carlos, Universidade de São Paulo, 186 p., São Carlos, 2006.

[78] SINCLAIR, J. L., Hydrodynamic Modeling. In: GRACE, J. R. et al. Circulating Fluidized Beds, Chapman- Hall. Cap. 5, pp. 149-180, 1997.

[79] SOMMERFELD, M. Validation of a Stochastic Lagragian Modelling Approach for Inter-particle collisions in Homogeneous Isotropic Turbulence. Int. J. Multiph. Flow, V.27, pp. 1829-1858, 2001.

[80] SUNDARESAN, S. Hydrodynamics of Multiphase Flow Reactors: Current Status and Challenges, AIChE Journal, Vol. 46-6, pp. 1102-1105, 2000.

[81] SUSSUMAn, M; PUCKetT, E. G. A Couple Level Set and Volume-of-Fluid Method for Computing 3D and Axismmetric Incompressible Two-Phase Flows. Journal of Computational Physics., V.162, pp. 301-337, 2000.

[82] SUSSUMAN, M; SMEREKA, P. Axismmetric Free Boundary Problems. Journal Fluids Mech., V.341, pp. 269-294, 1997.

[83] SUSSUMAN, M; SMEREKA, P.; OSHER, S. A Level Set Approach for Computing Solutions to Incompressible Two-Phase Flow. Journal of Computational Physics, V.114, pp. 146-159, 1994. 
[84] SYAMLAL, M., MFIX Documentation: Numerical Technique, EG and G Technical Report, DE-AC21-95M31346, 1998.

[85] SYAMLAL, M., MFIX Documentation: Theory Guide, U.S. Department of Energy, Morgantown Energy Techonology Center, Technical Note-DOE/MET-94/1004, 1993.

[86] SYAMLAL, M.; O'BRIEN, Simulation of Granular Layer Inversion in Liquid Fluidized Beds, International Journal. Multiphase Flow, V. 14, pp. 473-481, 1988.

[87] TAGHIPOUR, F.; ELLIS, N.; WONG, C. Experimental and Computational Study of Gas-Solid Fluidized Bed Hydrodynamics. Chemical Engineering Science, V.60, pp. 6857-6867, 2005.

[88] THAI, V. D.; MINIER, J. P.; SIMONIN, O.; FREYDIER, P.; OLIVE, J. Multidimensional Two-Fluid Model Computation of Turbulent Dispersed Two-Phase Flows. Numerical Methods for Multiphase Flows-ASME, V. 185, 1999.

[89] TOME, M. F.; MCKEE, S. GENSMAC: A Computational Marker-and-Cell Method for Free Surface Flows in General Domains. Journal of Computational Physics, V.110, n.1, pp. 171-189,1994.

[90] TRYGGVASON, G. ESMAEELI, A.; AL-RAWAHI, N. Direct Numerical Simulation of Flows with Phase Change. Computers and Structures, V.83, pp. 445-453, 2005.

[91] TSUJI, Y., TANAKA, T. YONEMURA, S. Cluster Patterns in Circulating Fluidized Beds Predicted by Numerical Simulation (Discrete Particle Model versus TwoFluid Model), Powder Technology. Vol. 95, pp. 254-264, 1898.

[92] TSUO, Y. P. Computational of Flow Regimes in Circulating Fluidized Beds. Tese (Doutorado), Illinois Institute of Technology, Chicago, 1989.

[93] TSUO, Y. P., GIDASPOW, D., Computation of Flow Patterns in Circulating Fluidized beds, AIChE Journal, Vol 36, n.6, pp. 885-896, 1990.

[94] UNVERDI, S.O.; TRYGGVASON, G. A Front-Tracking Method for Viscous Incompressible Multi-Fluid Flows. Journal of Computational Physics, V.100, pp. 25-27, 1991. 
[95] UNVERDI, S.O.; TRYGGVASON, G. Computation of Incompressible Multi-Fluid Flows. Physica D, V.60, pp. 70-83, 1992.

[96] VANDU, C. O.; KRISHNA, R. Influence of Scale on the Volumetric Mass Transfer Coefficients in Bubble Columns. Chemical Engineering Science, V.43, pp. 575-579, 2004 .

[97] WANG, Q. SQUIRES, K. D.; SIMONIN, O. Large Eddy Simulation of Turbulent Gas-Solid Flow in a Vertical Channel an Evalution of Second-Order Models, International Journal of Heat and Fluid Flow, V. 19, pp. 505-511, 1998.

[98] WELCH, J. E.; HARLOW, F. H.; SHANNON, J. P.; DALY, B. J. The MAC Method. Technical Report LA - 3425, Los Alamos Scientific Laboratory, New Mexico, 1966.

[99] WEN, C. Y.; YU, Y. H. Mechanics of Fluidization. Chemical Engineering Progress Symposium Series, V.62, n.62, pp. 100-111, 1966.

[100] YAN, A.; BALL, J.; ZHU, J.(J.) Scale-Up Effects of Riser Reactors (3) Axial and Radial Solids Flux Distribution and Flow Development. Chemical Engineering Journal, V.109, pp. 97-106, 2005.

[101] YOURONG, H.; HUILIN, L. QIAOQUM, S.; LIDAN, Y.; YOUNHUA, Z.; GIDASPOW, D.; BOUILARD, J. Hydrodynamics of Gas-Solid Flow around Immersed Tubes in Bubbling Fluidized Beds. Powder Technology, V.145, pp. 88-105, 2004.

[102] ZELENKO, V. L.; SCRGEEV, Y. A.; TJIN, T.; ISKE, P. L. Clusters and Particle Segregation in Gas-Solid Flow Through a Vertical Tube. Physica A, V.226, pp. 274-294, 1996.

[103] ZHANG, D. Z.; VANDERHEYDEN, W. B. High-Resolution Three-Dimensional Numerical Simulation of a Circulating Fluidized Bed. Powder Technology, V.116, pp. 133-141, 2001.

[104] ZHANG, M.; QIAN, Z.; YU, H. WEI, F. The Solid Flow Structure in a Circulating Fluidized Bed Riser/Downer of 0.42-m Diameter. Powder Technology, V. 129, pp. 46-52, 2003. 


\section{Anexo A}

\section{A1. Teoremas Integrais}

\section{Teorema de Gauss-Ostragradskii}

- Função escalar (tensor de ordem zero)

$$
\int_{V} \nabla f d V=\int_{A} f \mathbf{n} d A .
$$

- Função vetorial (tensor de primeira ordem)

$$
\int_{V} \nabla \cdot \mathbf{f} d V=\int_{A} \mathbf{f} \cdot \mathbf{n} d A .
$$

- Função tensorial (tensor de segunda ordem)

$$
\int_{V} \nabla \cdot \overline{\bar{f}} d V=\int_{A} \overline{\bar{f}} \cdot \mathbf{n} d A .
$$

\section{Teorema de Leibniz}

$$
\frac{d}{d t} \int_{V_{k}(t)} f(\mathbf{r}, t) d V=\int_{V_{k}(t)} \frac{\partial f}{\partial t} d V+\int_{A_{k}(t)} f\left(\mathbf{u}_{\mathbf{r}} \cdot \mathbf{n}_{k}\right) d A
$$

sendo $\mathbf{u}_{\mathbf{r}} \cdot \mathbf{n}_{k}$ a velocidade de deslocamento da superfície geométrica. 


\section{A2. Equações de Médias}

No modelo euleriano, um dado parâmetro escalar, vetor ou tensor pode ser definido

pela equação $f=f(\mathbf{r}, t)$. O parâmetro é estudado num ponto fixo do espaço $\mathbf{r}$ e num instante de tempo qualquer, $t$. Neste ponto e tempo, qualquer uma das fases podem estar presentes. Para simplificar a descrição, algum tipo de média é aplicado no balanço das equações locais instântaneas e condições de salto, obtendo-se as equações conservativas médias do modelo de dois fluidos. São geralmente aplicadas médias volumétricas, temporais ou estatísticas, cujos operadores são definidos a seguir:

- Operador de médias volumétricas

$$
\langle\cdots\rangle_{V}=\frac{1}{V} \int_{V}(\cdots) d x d y d z
$$

- Operador de médias temporais

$$
\langle\cdots\rangle_{t}=\frac{1}{T} \int_{t-T / 2}^{t+T / 2}(\cdots) d t
$$

- Operador de médias estatísticas

$$
\langle\cdots\rangle_{e}=\int_{\epsilon}(\cdots) d P(\mu)
$$

sendo que $P(\mu)$ representa a probabilidade do evento $\mu$ ocorrer e $\epsilon$ o espaço amostral. 


\section{Anexo B}

\section{Dificuldades}

Ao longo do processo de simulação numérica do escoamento gás-sólido em LFC no laboratório do NETeF (Núcleo de Engenharia Térmica e Fluidos) da EESC/USP utilizando o código MFIX, ocorreram os seguintes problemas:

- Devido à complexidade do processo hidrodinâmico de escoamento bifásico gás-sólido, o tempo de processamento e os arquivos de dados de saída emitidos pela código simulador impõem a disponibilidade de uma grande capacidade de armazenamento e de processamento de dados. Em alguns casos o processo foi interrompido por falta de espaço no disco rígido, sendo necessário, portanto, reiniciar a simulação após a transferência dos arquivos de dados para outra unidade de disco rígido.

- Sabe-se que a estratégia de processamento em paralelo reduz consideravelmente o tempo computacional gasto para finalizar uma simulação. Logo, houve uma investida de se tentar viabilizar este tipo de processamento utilizando os processadores dos três microcomputadores disponíveis. Optou-se por efetuar a estratégia mais comum de montagem de processamento em paralelo que se trata da comunicação MPI (Message Passing Interface) e do acesso remoto RSH (Protocolo de Acesso Remoto). A comunicação entre as máquinas era perfeita, mas o processo em paralelo não funcionou em nenhum dos testes aplicados em simulações de escoamento bifásicos com soluções numéricas conhecidas. O processo iterativo era interrompido observando divergência nos resultados numéricos por causas desconhecidas. As buscas por soluções baseando-se nas experiências internas e externas não deram resultado para que o problema fosse resolvido. 
- Quedas de energia local fizeram com que os processos de simulações fossem muitas vezes interrompidos. Em alguns casos esta interrupção de energia danificou o sistema operacional LINUX e a instalação do MFIX. Para o reestabelecimento do sistema foi necessário: (1) a formatação do disco rígido da máquina, (2) a reinstalação e configuração do sistema operacional, (3) a reinstalação do código MFIX e (4) a reinstalação do compilador Fortran. Se esse mesmo problema tivesse ocorrido numa arquitetura em paralelo, então acrescentar-se-ia ainda (5) a reinstalação da comunicação MPI, (6) a reinstalação do acesso remoto RSH e (7) testes para verificar o funcionamento da comunicação entre os microcomputadores.

- A simulação de escoamento bifásico gás-sólido exige conhecimento de vários aspectos do modelo escolhido. Os modelo de dois-fluidos incorporam correlações de origem experimental no fechamento das equações, sendo que os resultados finais de simulação são altamente sensíveis e dependentes dos parâmetros dessas equações. Assim, levou-se um tempo considerável no entendimento deste modelo e da sua forma de implementação no código MFIX. 